\title{
HOUSING AND THE CITY
}

\section{SUPPORTING THE PROCESS OF AGING IN PLACE THROUGH THE DEVELOPMENT OF ARCHITECTURAL GUIDELINES}

\author{
By \\ Tapiwa Molife \\ A thesis submitted to the Faculty of Graduate and Postdoctoral Affairs \\ in partial fulfillment of the requirements for the degree of
}

Master of Architecture

Carleton University

Azrieli School of Architecture and Urbanism

Ottawa, Ontario

(C) 2017

Tapiwa Molife 


\section{Housing and the City}

Supporting the process of aging in place through the development of architectural guidelines

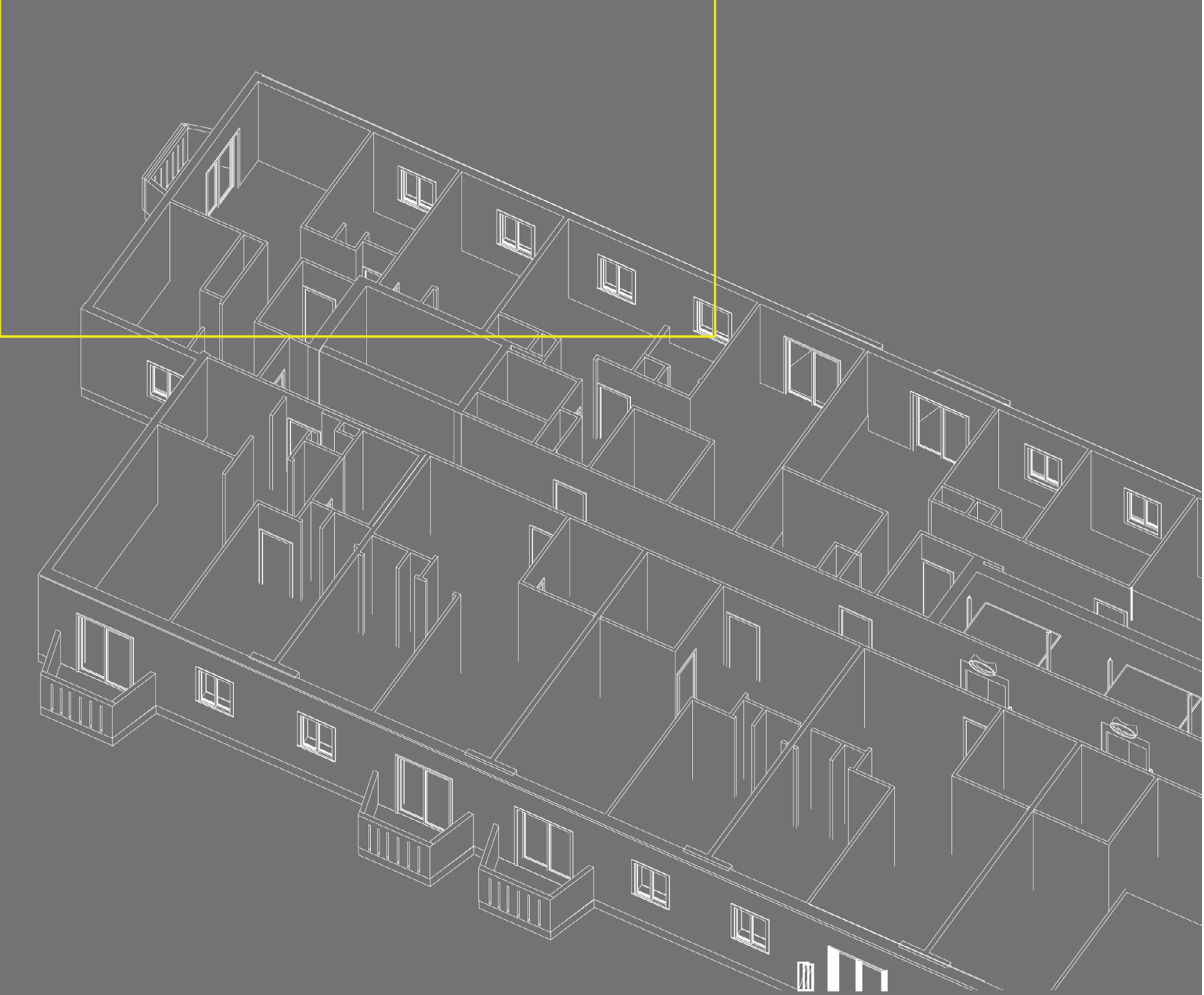




\section{Abstract}

As the baby boomer generation ages, there is a growing senior population across Canada and a shift in demographics that raises the issue of how to better provide appropriate housing for the aging population while maintaining their quality of life. Estimates show that by 2024, individuals aged 65 year and older will account for $20.1 \%$ of the population in Canada ${ }^{1}$. Generally, housing options include staying at home, assisted living, or moving into institutional care, however, what is the middle ground between residing at home and moving into institutional care? What is to be done with the existing housing stock? How can we adapt existing residential dwellings and neighborhoods to support the process of aging in place? This thesis explores how buildings can be adapted to support the process of aging in place through the development of guidelines and details. The proposal is situated within the context of existing mid- to high-rise dwellings in Ottawa, Ontario, but is intended to be implemented in new construction as well as retrofits of dwellings.

1 Canada's population estimates: Age and sex, July 1, 2015.http://www.statcan.gc.ca/daily-quoti dien/150929/dq150929b-eng.htm, accessed on September 15, 2016 


\section{Table of Contents}

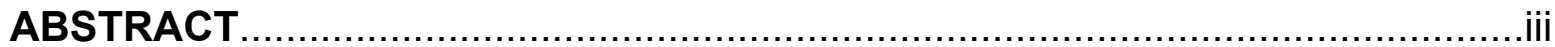

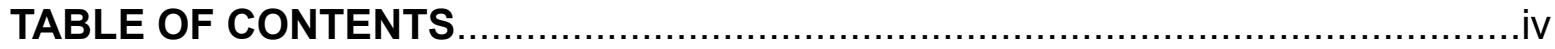

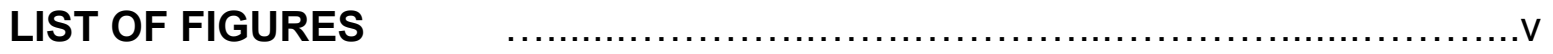

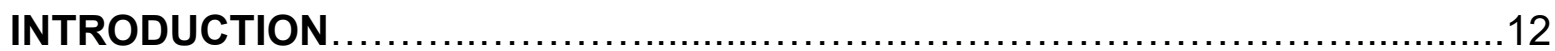

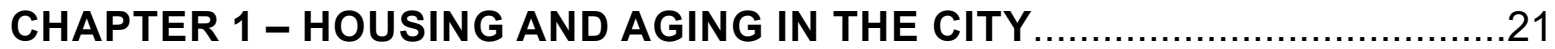

Housing Options

Aging in Place

Assistive Care

Long-term Care

Alternative Strategies

CHAPTER 2 - HOUSING MANUALS

Current housing standards and guidelines

Adapting manuals to address aging in place qualities

CHAPTER 3 - AGING IN PLACE - DESIGN MANUAL

Objectives

Design Guidelines

CHAPTER 4 - CONCLUSION.

APPENDIX 


\section{List of Figures}

Figure 1: Housing and the City, by Author

Figure 2: Image of city, by Author

Figure 3 : "Population aged 0 to 14 years and 65 years and older, as of July 1, 1995 to 2035, Canada". Accessed September 2016. http://www.statcan.gc.ca/daily-quotidien/150929/cg-b003-png-eng.htm

Figure 4: Continuum of care diagram, adapted from https://www.metlife.com/assets/ cao/mmi/publications/studies/2010/mmi-aging-place-study.pdf

Figure 5: Contiuum of Care diagram - Fostering aging in place, adapted from https:// www.metlife.com/assets/cao/mmi/publications/studies/2010/mmi-aging-place-study. pdf

Figure 6: "Unapproved Document O". Industries of Architecture. Edited by Katie Lloyd Thomas, Tilo Amhoff and Nick Beech. Routledge, November 2015. p. 329-332

Figure 7: "Unapproved Document O". Industries of Architecture. Edited by Katie Lloyd Thomas, Tilo Amhoff and Nick Beech. Routledge, November 2015. p. 329-332

Figure 8 : Ottawa Aerial image, Google Maps, https://www.google.ca/maps

Figure 9: Typical building axonometric drawing, by Author

Figure 10: Typical building plan, by Author

Figure 11: Population in East Industrial and Ottawa (average) by age group, Source: Ottawa Neighbourhood Study, accessed December 8, 2016

Figure 12: Seniors' Living Arrangements in East Industrial and Ottawa (average), Source: Ottawa Neighbourhood Study, accessed December 8, 2016

Figure 13: Mobility Status in East Industrial compared with Ottawa (average), Source: Ottawa Neighbourhood Study, accessed December 8, 2016 
Figure 14: Dwelling type in East Industrial compared with Ottawa (average), Source: Ottawa Neighbourhood Study, accessed December 8, 2016

Figure 15: Building Guidelines, by Author

Figure 16: Cover image: Aging in Place Guidelines, by Author

Figure 17: Renovation process diagram Adapted from Mikan: Save the Danchi: Mass Estates, a Project of the Future.Jovis, Berlin, 2011

Figure 18: Building axonometric drawing, by Author

Figure 19: Building threshold section, by Author

Figure 20: 3.3.1 Level threshold detail, Accessed January 2017, adatpted from "The External Landing and its Drainage" http://www.building.co.uk/Pictures/web/u/v/m/ figure1large.jpg

Figure 21: Seated dimensional data, Accessed December 2016, https://msis.jsc. nasa.gov/sections/section03.htm

Figure 22: Seating with handrail exploded axonometric drawing, by Author

Figure 23: Seating with handrail: section, by Author

Figure 24: Seating with handrail: section, by Author

Figure 25-27: Material options, Accessed January 2017. Rubber texture : http:// www.textures.com/download/rubber0049/67379; leather : http://www.textures.com/ download/leather0058/15237; bronze : http://www.textures.com/download/bronzecopper0032/13779

Figure 28: Handrail profile options, by Author

Figure 29: Area Plan: Entrance, by Author

Figure 30: View of Entrance, by Author 
Figure 31: Typical view inside entry lobby, by Author

Figure 32: Sketch: typical view inside entry lobby, by Author

Figure 33: Renovated lobby area, by Author

Figure 34: Plan, adapated nurse's station, by Author

Figure 35: Nurse's Station Section, by Author

Figure 36: Nurse's Station Section, by Author

Figure 37: Nurses's station diagram, by Author

Figure 38: Area Plan: Nurse's Station, by Author

Figure 39. Area Plan: Nurse's Station, by Author

Figure 40: Rendered View: Nurse's Station, by Author

Figure 41: Plan: Hallway, by Author

Figure 42: Elevation: Hallway, by Author

Figure 43: Handrail Section, by Author

Figure 44: Handrail detail, by Author

Figure 45 : Area Plan: Hallway, by Author

Figure 46: Current typical corridor conditions, by Author

Figure 47 : Hallway handrail system diagram, by Author

Figure 48 : Hallway system exploded axonometric drawing, by Author 
Figure 49: Handrail system section, by Author

Figure 50: Rendered View: Hallway, by Author

Figure 51: Stairwell section, by Author

Figure 52: Seating diagram, by Author

Figure 53: Excerpt from 2015 National Building Code

Figure 54: Area Plan: Stairwells, by Author

Figure 55. Sketch: Stairwells, by Author

Figure 56: Stairwell component variations

Figure 57 : Stairwell options, by Author

Figure 58. Rendered View: Stairwell, by Author

Figure 59 : Stair landing plan, by Author

Figure 60 : Stairwell options diagram, by Author

Figure 61: Rendered view of resting area

Figure 62: Stairwell landing plan, by Author

Figure 63: Rendered View: Stairwell, by Author

Figure 64: Rendered View: Stairwell, by Author

Figure 65: Washroom plans, by Author

Figure 66: Excerpt from 2015 National Building Code

Figure 67: Excerpt from 2015 National Building Code

Figure 68: Exploded axonometric drawing - washroom diagram, by Author 
Figure 69: Area Plan: Dwelling, by Author

Figure 70: Existing Plan: Dwelling, by Author

Figure 71: Modified Plan: Dwelling, by Author

Figure 72: Axonometric: Washroom grab bar intreventions 


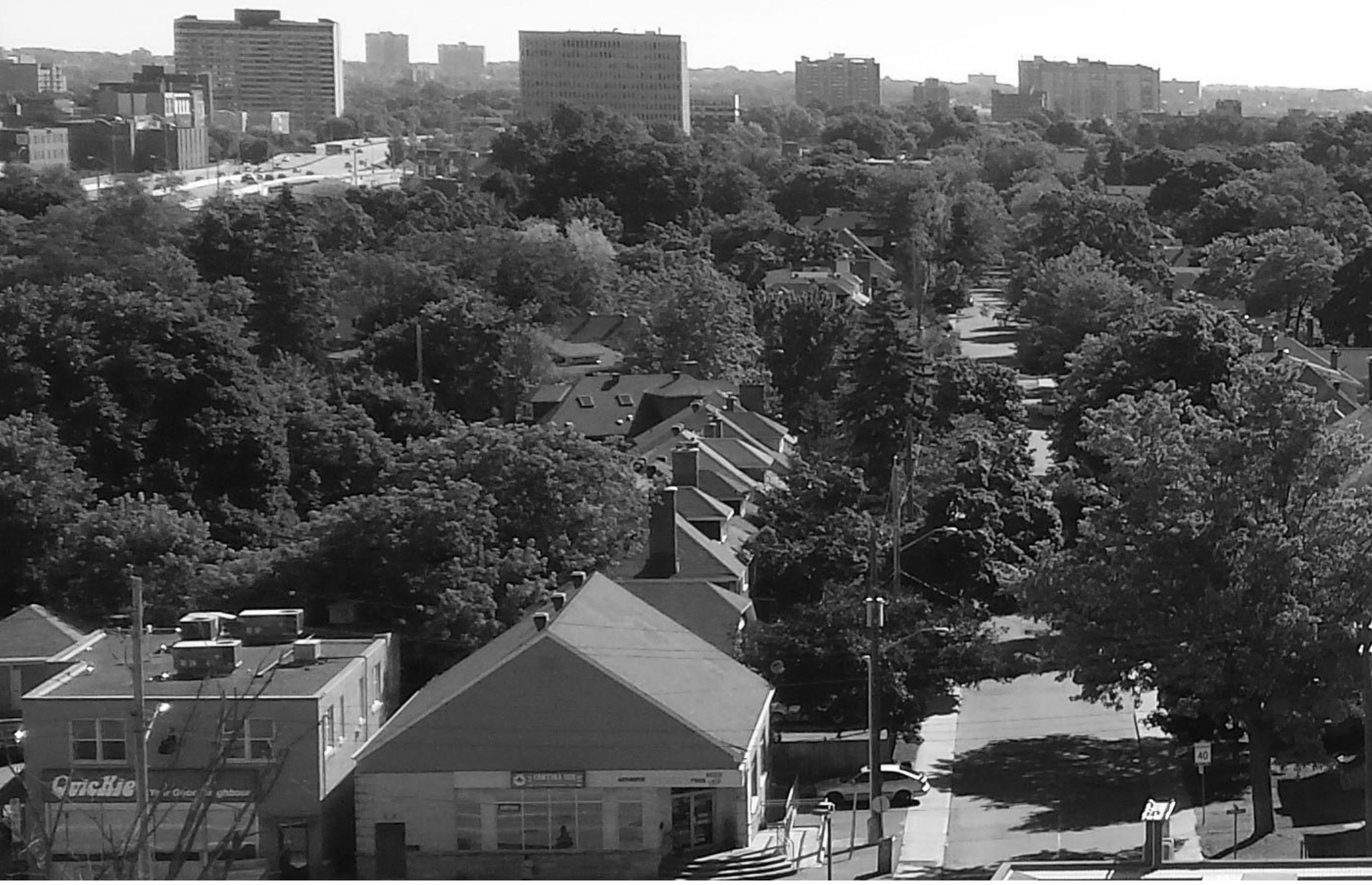




\section{INTRODUCTION}

Aging in Place is the process of staying in one's own home or neighborhood throughout the phases of life and encompasses the social, mental, and physical aspects of the aging process and decline in physical mobility. By adapting residential dwellings, individuals can live an independent life for longer in their own home their whole life, or delay the need to move into institutional care. The objective of this thesis is to propose guidelines so that individuals can prolong their stay in their own homes as they experience a decline in physical mobility and to reduce the need to move into institutional care. The ability to perform simple everyday tasks (ie. bathing, cooking, walking) becomes challenging as mobility becomes impaired. Being able to perform simple everyday tasks is integral to how independent an individual can be and whether or not they require further support to perform those tasks. This sense of autonomy and independence is also important to the quality of life that a person will experience. 
The latest population statistics show that individuals aged 65 years or older make up $16 \%$ of the population in Canada in 2015 , and are projected to account for $20 \%$ of the population by 2024 (Figure 3 ). This demographic shift accentuates the need to provide adequate housing options for an ageing population. For those wishing to age in place in their own home and neighborhood and prevent institutional care if possible, the retrofitting of the existing housing stock will give the elderly an opportunity to maintain the same quality of life they are accustomed to and to preserve a sense of independence and identity. Retrofitting existing residential settings will help meet some of the housing requirements of the aging population while also reducing the costs

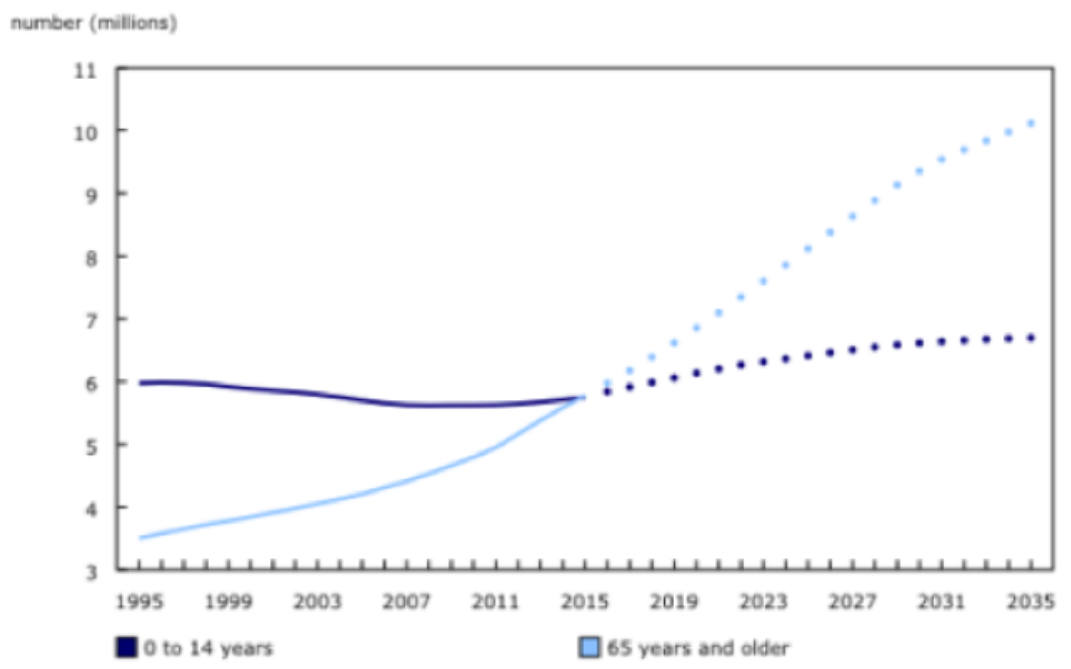

Figure 3: Population aged 0 to 14 years and 65 years and older, as of July 1, 1995 to 2035, Canada. Source: http://www.statcan.gc.ca/daily-quotidien/150929/cg-b003-png-eng.htm. accessed September 2016 
associated with institutional care, and help maintain the cohesiveness and sense of place that aid in an individual's overall sense of well-being.

This thesis is a proposal for a series of architectural guidelines for the process of ageing in place. The guidelines are a speculative "proposal" that explores the role of architecture in the realm of building regulation. The guidelines serve to explore how the process of ageing in place can be supported through architectural strategies that aim to address the qualities of wellbeing and comfort. This thesis explores the guidelines in a series of strategies that provide the minimum standards and expand on them to create a series of guidelines that each incorporate elements/aspects of wellbeing and comfort into the design for ageing in place strategies. The guidelines are based on the belief that the role of architecture also lies in the realm of policy making. Rather than a reactive measure the guidelines are a proactive tool for addressing the needs of specific user groups - specifically the ageing population. 
This thesis explores how architectural strategies can be employed in the context of the existing housing options for seniors in Ottawa, to help maintain their independence and sense of identity while aging in place. It addresses the following question: Does the existing built environment meet the needs of the ageing population, and, if not, how can we adapt existing residential settings to better support the ageing process? Through the review of literature on environmental gerontology, and accessibility standards, this thesis will illustrate how improving residential settings will serve to meet some of the housing requirements of the aging population, while also reducing the costs associated with resource and energy use in new construction. 
This thesis explores the use of narrative and details as a manual for designing for aging in place. The adapting of a residential building in Ottawa, Ontario investigates the role of a building in providing a safe, secure, inviting, and engaging environment to occupants and visitors. The following design manual provides guidelines that suggest the use of particular details.

The proposal is for the design of details as part of a larger set of guidelines in a manual for the retrofitting of existing housing stock to aid in the process of aging in place.

The details are situated within the context of mid- to hihg-rise dwellings in Ottawa. The design proposal is intended to also be applied to other residential settings as well new construction.

The guidelines presented in this thesis address five key factors that would allow older adults to age in place including:

1. Entryways;

2. Communal spaces which support various resident activities;

3. A live-in nurse's station;

4. Corridors and hallways that allow for places to rest and socialize;

5. Individual dwelling units that support the resi dents' sense of independence, privacy, and dignity. 
Chapter one situates the housing history and demographics trends in North America, exploring the current models of housing options for seniors such as long-term care, assistive care, and aging in place. In addition, it provides a background of the process of aging in place in the context of the city and community, which serves as a framework for the guidelines proposed in this thesis on how to successfully age in place.

Chapter two looks at existing Building regulations and how they can respond to the needs of particular groups while also fostering a sense of wellbeing. The chapter also makes reference to current developments of guidelines that look at common aspects of design that can integrate elements of quality of life.

Chapter three discusses the proposed set of guidelines for retrofitting spaces within a residential environment to better accommodate the needs for older individuals who may wish to age in place. It should be noted that these guidelines are not exhaustive; they are meant to contribute to the discussion of designing 
for ageing in place. Shared spaces within residential environments include entryways; common areas which can accommodate various activities; and circulation pathways such as hallways, corridors, and stairwells. These shared spaces can help to meet the social and environmental needs of the ageing population and to improve the quality of life and their ability to age in place.

The manual also provides a series of guidelines for adapting dwelling units within residential settings. By analyzing existing living units in terms of plan and housing requirements of a resident, a living unit can provide privacy, and be adapted to help an individual maintain a certain level of independence and autonomy. Guidelines that consider barrier-free access to washrooms and living spaces will be presented.

Chapter four is a summary and conclusion on the guidelines presented in the thesis in relation to existing policies and housing options. 


\section{THESIS QUESTION:}

How can design strategies incorporate notions of aging

in place to become a series of guidelines, actively sup-

porting/assisting in the quality of life and well-being in

the process of aging in place? 


\section{METHODOLOGY}

The methodology used in this thesis focuses on the use of design guidelines as a tool for improving the adaptation of residential dwellings for the process of aging in place. The main themes explored are:

1. Background on different housing options including the home, assistive care, and long-term care homes;

2. Research and analysis of current design standards and guidelines as it relates to aging in place and the environmental characteristics integrated into the design;

3. Research on building organization including factors of well-being and quality of life in the built form; 4. Development of design guidelines that foster well-being and reinforce a sense of identity through interventions in specific rooms and activity spaces (building entrances, bathrooms, hallways, stairwells, and nurses station). 


\section{CHAPTER 1 - HOUSING AND \\ AGING IN THE CITY}




\section{Housing Options}

Considering designing for older individuals, it is critical to provide an environment that supports the needs of occupants in order to help maintain their independence for as long as possible. This can be done through integrating environmental supports, and providing spaces that foster social connections which will aid in the process of aging in place. 


\section{Aging in Place - Continuum of care diagram}

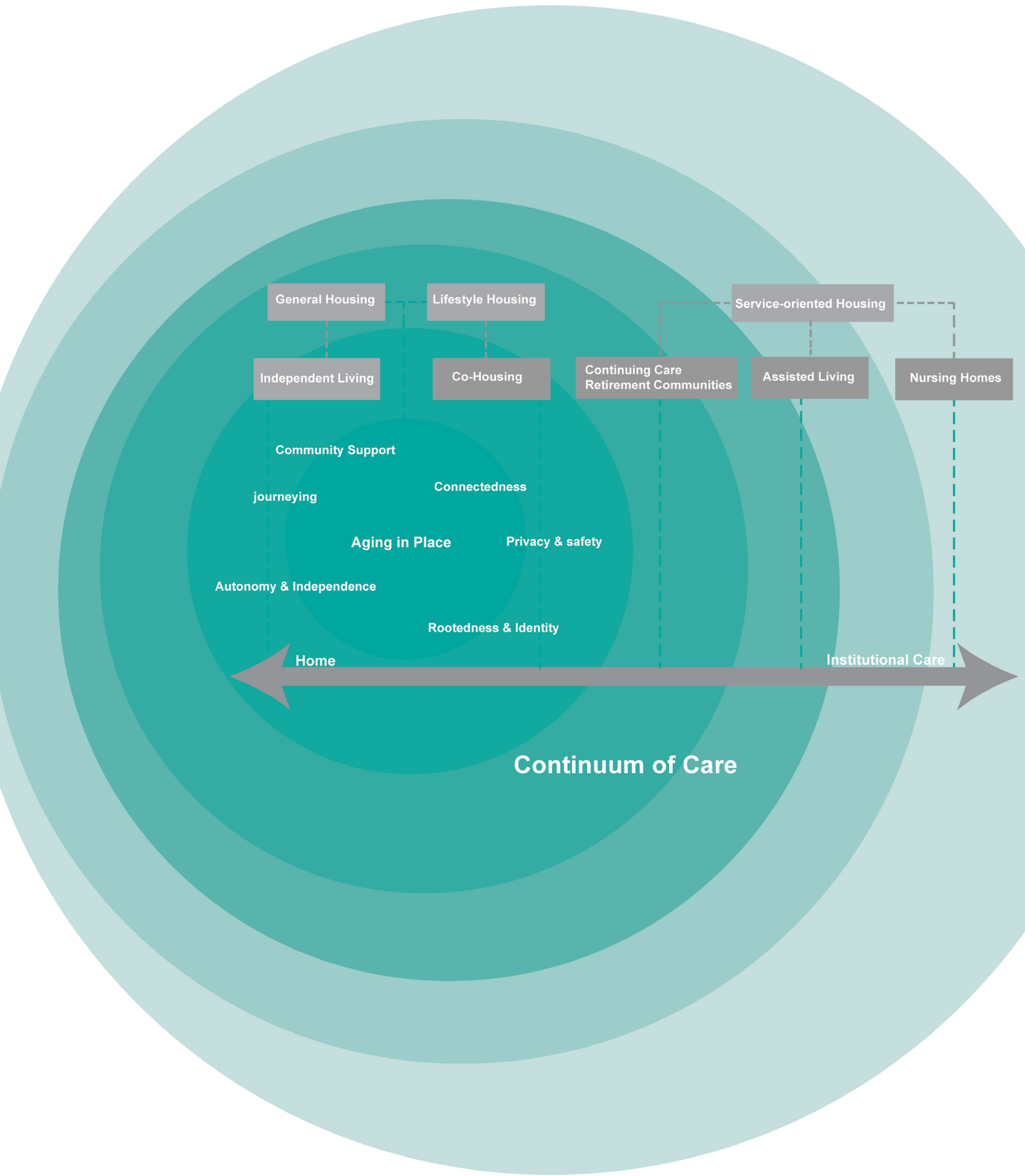

Figure 5: Contiuum of Care diagram - Fostering aging in place adapted from https://www. metlife.com/assets/cao/mmi/publications/studies/2010/mmi-aging-place-study.pdf, accessed November 6, 2016 
Current housing options for older individuals are based on the three models of care described in Aging, Autonomy, and Architecture (1999) by Schwarz and Brent. From the order of highest level of autonomy and independence and lowest level of extra care required, the three models are defined as the home model of care (aging in place), social model (assisted living), and medical model (long-term care or nursing homes). Aging in place facilitates an older person to stay in his or her own home and neighborhood for as long as possible. Assisted living is an alternative to long-term care which offers the level of care and security of a long-term care facility but still enables the individual to hold onto a sense of home by personalizing living units and providing social support. Long-term care facilities, which are based on the medical model for care, provide medical support for individuals who require $24 / 7$ assistance within a residential facility. 
Our physical environment can have an impact on how we socialize and interact with our surroundings and those around us. Certain layouts and spaces such as double loaded corridors, which are typical to multi-unit residential dwellings, can create an institutional atmosphere that does not foster socializing. These spaces can lead to isolation and loneliness as occupants are separated from others and have little opportunity to interact with others through different spaces and activities.

The current options for housing for older individuals require relocating outside of the home and often times leaving the neighborhood that they have become familiar with and have social ties to. The baby boomers will age in assisted living environments, CCRC's (Continuing care retirement communities), elder co-housing, NORC's (Naturally occurring retirement communities), nursing home, as well as aging in place. Financial drivers, values and expectations, and level of care required, are some of the factors that play a role in deciding which housing option might be best for an individual. 
The current housing options differ in the private and public realms that are present and how the individual interacts in each one. As one moves from the home to assistive living and then to institutional care, there is a decreased level of autonomy and control of the private realm and less opportunity for socializing in the public realm. The ability for an individual to participate in both the public and private realm in their surrounding allows for a sense of identity and well-being that is lost when one has to move and live in an institutional setting. By prolonging the amount of time that a person can remain in their home, it can help to preserve memory and connection to place as well as to maintain social connections that sustain a good quality of life in terms of dignity, individuality, relationships, spiritual well-being and autonomy. 


\section{Aging in Place}

Aging in place is a term defined as "remaining living in the community, with some level of independence, rather than in residential care"1. Aging in place is a process that allows an individual to maintain a sense of independence and a connection to both the home and the social support of community. Aging in place as an advantage in relation to retaining a sense of identity through independence and a sense of community, promotes a sense of well-being. With the growing population of individuals who are over the age of 65 , there is a growing need to address the issue of housing options in terms of quality and suitability to age in place.

1 Davey, Nana, de Joux, \& Arcus, "The meaning of 'aging in place' to older people", The Gerontologist, 2012, p. 133 


\section{Memory and remaining in the home}

Literature on environmental gerontology highlights the role that personal competence and the physical environment in an older person's well-being, and showing how changes at home (such as removing obstacles or introducing mobility aids) can enhance independence. Quality of life can be defined as:

Certainly, the quality of life resulting from housing types reflects a combination of: (1) personal choice of current housing; (2) the match between personal autonomy or independence with housing resources; and (3) social support provided to maintain residence in a specific housing type. Living in one's home or personal dwelling should provide the highest degree of personal autonomy and access to resources of all types. Research indicates that independent living promotes life satisfaction, health, and self-esteem. ${ }^{2}$

2 Janine L. Wiles, Annette Leibing, Nancy Guberman, Jeanne Reeve, and Ruth E.S. Allen, The Meaning of "Aging in Place" to Older People, The Gerontologist Vol. 52, No. 3, 357-366, October 7 , 2011 
The connection between a sense of identity and attachment to place is significant in terms of the daily activities one performs such as cooking, eating, reading, and sleeping. Living at home provides a sense of identity, safety, and connectedness and are some of the factors that make a homelike setting comfortable.

The types of assistance provided through home care rather than medical care are much cheaper and are vital to help seniors stay in their homes longer. Social support and autonomy are key factors older adults require to stay at home. ${ }^{3}$ According to the World Health Organization, remaining in one's home and community also lowers the costly need for institutional care that are associated with assistive living and long-term care. ${ }^{4}$ What leads to leaving the home?

With the death of a spouse, decline in mobility and health, and/or lack of social support, an older individual may require a higher level of extra care than available in a home setting. An option may be to move into an assistive care environment that will help to meet the needs of the individual. ${ }^{5}$

3 Ellen D Taira, Jodi Carlson, Aging in Place: Designing, Adapting, and Enhancing the Home Environment, Routledge, 2014, p. 105

4 "Global Age-friendly Cities: A Guide", http://www.who.int/ ageing/publications/Global_age_friendly_cities_Guide_English.pdf accessed March 4, 2016

5 Schwarz, Brent, and Ruth Brent Aging, Autonomy, and Architecture, The Johns Hopkins University Press, 1999, p.81 


\section{Assisted Living}

Although most individuals may want to live in their home for as long as possible, assisted living is an available option for those who require extra support. Assisted living settings provide an older individual with the services, care, and security of long-term care facilities (medical model) but are also meant to provide a homelike atmosphere that is reflective of a more social model. Assisted living is defined as:

Assisted living is a long-term care alternative that involves the delivery of professionally managed personal and health care services in a group setting that is residential in character and appearance; it has the capacity to meet unscheduled needs for assistance, while optimizing residents' physical and psychological independence. ${ }^{6}$ 
Assisted living is an alternative to moving into a long-term care facility, however, nursing homes may be the best option for someone who requires a higher level of care.

Assisted living programs aid older individuals in their desire to remain independent and maintain their quality of life. Assisted living settings come in a variety of types including facilities such as retirement homes that are private sector accommodations with support services and staff care for residents available 24 hours per day, to meet the regular care of residents. Other types of assisted living facilities include co-operative housing, where residents do not own equity in a home but instead take part in the decision making process for their community in terms of how it is run. These types of living programs and arrangements are known as a 'social model' since the individual still maintains a high level of independence and opportunity for interaction. 


\section{Long-term care Facilities}

Although most people may wish to age in their own homes, seniors may not always have the choice to do so when they require a level of care that is not available through home care. For adults who have cognitive impairments that evolve to the point where they need a level of support and care that is not available in the home, moving into a long-term care residence is one of the options available to them. Long-term care facilities, or nursing homes, are suited for the elderly and people who do not require hospitalization but require extra care beyond that available at home care or in retirement homes.

There is a growing population of older individuals in Canada who stay in long-term care (LTC) facilities with over 600 facilities in Ontario alone that house more than 70,000 residents as of 2005 . As of May 2015, the wait list for long-stay beds was $23,443 .^{7}$ These figures show the demand on the institutional system for providing enough facilities and support to meet the needs of the seniors and individuals who require long-term care. Long-term care facilities are part of the 'medical model' of care and generally are the last resort for an individual who requires extra care and can no longer remain in their home or assistive care.

7 "About long-term care in Ontario: Facts and figures" http:// www.oltca.com/oltca/OLTCA/LongTermCare/OLTCA/Public/ LongTermCare/FactsFigures. aspx?hkey=b4823fa8-b615-49e38097-e67fa4224d40 (accessed on April 18, 2016) 
Long-term care facilities are sometimes built almost as hospitals with an institutional feel, where they should be seen as homes where people live. In Holding On To Home, Cohen describes how longterm care homes do not always reflect the needs and preferences of residences and require designers and planners to think critically as to how to design residential dwellings for an elderly demographic that may be experiencing different levels of physical and cognitive impairment.

\section{An Alternative Strategy}

Based on the current housing options available to senior, this thesis proposes the design of details as part of a larger set of guidelines that serve as an alternative to some of the standardized and institutional details that are used in the design of residential dwellings for the elderly. This is done through reading of the literature of design for physical and cognitive impairment and how the built environment can act as a support to individuals. Uriel Cohen outlines his five principles as: providing public to private realms, having positive outdoor spaces, clusters of small activity spaces, other living things, and providing opportunities for meaningful wandering ${ }^{8}$. In adapting the principles to an existing setting, the adapted guidelines are meant to move residential dwellingsfrom not providing welcoming transitions from public to private realms 
to providing a welcoming entrance; from not having activity spaces to providing areas for gathering, socializing, and medical care; from not having areas for exercise to adapting the existing stairwells to corridors to foster movement; and to provide a feeling of home even when living in a multi-residential dwelling.

The design proposal is meant to be adaptable to an existing structure or for new construction. The role of the senses in satisfying our need for a connection to the harmony and equilibrium of our surroundings probes the investigation of how architecture can be a positive factor in stimulating and engaging our senses. Our experience of architecture is one that is generally limited to the visual perception of the space that does not engage the entire body and its other senses. As Juhani Pallasmaa states in The Eyes of the Skin: Architecture of the Senses, "[t]he weakening of the experience of time in today's environments has devastating mental effects...We have a mental need to grasp that we are rooted in the continuity of time, and in the man-made world it is the task of architecture to facilitate this experience" . ${ }^{9}$ 
Pallasmaa acknowledges that space can have an effect on our wellbeing and thus our built environment should provide an experience that grounds us in place and time by appealing to all of our senses. These aspects, which may not be included in the design phase for a residential dwelling are important and can be incorporated into design standards and guides.

The building codes are at times not easy to follow and serve as minimum standards which do not address the characteristics of the aging process that have an impact on an older adults' relationship to their environment including cognitive impairment, loss of strength and balance, visual and hearing impairment.

People want to stay in their own homes, and although they may have certain mobility or cognitive impairments, with the proper support and care, they can stay at home for a longer period of time and the model of care can be changed to allow individuals to maintain their lifestyle for as long as possible.

Moving into institutional care can be expensive and new construction is costly and may not be constructed in enough time or in large enough numbers to accommodate the rising needs. As such, making use of the main circulation routes, such as stairwells and hallways, entryways, individual living units, the building can begin to evolve to meet the requirements of the population while still allowing them to remain in their neighborhoods and maintain their ties to the sense of place. 


\section{CHAPTER 2 - HOUSING MANUALS}


New construction and existing buildings are regulated by different types of regulation including construction codes. The construction codes including a code which is meant to provide a minimum level of safety and protection for the building occupants as well as the public. The design, construction, modifications, repairs, and demolition of buildings are regulated to ensure the minimum standard of health and safety is met. The building codes generally provide either a prescriptive or performative approach to complying to the codes. The prescriptive approach details the materials, size, and construction techniques that have to be used, while the performance approach sets a specific level of performance that has to be met in order to be acceptable. The current codes are generally prescriptive. Updates are made to the code that relate to elimination or addition of references or requirements. Building codes change to adapt new technologies and products, and to the evolving needs of the building occupants. ${ }^{10}$

Housing codes provide the minimum level of health required in existing residential occupancies such as one- and two- family dwellings, apartments, and hotels. Additional guidelines can be used to encourage the adoption of health and safety guidelines that address the needs of particular occupants, in this case, for those who wish to successfully age in place.

10 David B. Hattis, "How existing buildings and building rehabilitation are regulated", Bulletin of the Association for Preservation Technology, Vol. 13, No.2, APT, 1981, p.9 
"Although local building regulation is the political responsibility of local government - and regulations are thus formally enacted and enforced by elected representatives - the technical complexity of such standards suggests that local building officials exercise considerable influence in proposing and evaluating alternative sets of standards." 11

In The Unapproved Document O, by Sarah Wigglesworth, the design guidelines presented make use of narrative as well as informative graphics which reinsert the human figure into the design process. The manual also acts as an agent for promoting a greater understanding of how the physical environment can serve as a support for older individuals who may be experiencing mobility impairments. By acting as an agent and bridge between the standard details and the actual needs of occupants, the manual serves to foster a means of knowledge exchange between government requirements and occupants.

11 Oster and Quigley, 365, Regulatory barriers to the diffusion of innovation: some evidence from Building Codes, The Bell Journal of Economics, Vol. 8, No. 8 (Autumn, 1977
The Building Regulations 2016

\section{Design for Ageing}

UNAPPROVED DOCUMENT

01 General Guidance

O2 Dwellings

2016 edition - for use in England*

Figure 32.2 Higure 322 22 Doced Doument O: Design for Ageing:
Williams at Sarah Wigglesworth Architects

Figure 6: Unapproved Document O, Sarah Wigglesworth

\section{1}

$$
\text { Section 1: Dwellings }
$$

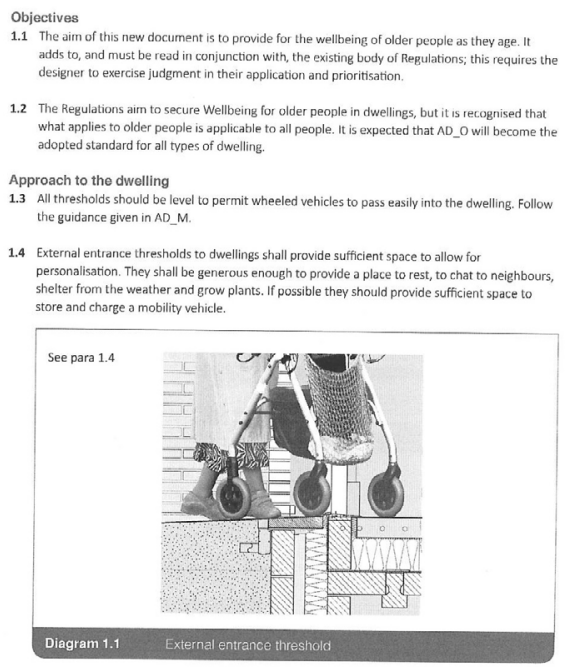

Figure 7: Unapproved Document O, Sarah Wigglesworth 
The design of the built environment based on standard details does not necessarily address the emotional and spiritual well-being of individuals occupying those spaces. This standardization has led to what are sometimes more sustainable and haptic details not being used because they are not readily understood or implementable without the support of the code.

The details implemented can be developed to make use of recycled materials and begin to speak to recycled architecture and sustainability. The process of reusing materials can be understood as a new way to explore the technologies of dwelling. Seen from this perspective, the technologies that arise from necessity can be converted into new technological solutions. 
The design professional can facilitate the incorporation of designs that ensure accessibility and social aspects are addressed, in this case for the process of aging in place. Initiating spatial agency through design guidelines can help to speak to the social and physical needs of aging in place and highlight the importance of designing details that address the needs of the aging population.

The details and guidelines also work to give an adaptability to homes that allows senior individuals to maintain their way of life in their homes. Although not ideal conditions, the guidelines begin a dialogue of the right to the city for all citizens and speaks to the issue of housing for the aging population in Canada.

By engaging directly in the design and construction of residential dwellings for those wishing to age in place, there is a close link to understanding the needs of building occupants, and designing details and adaptations that are specific to place and provided a service to the community. The durability of the social aspects of living in the multi-unit residential buildings can be addressed by providing spaces of sharing, engaging, and movement for senior residences and other occupants. 
Another aspect of materiality and the sustainability aspect of residential dwellings is the use of recycled or alternative materials from those found in building codes.

One of the key features of cities is density, however sensitivity to the social fabric of a community has to be taken into account and constructing high-rises may not always be the best solution. One of the questions to ask is if there are other ways of densifying cities that also respects organically developed social structure. The proposal for the Ottawa region and surrounding cities includes multi-unit residential buildings within the city and periphery. This would have the positive effect of protecting the existing social fabric of the city. Construction costs can be high and are generally unaffordable for lower income groups, who make up a large proportion of seniors living in multi-unit dwellings. More cost-efficient lower buildings allow people of different income groups to meet the basic need of having a home to dwell in.

This question has helped to guide this research and this thesis and can be seen in the design guidelines presented hereafter. 
Ottawa 2015 Accessibility Design Standards

Common Elements

Ramps

Stairs

Guards and Handrails

Rest Areas

Seating, Tables and Work Surfaces

Exterior Elements

Parking

Passenger Loading Zones

Exterior Paths of Travel

Curb Ramps and Depressed Curbs

Interior Environments

Entrances

Doors and Doorways

Interior Accessible Routes

Washrooms

Showers

Systems, Controls and Communications

Assistive Listening Systems

Acoustics

Fire and Life Safety Systems

Lighting

Signage and Wayfinding

Windows

Special Facilities and Spaces

Meeting and Multi-Purpose Rooms

Cafeteria and Dining Facilities

Recreational and Community Facilities

Balconies and Terraces

Visitability-Housing

Inclusive Play Space Design Guide

Public Transit 


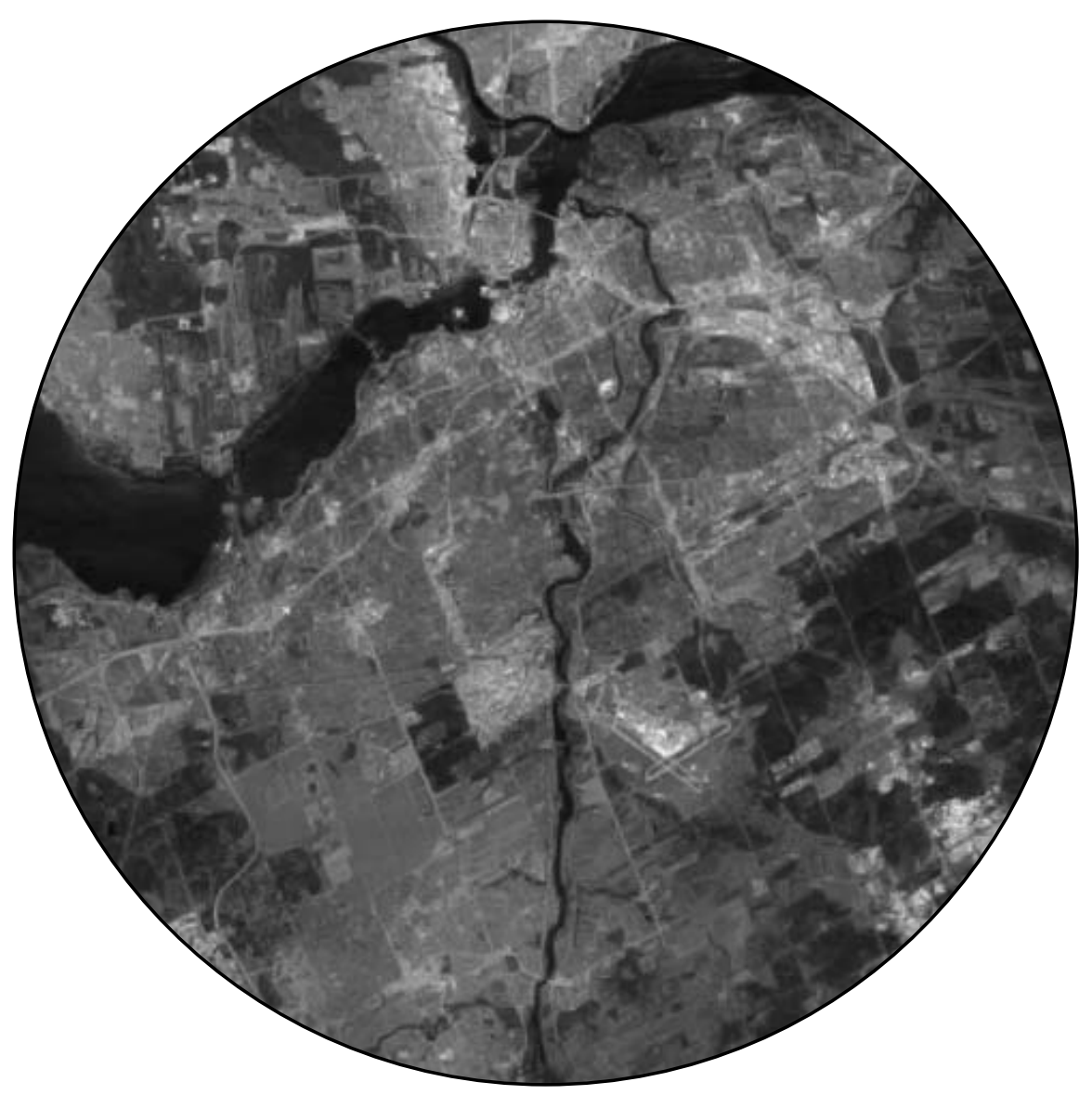

Figure 8. Ottawa Aerial image Source: Google Earth

\section{Existing Mid- to High-Rise Housing - Ottawa}

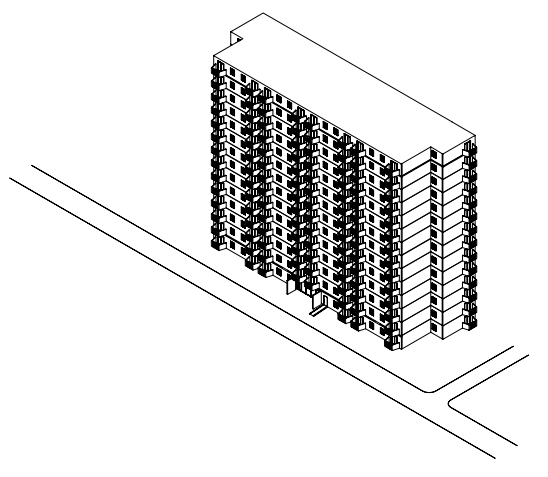

Figure 9. Typical building axometric drawing Source: Tapiwa Molife

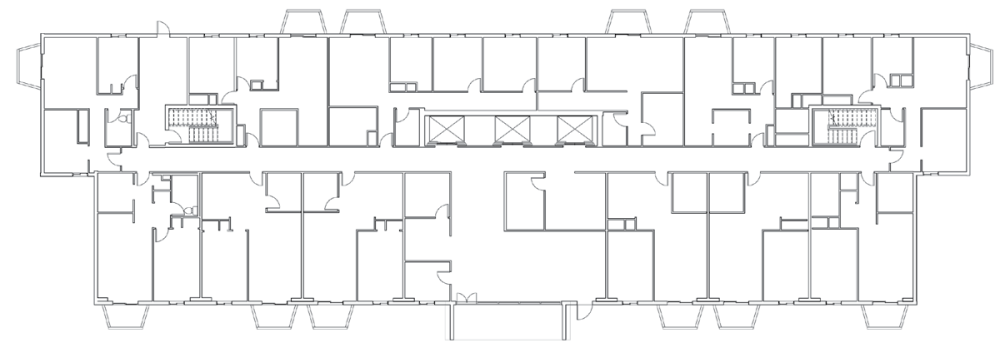

Figure 10. Typical Building plan Adapted from Paramount Properties 


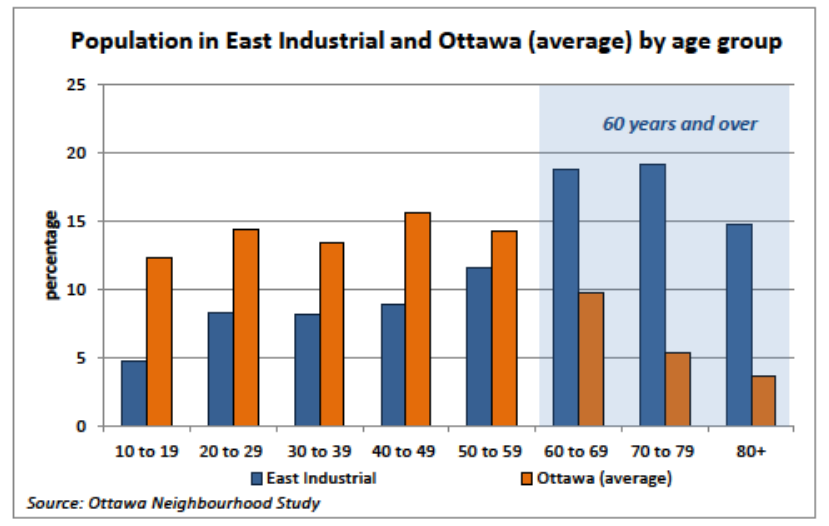

Figure 11

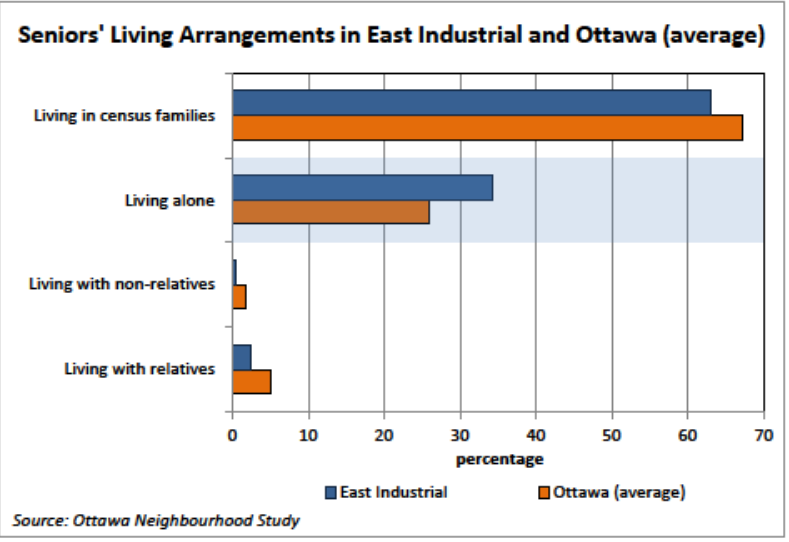

Figure 13

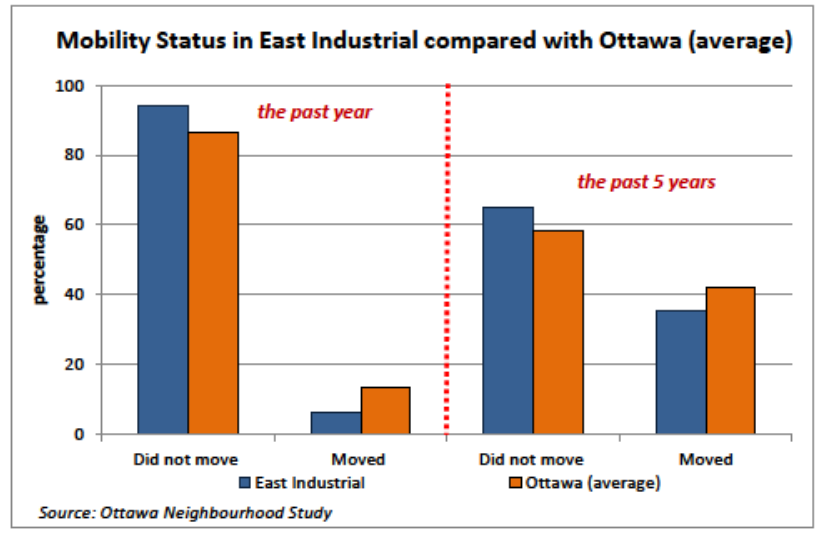

Figure 12

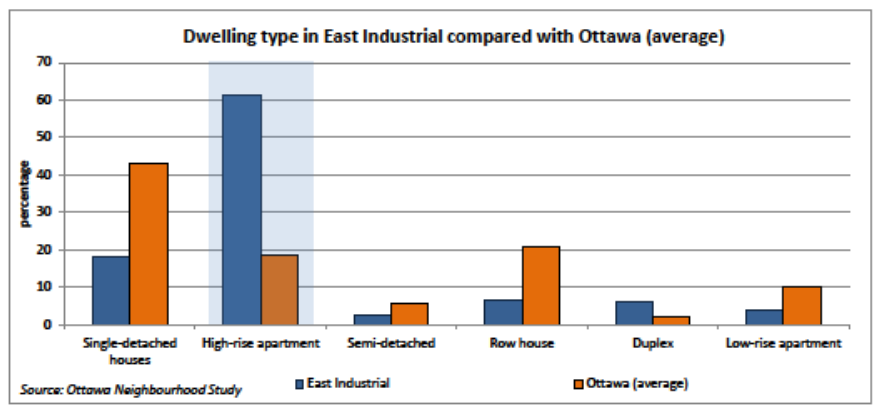

Figure 14 


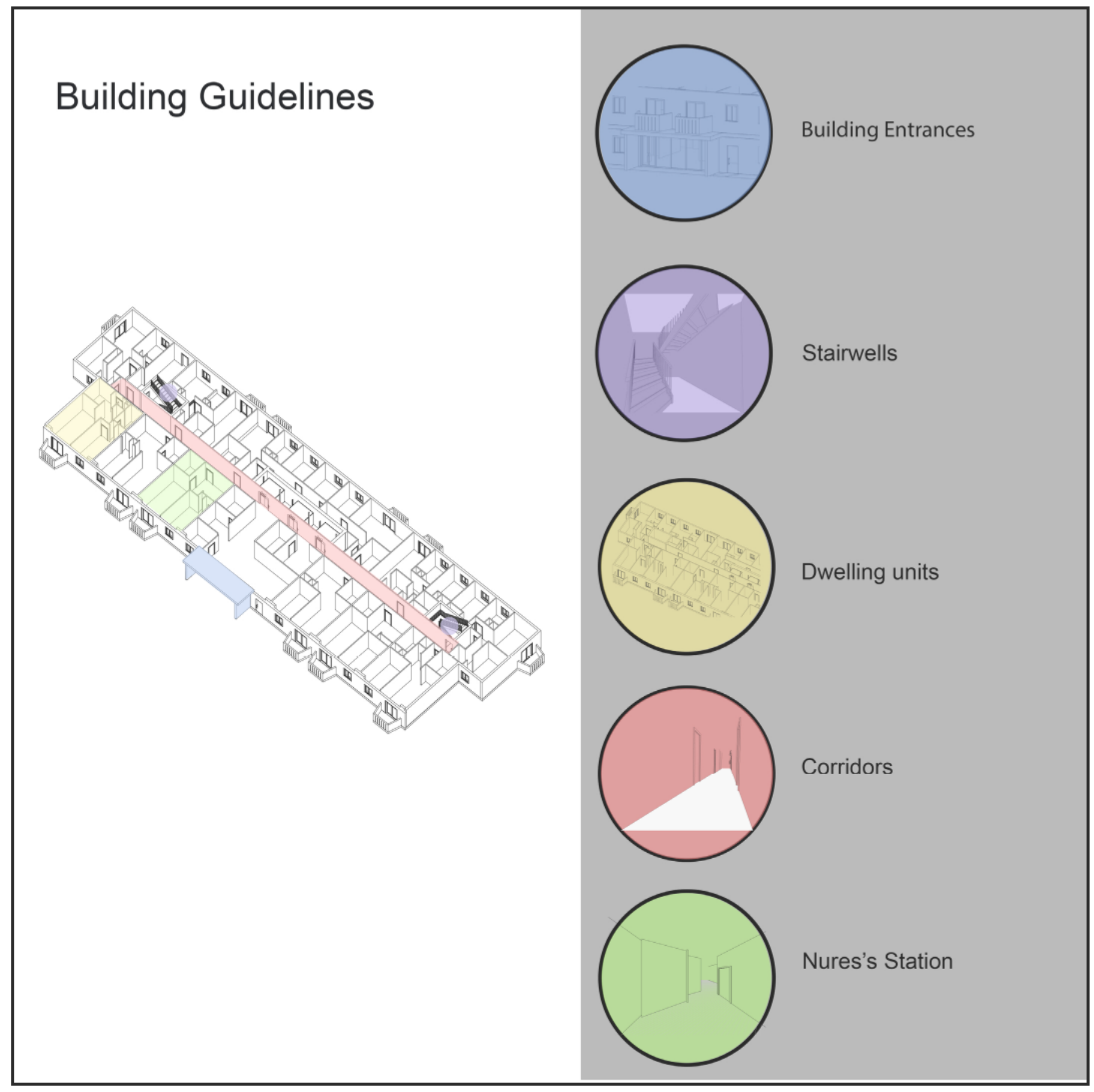

Figure 15: Building Guidelines Source: Tapiwa Molife 


\section{Aging in place Guidelines}

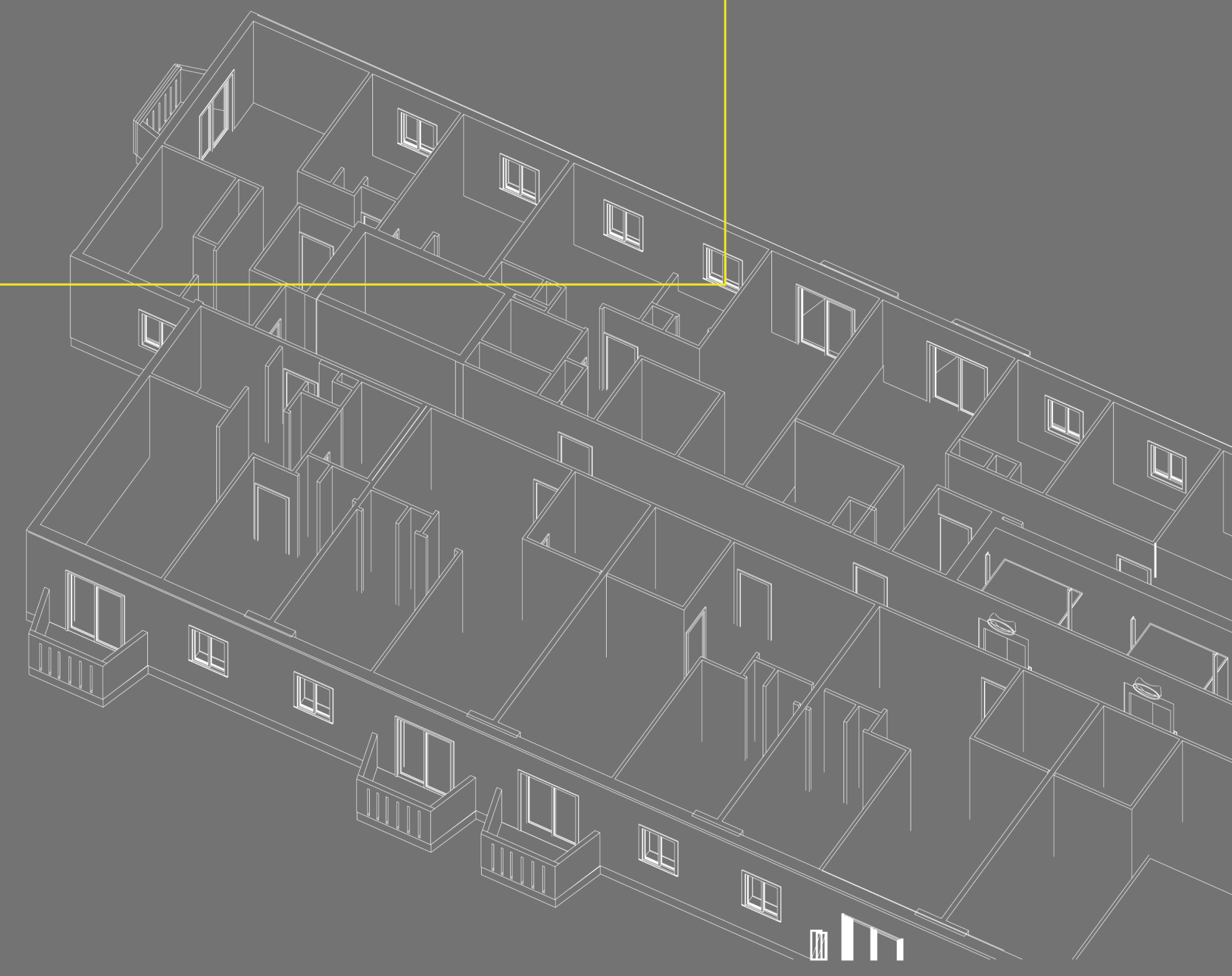




\section{Part Two Aging in Place}

DESIGN GUIDELINES MANUAL 


\section{Existing Building}

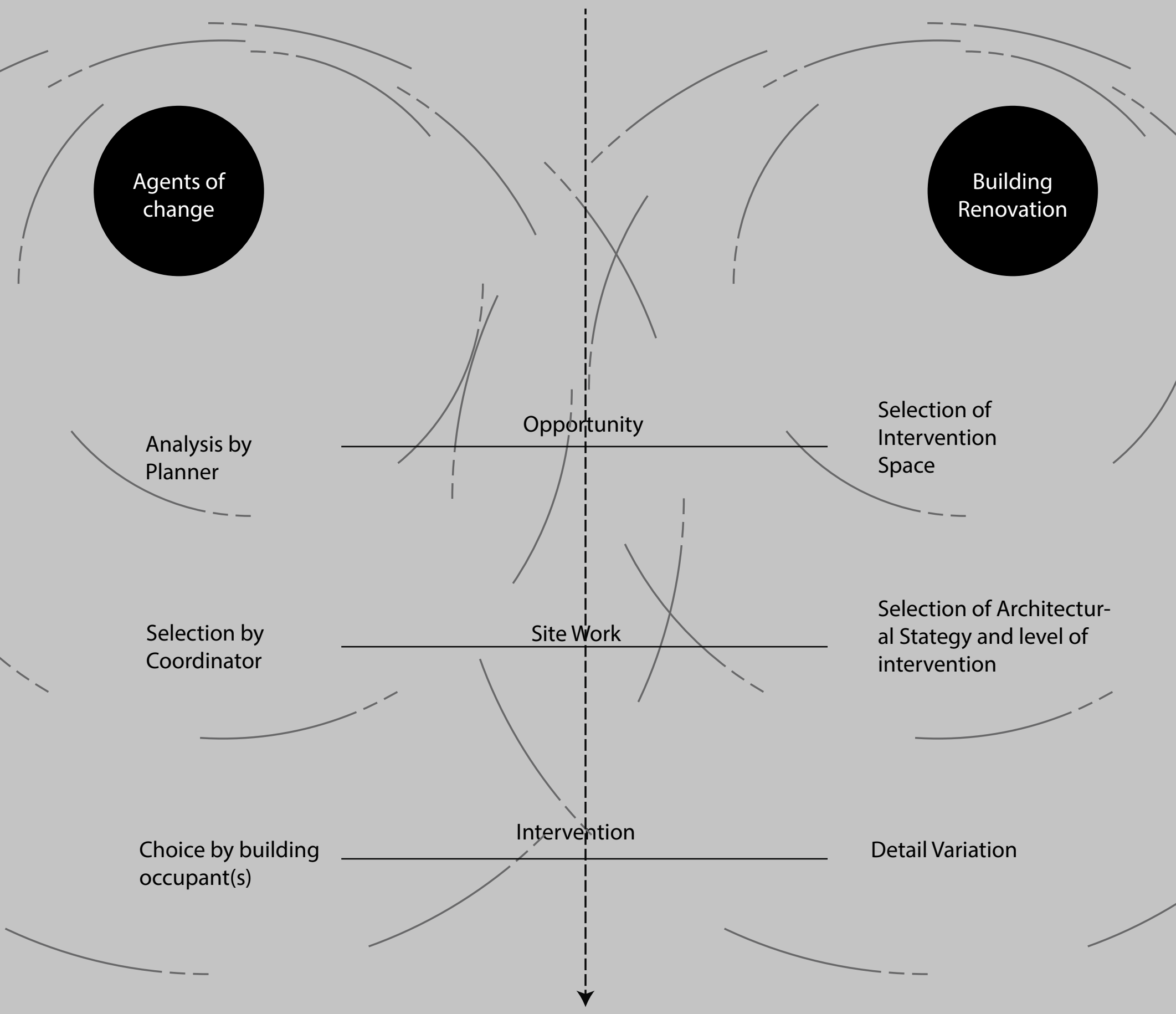

Renovated Space 


\section{Key Architectural Strategies}

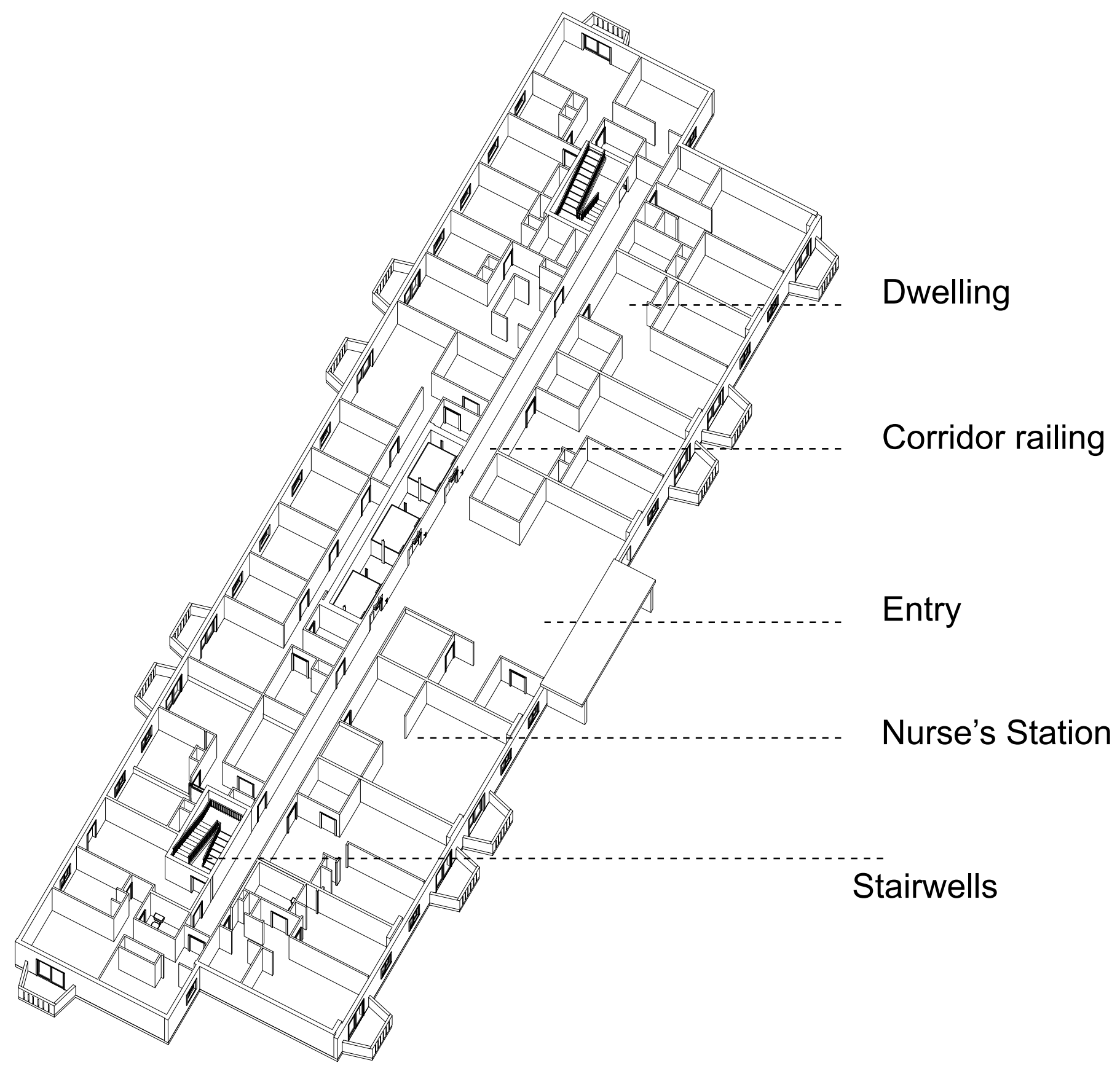

Figure 18: Building Axonometric drawing 
3.1 INTRODUCTION 


\subsubsection{THE MANUAL}

This manual is meant to serve as a companion to the standad building codes by presenting guidlines for the adaptation of existing residential dwellings to better serve older individuals in successfully aging in place.

The details presented in the guidelines directly speak to the connection between the built environment and the supportive needs of the aging population and the evolving of physical impariments and loss of mobility. This continues the discussion and passing of information on how professionals can effectively design for the process of aging in place.

These guidelines are not exhaustive but serve to present details and concepts that can be applied to appropriate existing residential dwellings as well for new construction. 


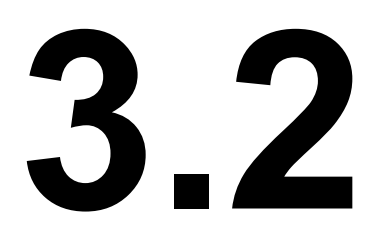

GUIDING PRINCIPLES 


\subsubsection{Guiding Principles}

1. Create a welcoming public space in the front lobby area that offers both security and spontaneity for residents and visitors.

2. Break up corridor paths and create a supportive system of assistive wal king, decoration, seating, and a greater sense of connection to place and home by adapting the existing semi-public circulation spaces of corridors to become opportunities to create a sense of place and an inviting external threshold to the micro community of each floor in the daily life of the resi dents in the building.

3. Make use of underused spaces such as stairwells as an opportunity to create spaces for exercise

4. Create a series of architectural interventions that connect various activities that are accessible

5. Foster the role of the public space in the apartment building through distinct architectural strategies, that are common to the public realm of the buil ding. 
3.3 Building Entrances 


\subsection{BUILDING ENTRANCES}

\section{Objective:}

Entry into a building includes all access points for the coming and going of residents and visitors. The building entrance consists of the threshold, the circulation route through the building, any vestibule area or lobby area within the interior. Thresholds serve as the transition from the public to the semi-private realm of the building. Building entrances reinforce the character of the public realm, and provide a local identity to the occupants and offers space for occupants and visitors to rest and socialize. These guidelines aim to prioritize creating spaces for all to have access to and to enjoy.

\subsection{1}

Provide a smooth transition from exterior to interior by providing safe and continuous access such as level thresholds and ramps for transitions from zones, as well as providing adeqaute lighting.

\section{4 .2}

Enhance the character of the entryway and encourage occupant use by considering the needs of all building occupants and differing accessibility needs.

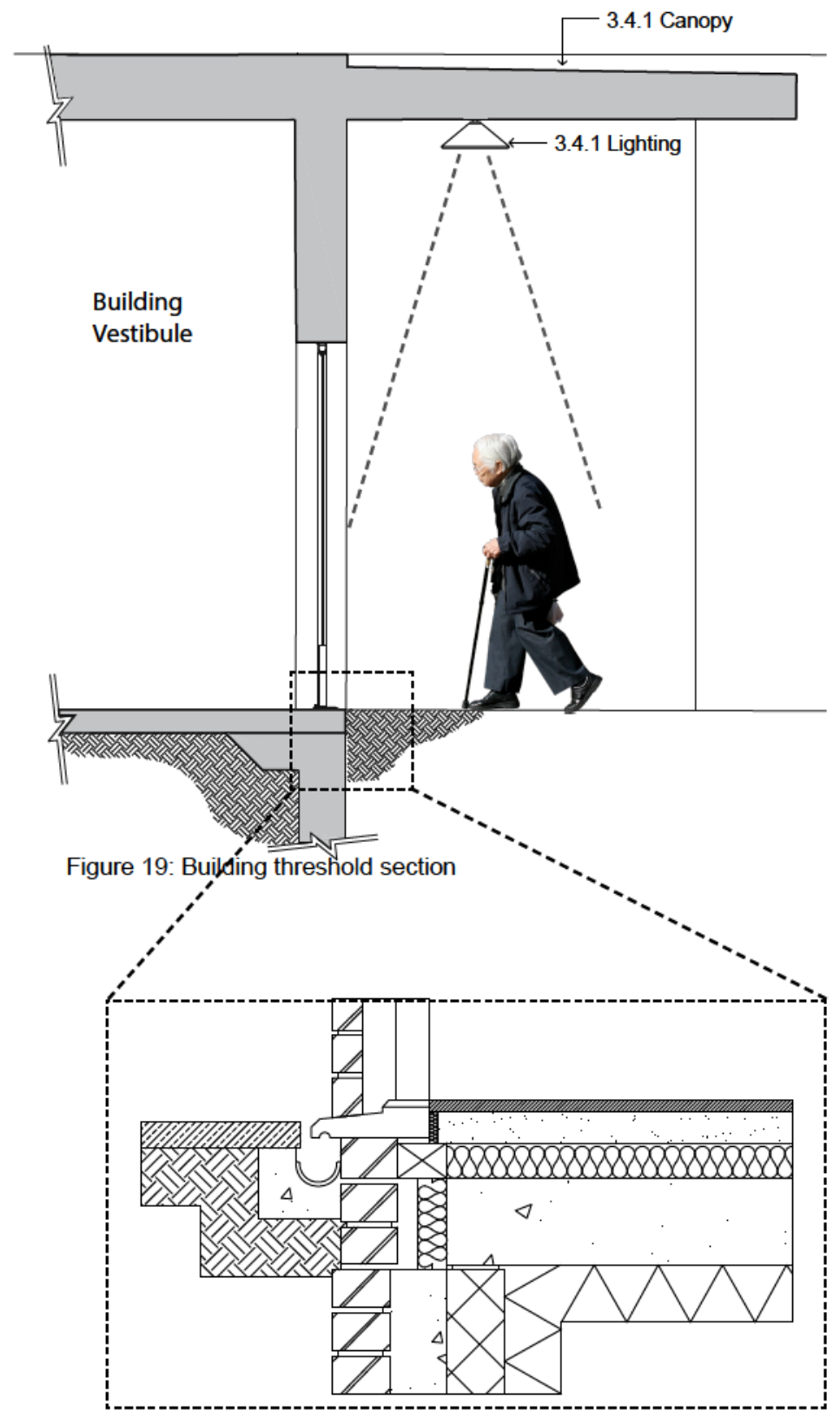

Figure 20: 3.3.1 Level threshold detail 

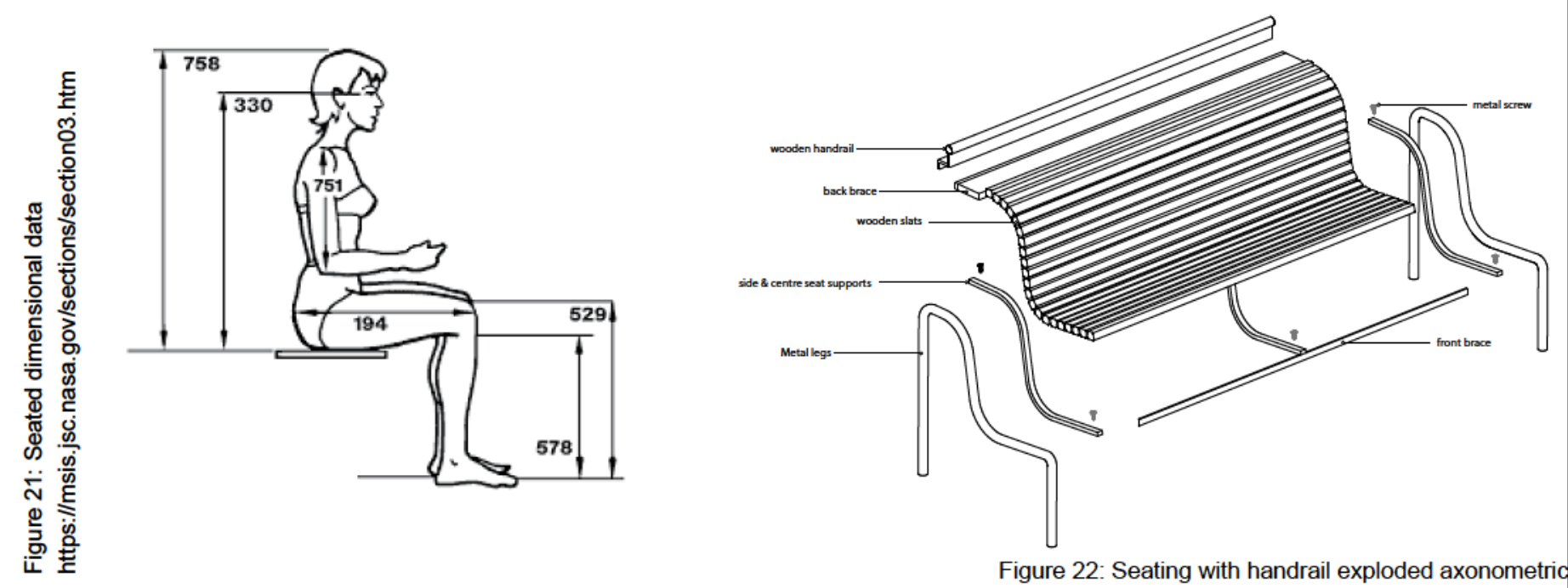

3.3 .3

The entry functions as part of the 'four faces' of the building that are visible to the public. As such, having an entry that is inviting enhances the quality of the space to feel more like 'home' and not like an institutional setting. The entry is part of the main circulation route and providing uses at the entrance helps to enhance the arrival and departure of residents and visitors as well as a place to pause. Seating in the lobby area also provides views to the exterior street and the drop-off areas.

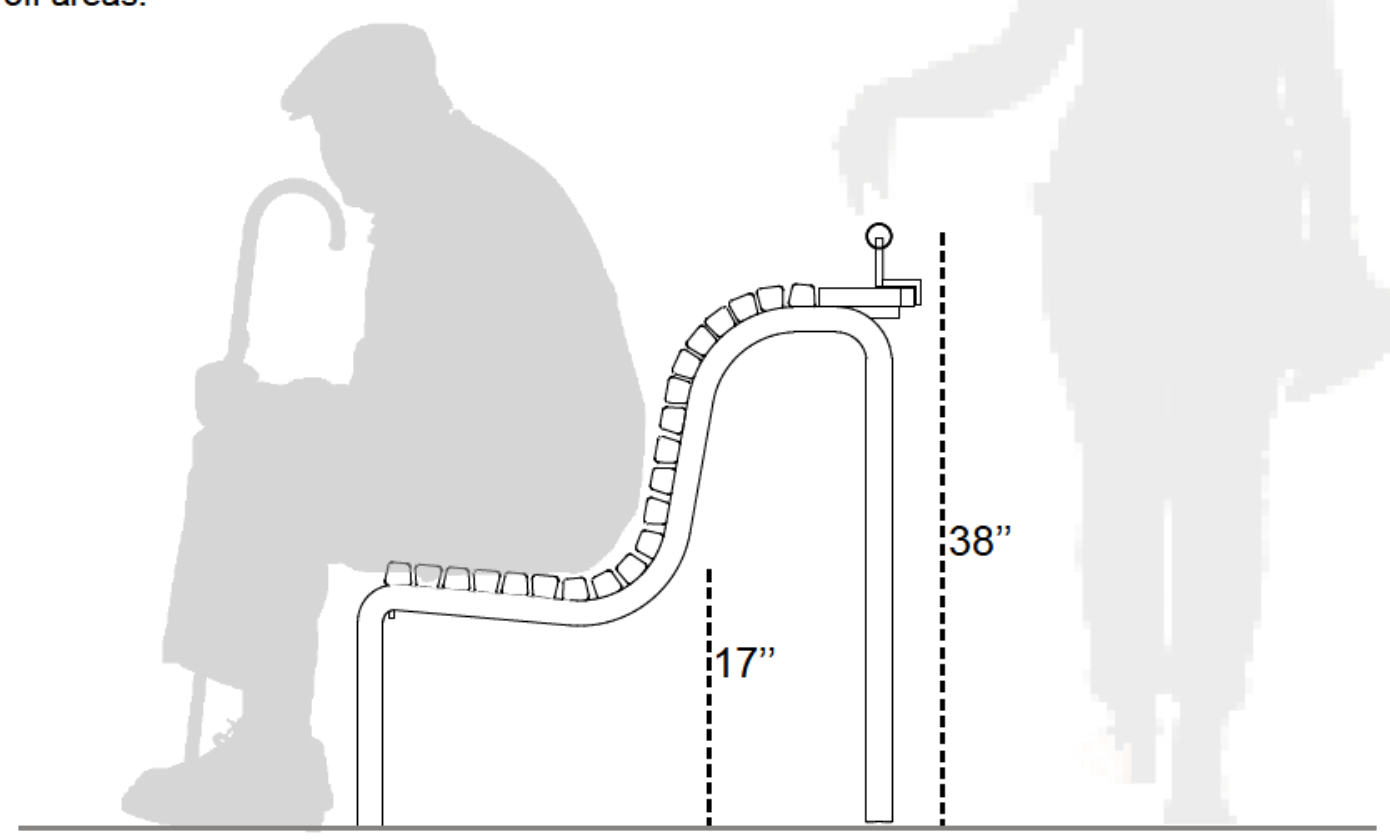

Figure 23: Seating with handrail 


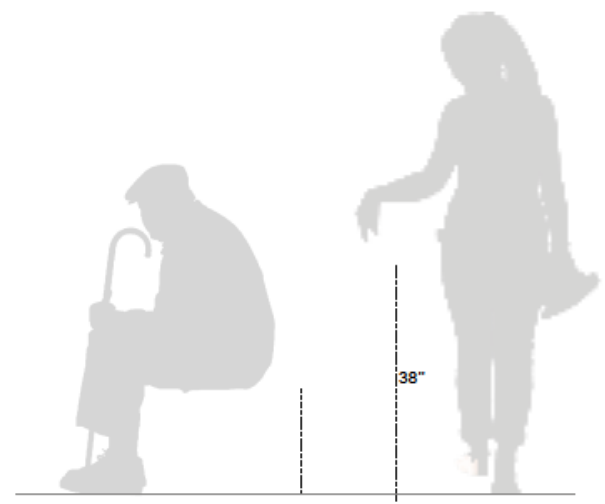

Figure 24: Seating with handrail

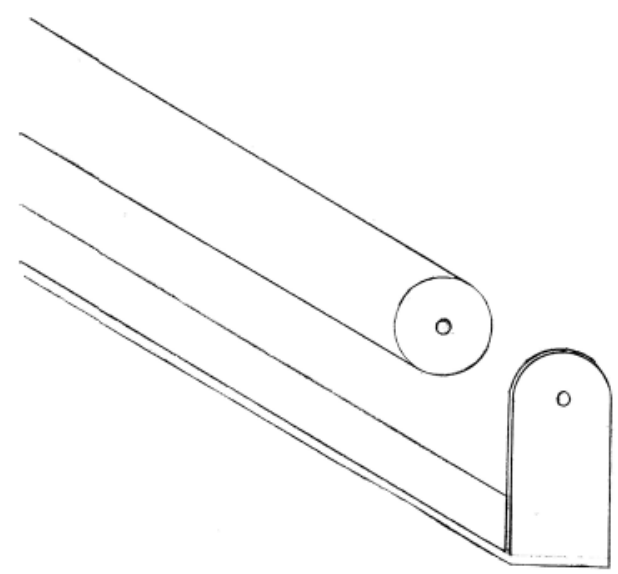

\section{Materials}
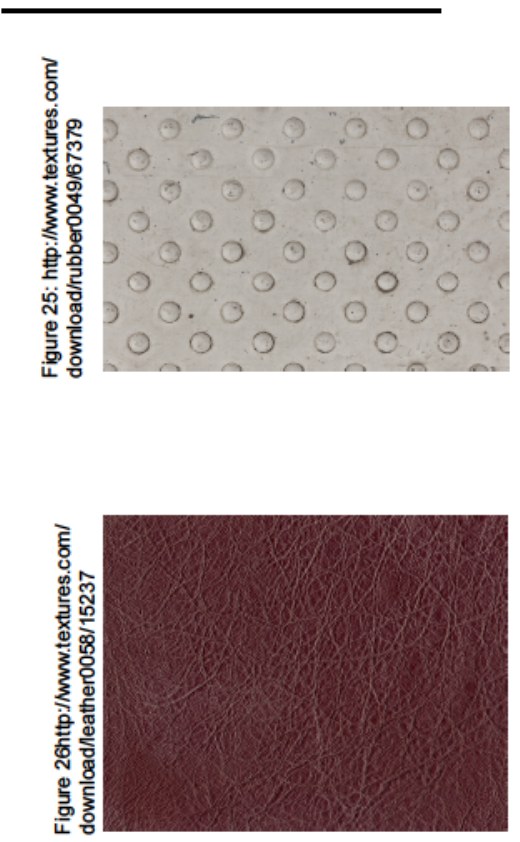

Leather provides a soft texture and warm color to thebuilt-in handrail

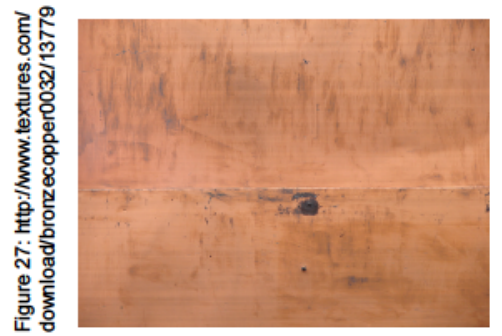

bronze finish handrail ofers a simple and durable option
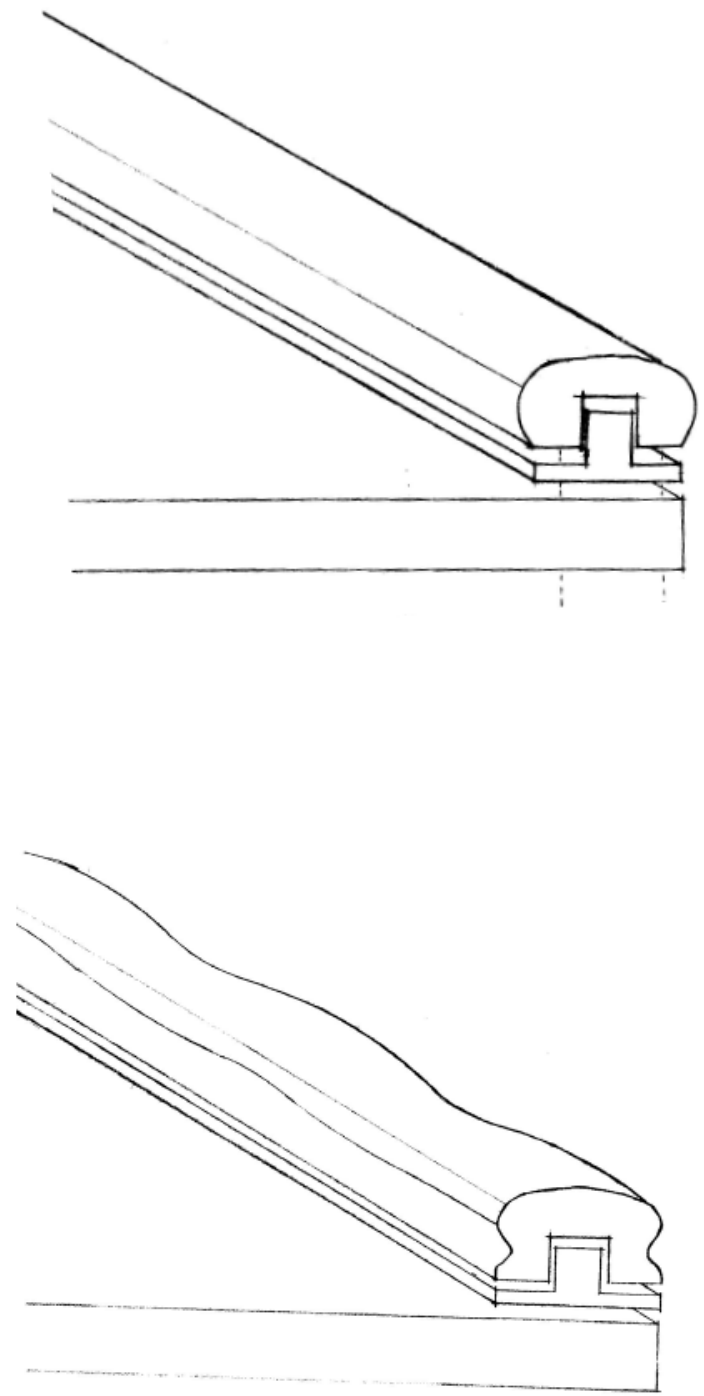

Figure 28: Handrail profile options 


\section{Building Entrance}

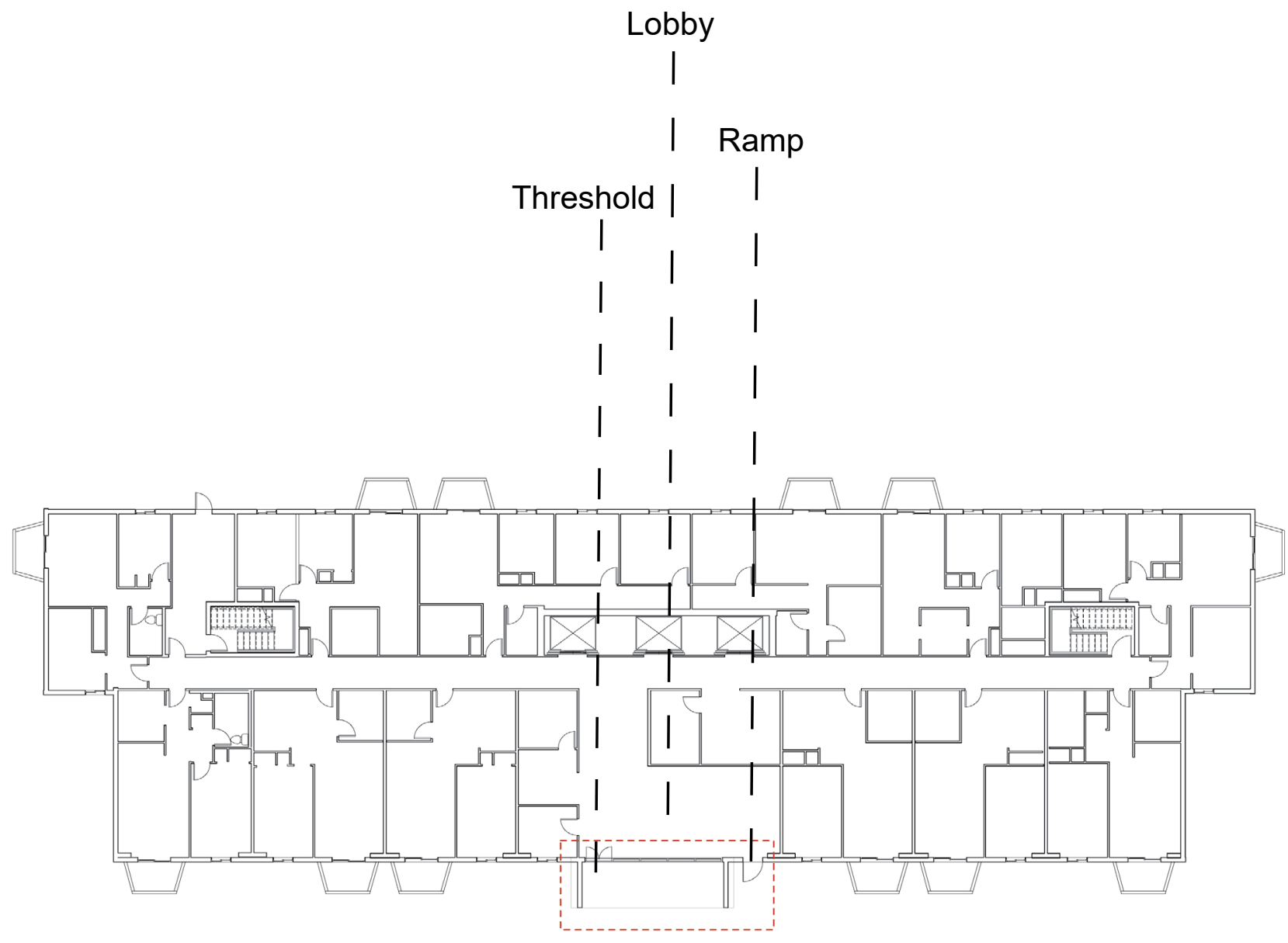

Figure 29. Area Plan: Entrance 


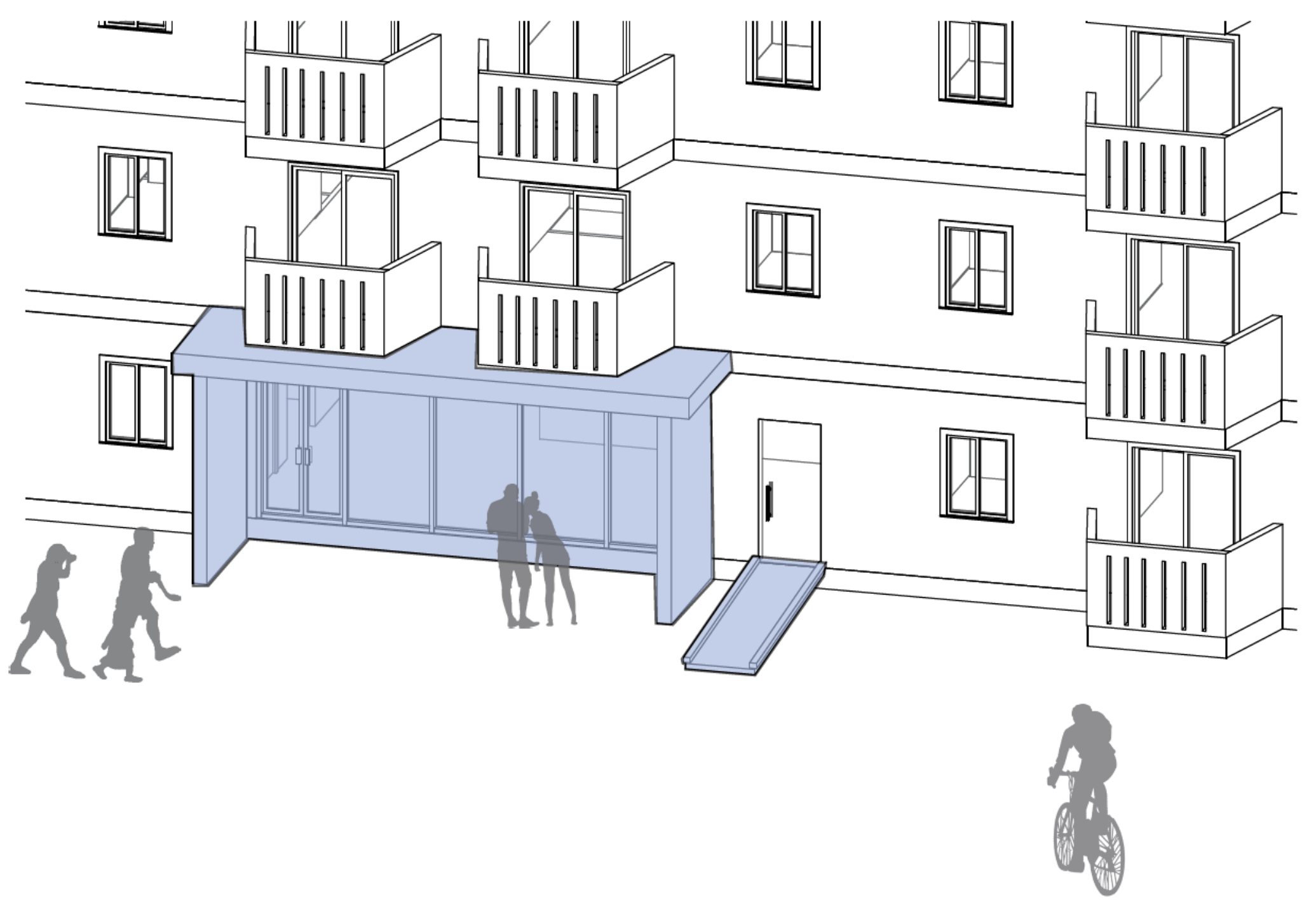

Figure 30. View of Entrance 


\section{Project Description:}

The project consists of providing a homelike atmosphere to the entrance space. For this, the proposed interventions are:

- Enhance the quality of the space by restructuring the lobby area and providing clusters of mobile and fixed furnishing;

- Install acoustic ceiling treatment;

- Replace wall finishes by either re-painting or using a wall treatment of wood paneling;

- Enhance the quality of lighting by placing spot lighting and/or lighting fixtures throughout the lobby area.

Classification of Alteration Work:

Minimal alterations - Level 1: existing buildings undergoing Level 1 alterations which include replacement/ addition of elements or fixtures. Alterations require minimal space reconfiguration and can be completed immediately with a minimal budget.

Expanded - Level 2: alterations that may include space reconfiguration. Alerations can be performed over time.

Expanded - Level 3 - alterations which include extensive renovations and/or space reconfiguration 


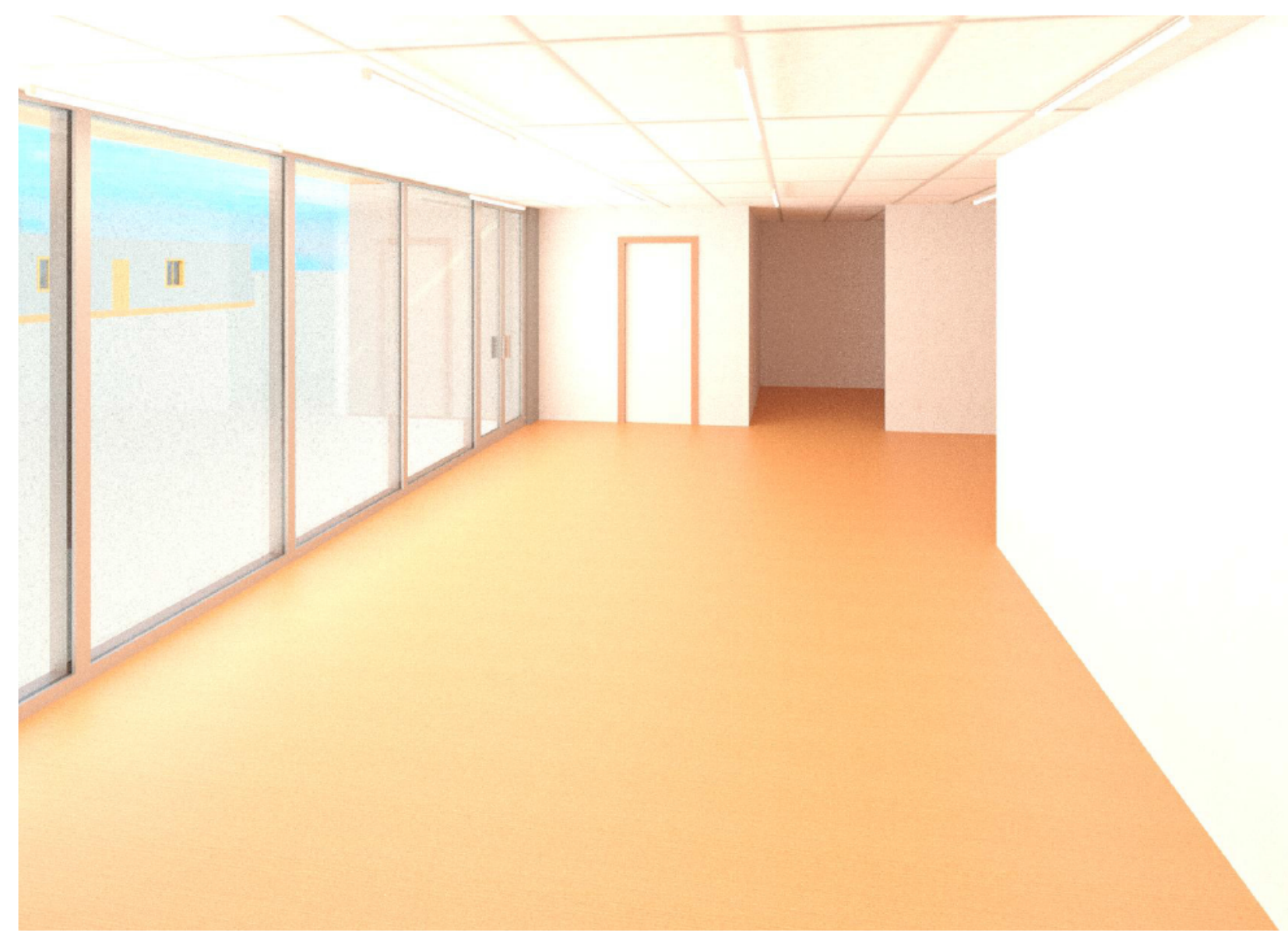

Figure 31: Typical view inside entry lobby

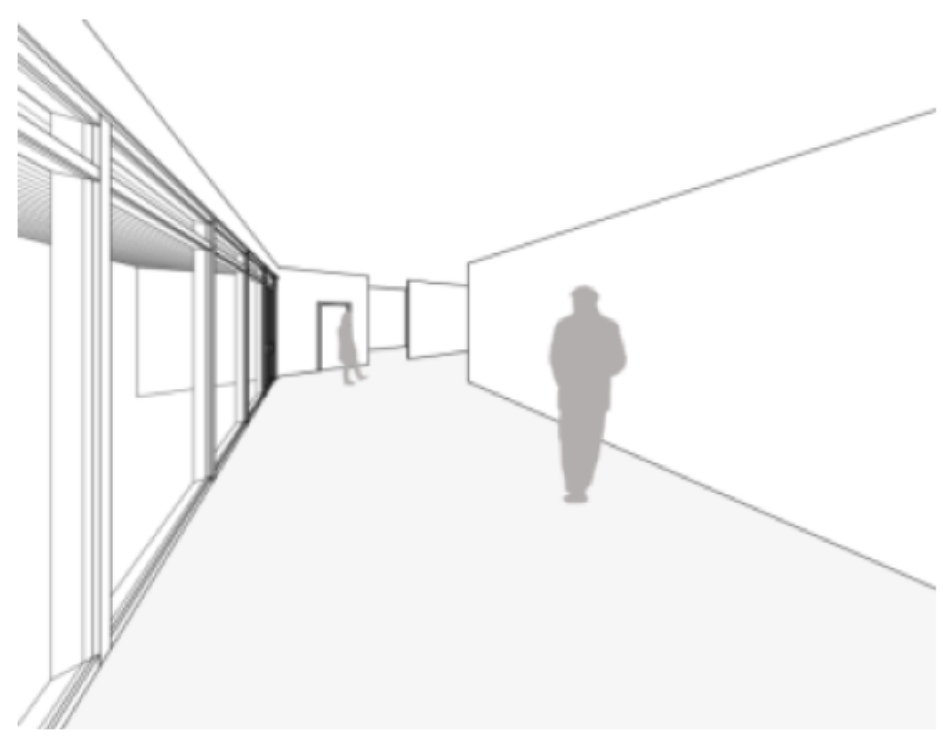

Figure 32: Sketch: typical view inside entry lobby 


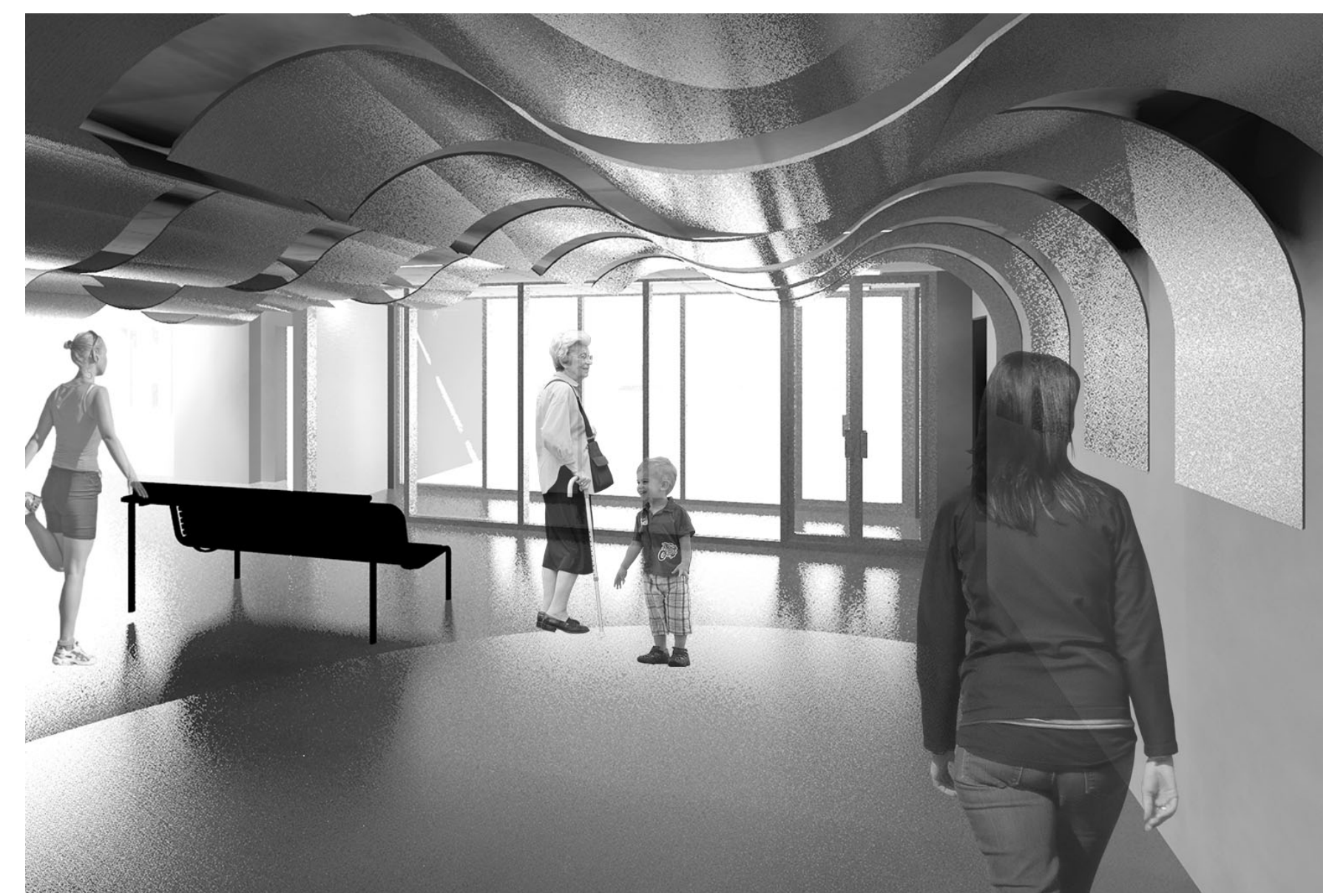

Figure 33: Renovated lobby area

Incorporate active uses along the building entry to enhance the quality of the space and the relationship with the public realm of the building. This can be done through the design of lobby space, seating area, small stores, and communal spaces in the entry area. 
3.4

Nurse's Station 


\subsection{NURSE'S STATION}

\section{Objective:}

In order to age in place successfully, the adaptation of residential environments has to address the loss of balance, visual, hearing and cognitive impairment that individuals may experience as they age. Residents may require extra care, which can be provided by a community resource or program. In the case of multi-unit dwellings, converting on the units into a nurse's station will help to meet the care needs of those individuals who require it.

Nurse work areas can be investigated to determine the size, activities performed in considering the spatial requirements of the room.

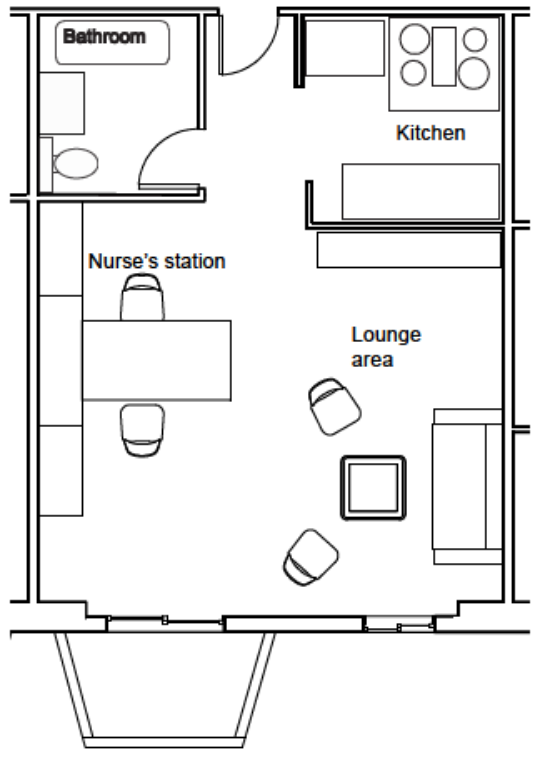

Figure 34: Plan

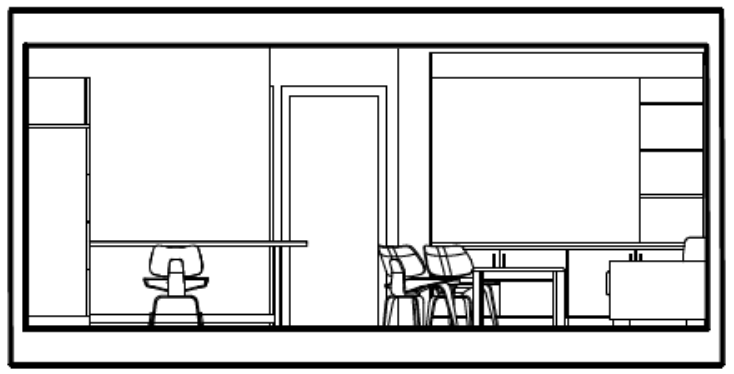

Figure 35: Section

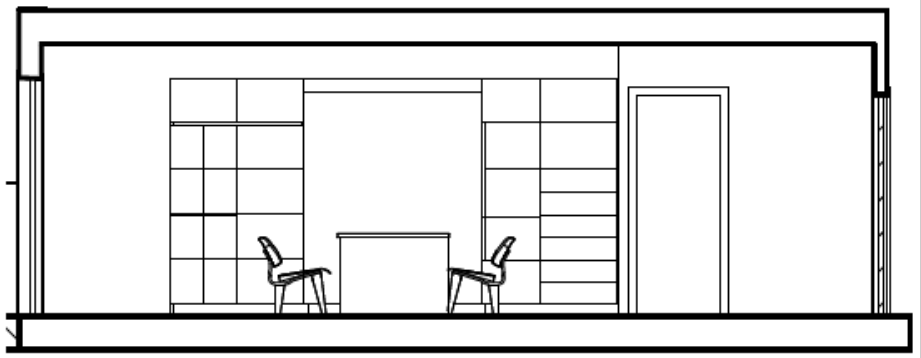

Figure 36: Section 


\subsection{NURSE'S STATION}

\subsection{1}

Renovate an existing unit to serve as a nurse's station

to provide medical support and room for social interac-

tion

(1) Media wall

Technology can be integrated to

allow for access to offsite healthcare

services

2. Seating area

Furniture is arranged to create an open

and inviting area that allows for socializing

to to promote an emotional connection and

well-being

3) Cabinetry

Built-in cabinetry to proivde storage space

4 Nurse's station

A nurse's station can be used by staff to meet with residents and to do their work.

5. Kitchen millwork

6 Built-in bed

A built-in bed provides the option

of overnight stays and can be

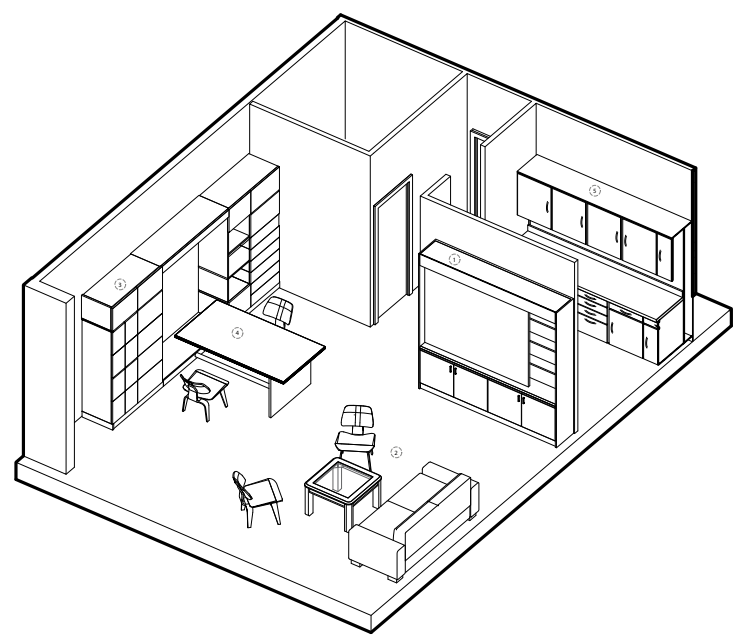

stored away to not take up floor area in the unit.

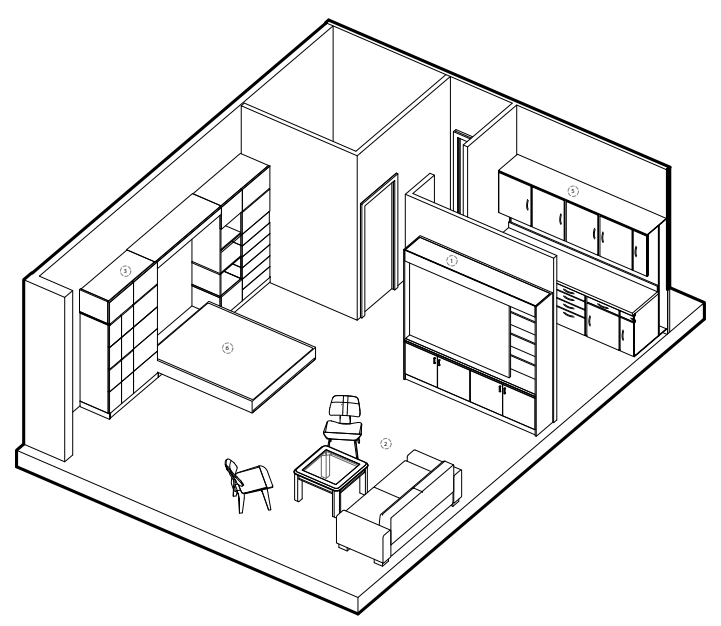

Figure 37: Nurses's station diagram 


\section{Nurse's Station}

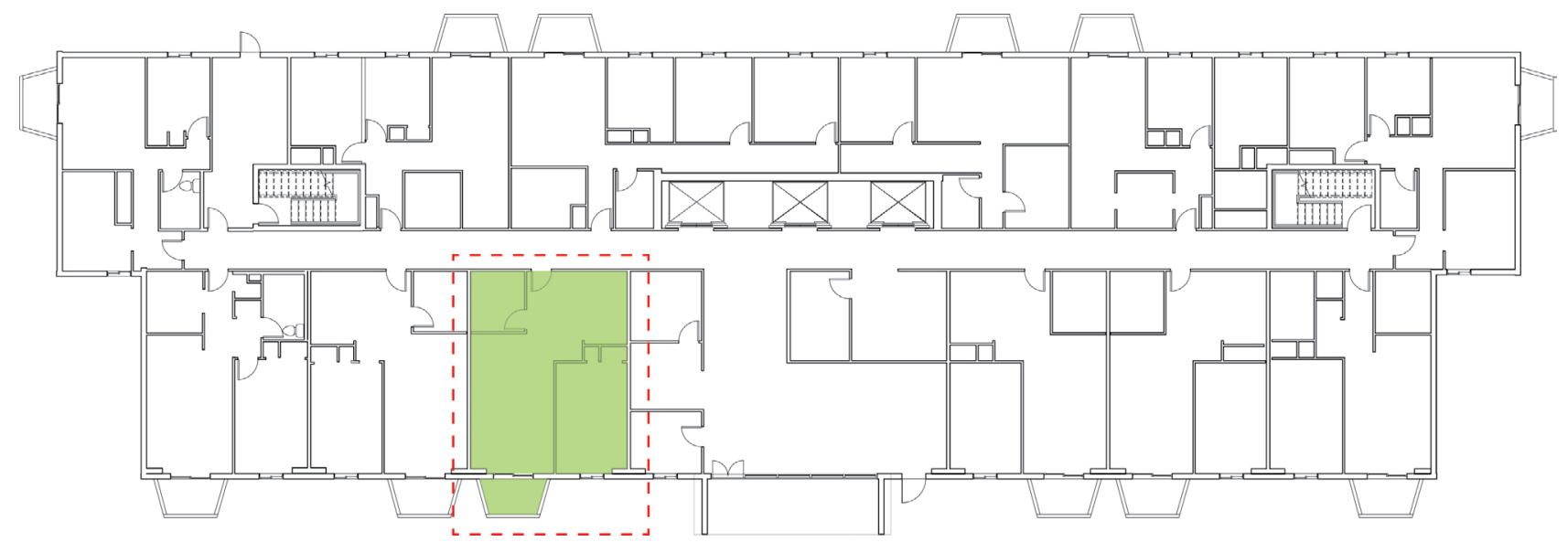

Figure 38. Area Plan: Nurse's Station 
Classification of Alteration Work:

Minimal Alterations - Level 1: existing buildings undergoing Level 1 alterations which include replacement/ addition of elements or fixtures. Alterations require minimal space reconfiguration.

Expanded - Level 2: alterations that may include space reconfiguration.

Expanded - Level 3: alterations which include extensive renovations and/or space reconfiguration

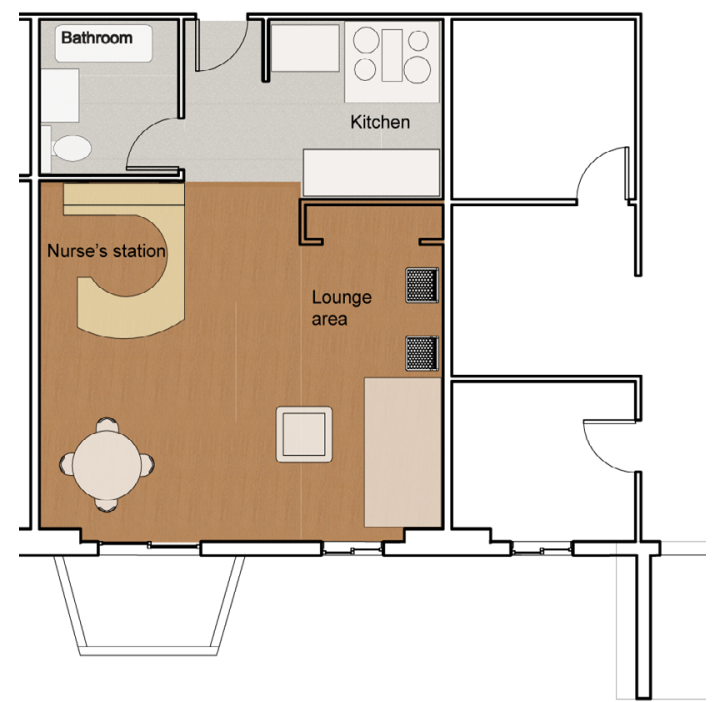

Figure 39. Area Plan: Nurse's Station

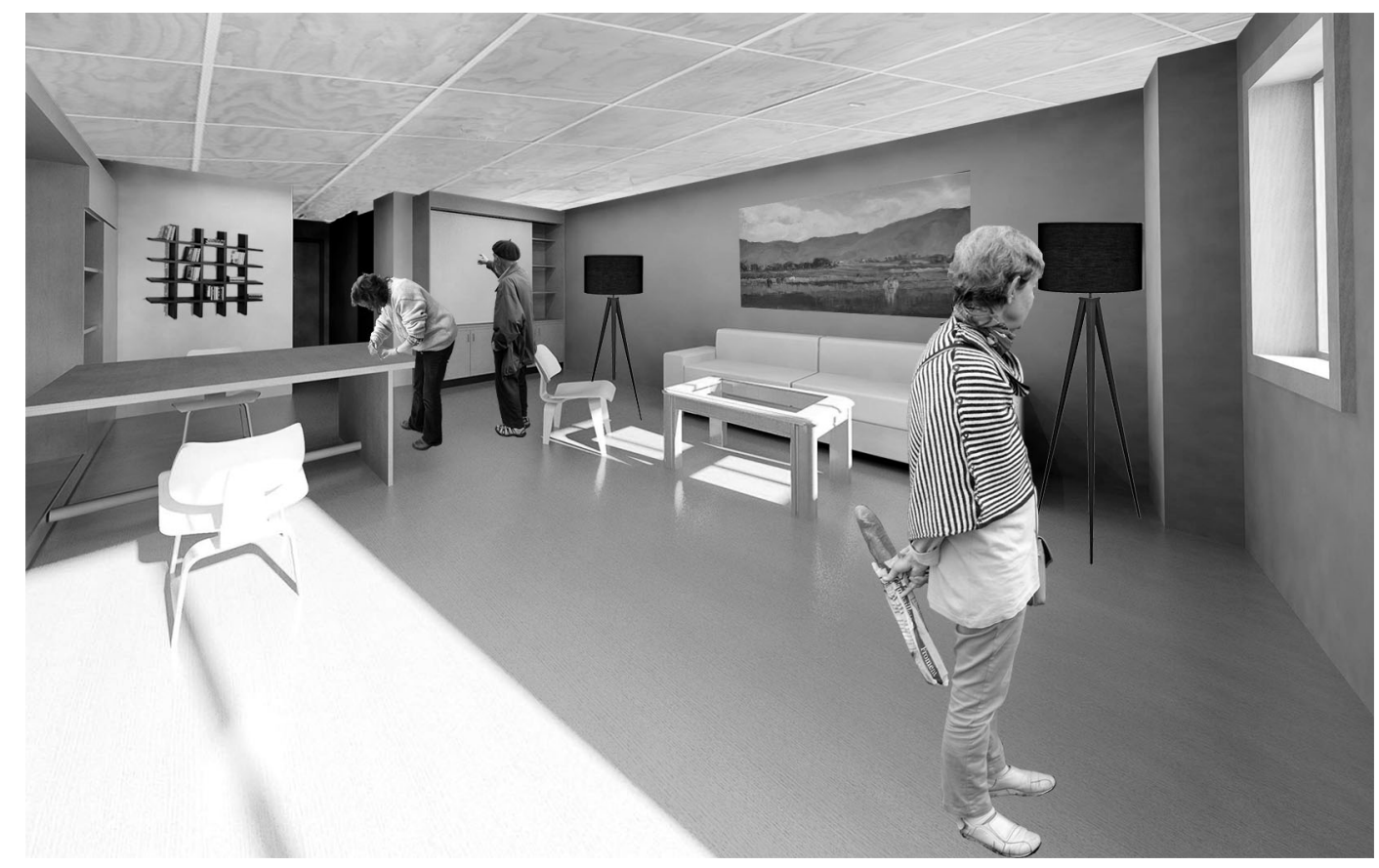

Figure 40. Rendered View: Nurse's Station 
3.5 Hallways 


\subsection{HALLWAY}

\section{Objectives:}

Corridors and hallways are part of the accessible routes within a building. In a residential setting, the corridors lead to rooms, activity spaces or other spaces. The hallway is the link between the private realm of the living units and the semi-public realm of the building. Instead of having an institutional look, elements such as handrails, furniture, and displays can start to create a sense of identity and place in the halIways. These elements can help to extend the private realm into the hallways and enhance the quality of the space transitioning from the public to private spaces. By creating a pleasant atmosphere along the long corridors, residents have another opportunity to socialize as well as to maintain a sense of place and home as they reach their living unit.
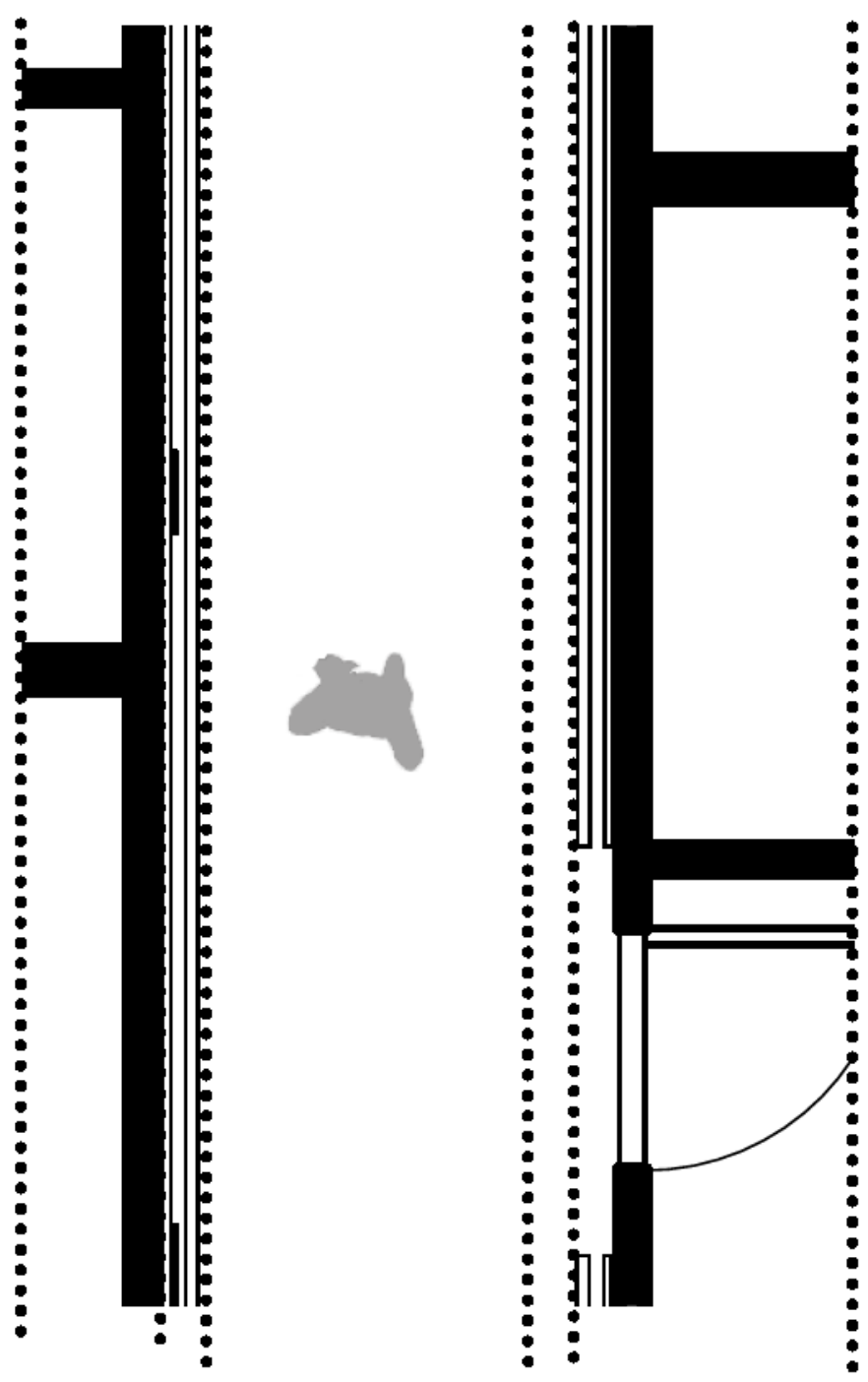

Figure 41: Hallway Plan 


\subsection{1.}

Modular handrail element with adaptable components for wood, ceramic, textured, and steel sections of railing. Used to circulate through lobby and provide assistance to occupants.

3.5.2.

Provide pull-down seating/benches found at intervals along hallway used for gathering or rest area.

3.5.3.

Integrate architectural detailing such as the changes of materials and color to break the monotony of the continuous hallway.

\subsection{4.}

Provide details such as handrails with lighting and paintings to create a homelike atmosphere
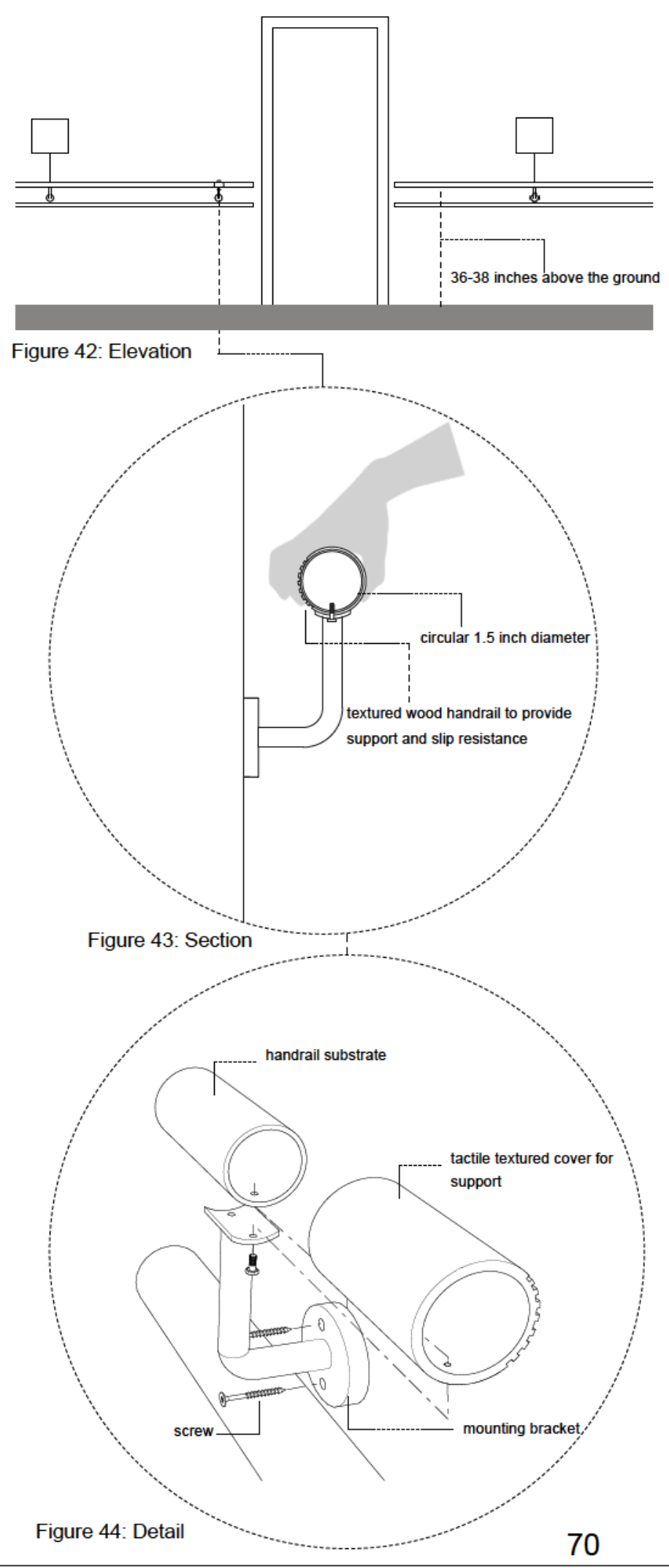


\section{Hallways}

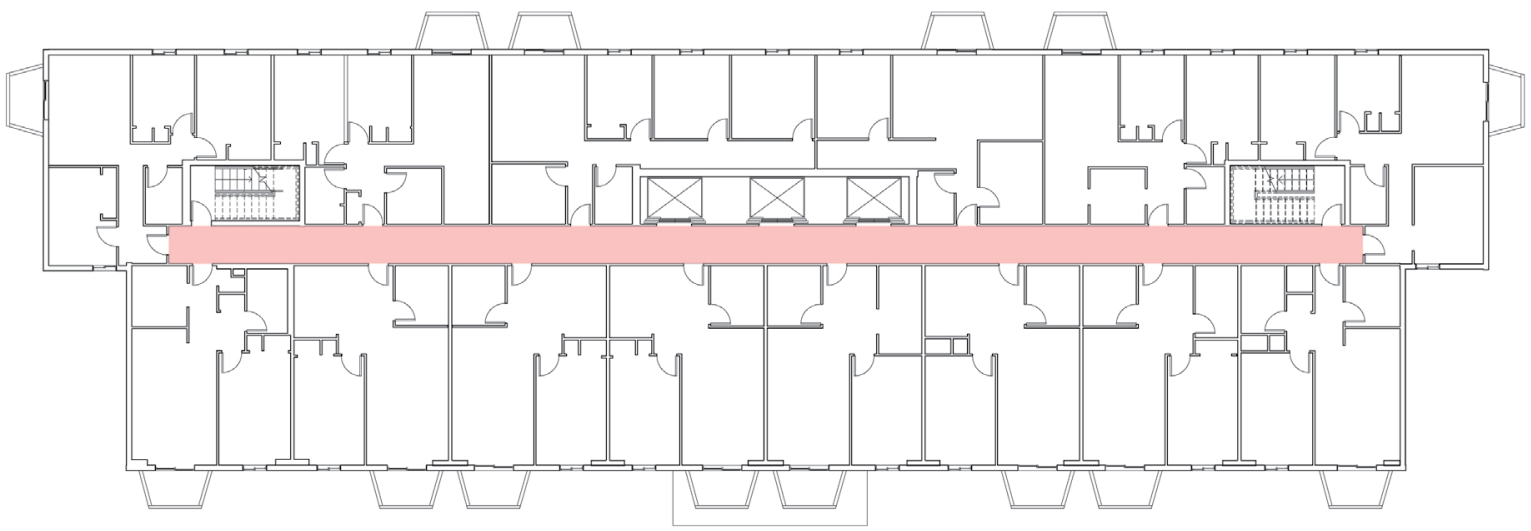

Figure 45. Area Plan: Hallway 


\section{Hallways}

\section{Objectives:}

Corridors and hallways are part of the accessible routes within a building. In a residential setting, the corridors lead to rooms, activity spaces or other spaces. The hallway is the link between the private realm of the living units and the semipublic realm of the building. Instead of having an institutional look, elements such as handrails, furniture, and displays can start to create a sense of identity and place in the hallways. These elements can help to extend the private realm into the hallways and enhance the quality of the space transitioning from the public to private spaces. By creating a pleasant atmosphere along the long corridors, residents have another opportunity to socialize as well as to maintain a sense of place and home as they reach their living unit.

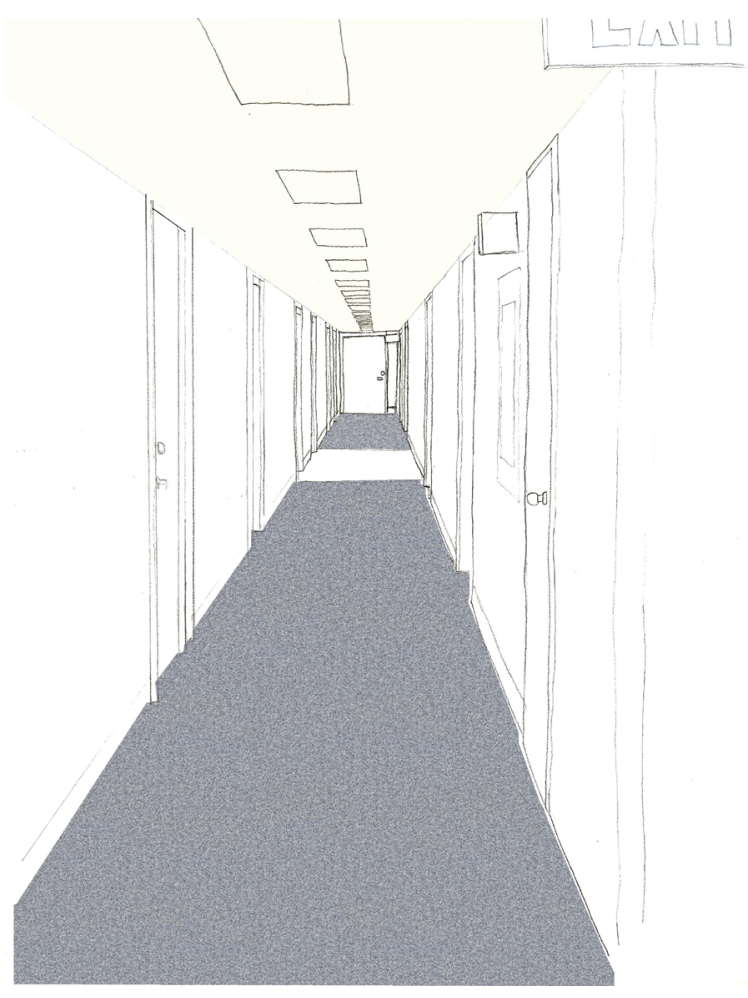

Figure 46: Current typical corridor conditions 


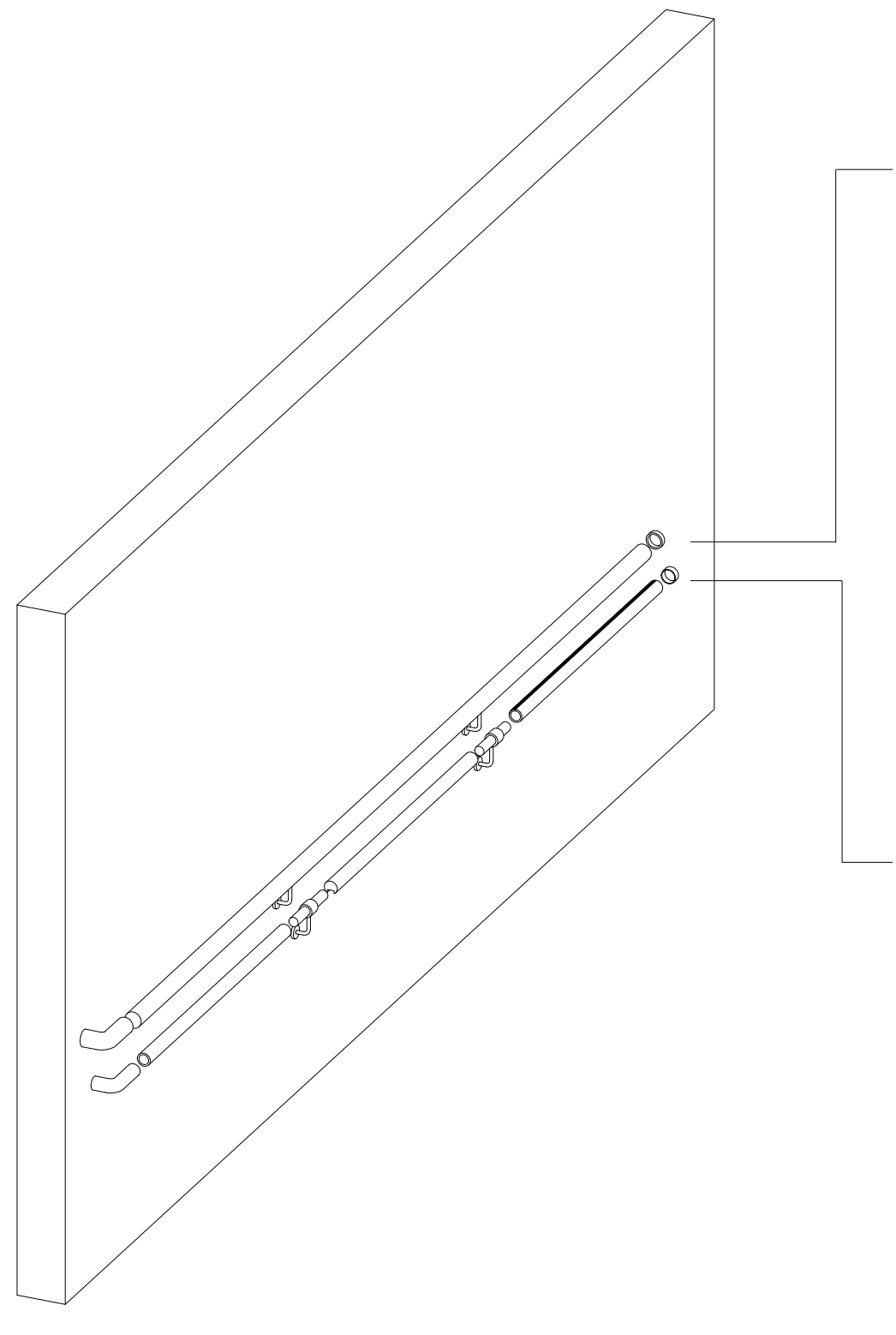

Figure 47: Hallway handrail system

\section{Primary handrail}

Continuous handrail for fall prevention with round or oval profile to allow for a better grip. Installed at standard height of $32-36$ " with enamel or gloss finish

\section{Secondary handrail}

Modular handrail compo-

nents including material choices of wood, metal, PVC with various textured finishes foto encourage proactive use of handrails and sensorial experience for users 
(a) Handrail end curve elbow

(b) Handrail

C Wall bracket

(d) Handrail

(e) Handrail connector

(f) Handrail

(g) Handrail endcap

Figure 48:Handrail system exploded axonometric

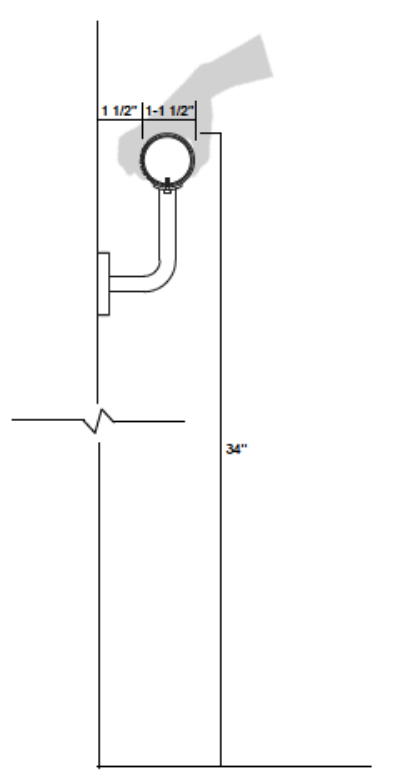

Figure 49:Handrail system section 
Classification of Alteration Work:

Minimal Alterations - Level 1: existing buildings undergoing Level 1 alterations which include replacement/ addition of elements or fixtures. Alterations require minimal space reconfiguration.

Expanded - Level 2: alterations that may include space reconfiguration.

Expanded - Level 3: alterations which include extensive renovations and/or space reconfiguration.

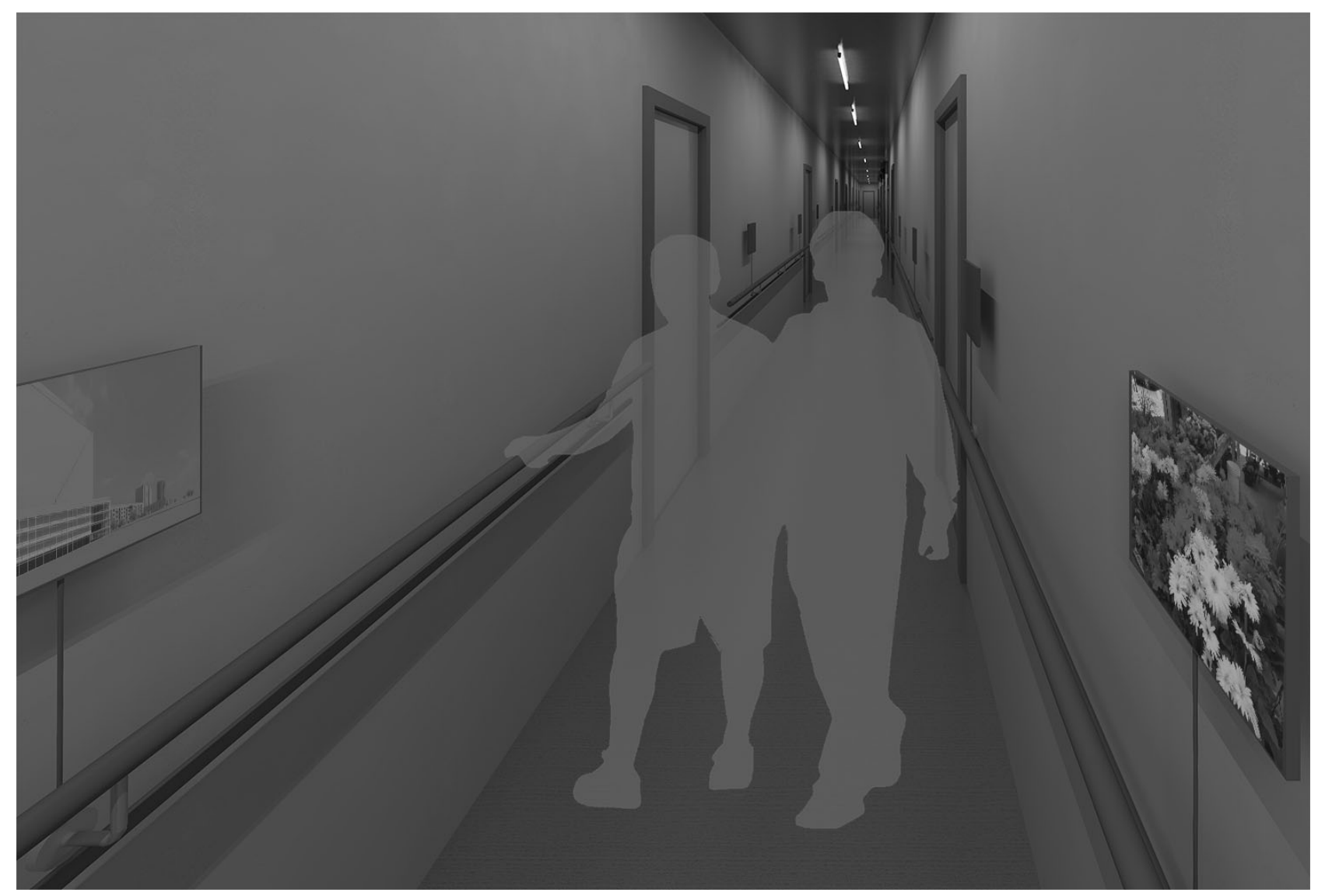

Figure 50. Rendered view: Renovated hallway 
3.6

Stairwells 


\subsection{STAIRWELLS}

Objective:

To maintain the quality of life and well-being of individuals as they age, it is important to incorporate participation and physical activity into daily life. Stairwells can also serve as an opportunity for exercise, as individuals walk up and down the stairs.

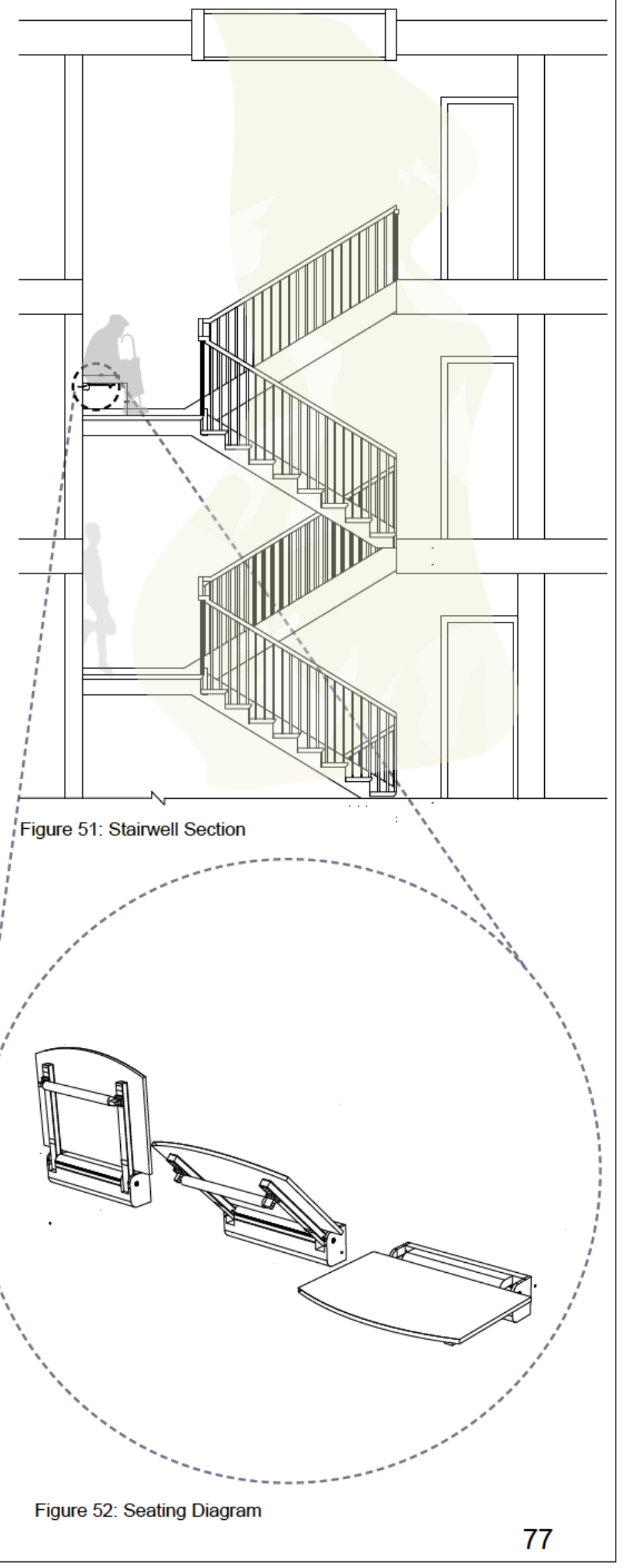


3.4.6.3. Maximum Vertical Rise of Stair Flights and Required Landings

1) No flight of stairs shall have a vertical rise of more than $3.7 \mathrm{~m}$ between floors or landings, except that a flight of stairs serving as an exit in a Group B, Division 2 occupancy shall have a vertical rise not more than $2.4 \mathrm{~m}$ between floors or landings.

2) Except as provided in Sentence (3), a landing shall be provided

a) at the top and bottom of each flight of interior and exterior stairs,

b) at the top and bottom of every section of ramp

c) where a doorway opens onto a stair or ramp,

d) where a ramp opens onto a stair, and

e) where a stair opens onto a ramp.

3) A landing may be omitted at the bottom of an exterior stair or ramp, provided there is no gate, door or fixed obstruction within the lesser of

a) the width of the stair or ramp, or

b) $1100 \mathrm{~mm}$.

3.4.6.4. Dimensions of Landings

(See Note A-3.4.6.4.)

1) Except as provided in Sentence (2), a landing shall be at least as wide and as

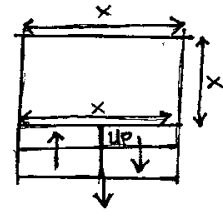

widen length of landing shouke be it least

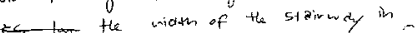

unich it occurs.

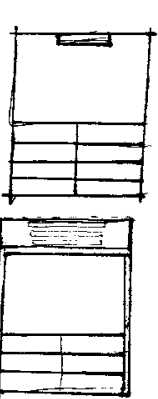

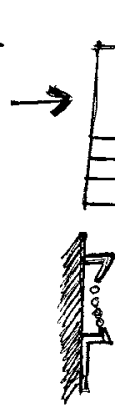

$\rightarrow$ Resting aros on

continumes hendraiss

3.4.6.5.

way in which if occurs.

2) In a straight stairway and in a stairway that turns less than $90^{\circ}$. the length of the landing need not be more than the lesser of

a) the required width of stair, or

b) $1100 \mathrm{~mm}$.

3) The length of a landing shall be measured perpendicular to the nosing of adjacent steps, at a distance equal to half the length required in Sentence (2), from the narrow edge of the landing.

4) Where a doorway or stairway empties onto a ramp through a side wall, there shall be a level area extending across the full width of the ramp, and for a distance of $300 \mathrm{~mm}$ on either side of the wall opering, except one side if it abuts on an end wall.

5) Where a doorway or stairway empties onto a ramp through an end wall, there shall be a level area extending across the full width of the ramp and along its length for not less than $900 \mathrm{~mm}$.

\section{Handrails}

1) One handrail shall be provided on stairs that are less than $1100 \mathrm{~mm}$ in width.

2) One handrail shall be provided on each side of

a) stairs that are $1100 \mathrm{~mm}$ or more in width

b) curved flights of any width, and

c) ramps.

3) In addition to Sentence (2), intermediate handrails shall be provided so that

a) a handrail is reachable within $750 \mathrm{~mm}$ of all portions of the required exit width,

b) at least one portion of the stair or ramp between two handrails is the minimum width required for stairways or ramps (see Sentences 3.4.3.2.(8) and 3.4.3.3.(4)), and

c) all other portions of the stair or ramp between two handrails have a clear width of $510 \mathrm{~mm}$ or more.

4) Where a stair or ramp is wider than its required exit width, handrails shall be located along the most direct path of travel. (See Note A-3.4.6.5.(4).)

Figure 53: Excerpt from 2015 National Building Code 


\section{Stairwells}

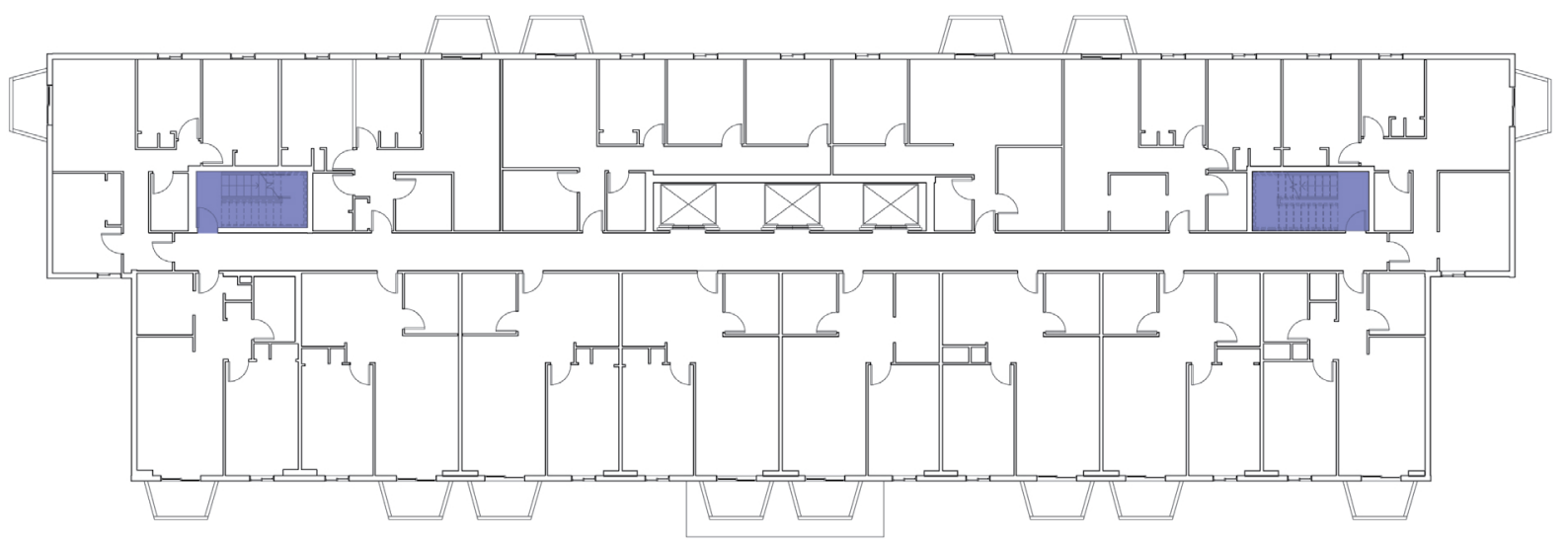

Figure 54. Area Plan: Stairwells 


\section{Objective:}

To maintain the quality of life and well-being of individuals as they age, it is important to incorporate participation and physical activity into daily life. Stairwells can also serve as an opportunity for exercise, as individuals walk up and down the stairs.

Individuals with Alzheimer's often gradually lose their ability of cognitive mapping (Zeisel, 2006). The ability to remember how to map the physical environment is one that becomes increasingly difficult as Alzheimer's progresses and damages the brain. Aimless wandering is commonly referred to as a result of the loss of cognitive mapping functioning (Zeisel, 2006). Aimless wandering can be characterized by a sense of anxiety in individuals confronting physical environments which are not naturally mapped for way-finding but instead require instruction and are confusing.

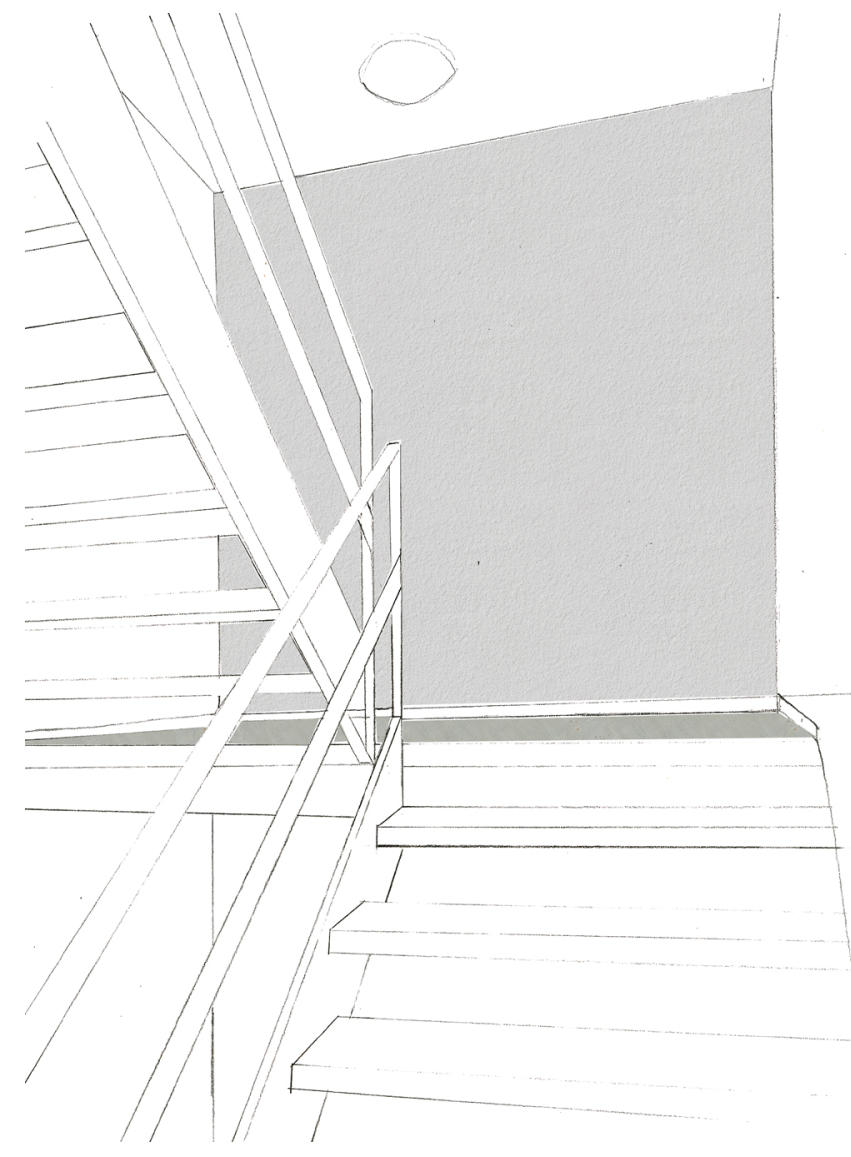

Figure 55. Sketch: Stairwells

By introducing landmarks in the physical environment and breaking the monotony of long corridor, it may be possible to aid the naturally mapping of the physical environment and in turn provide opportunities for meaningful wandering where patients have clear landmarks and destinations to help cue their memory of their environment. A positive result of reducing anxiety in individuals wandering through the interior physical environment of the healthcare facility can be a key factor in supporting the therapeutic effects of such environments on occupants. 


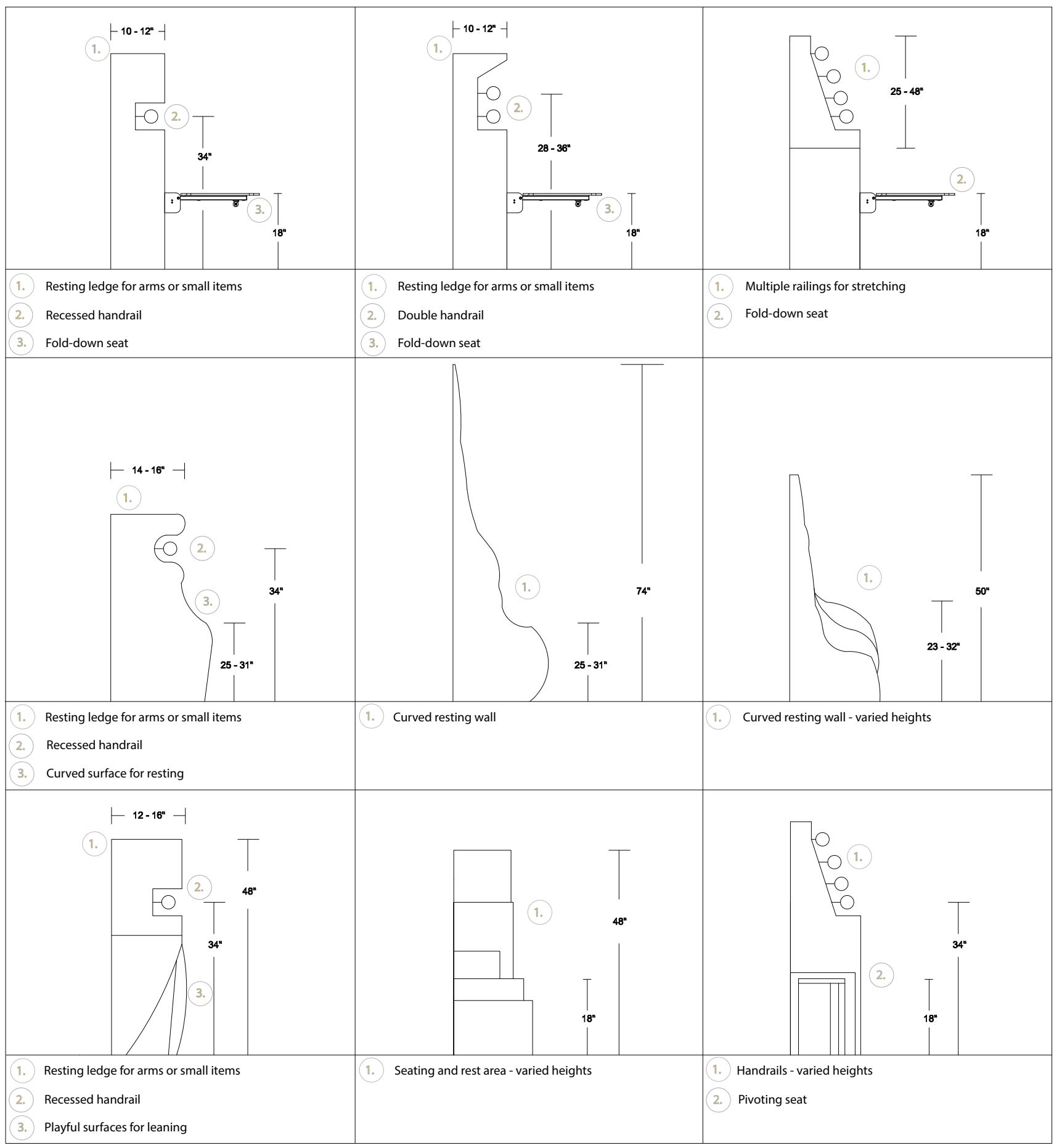

Figure 56: Stairwell component variations 
Classification of Alteration work:

Minimal Alterations - Level 1: existing buildings undergoing Level 1 alterations which include replacement/ addition of elements or fixtures. Alterations require minimal space reconfiguration.

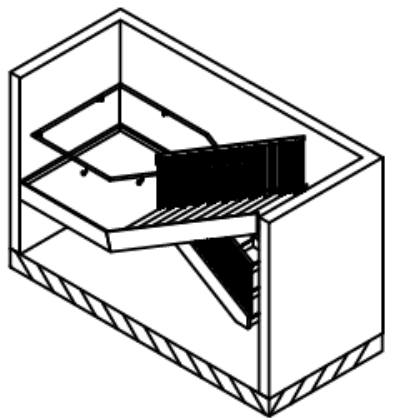

Continuous handrail with fold-down seating

Figure 57: Stairwell options

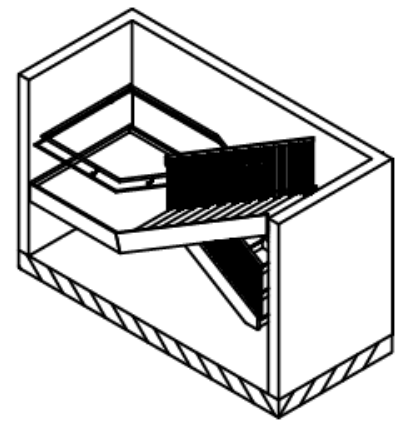

Double Continuous handrail

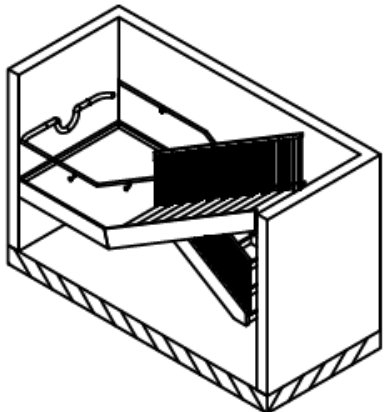

Curved handrail for leaning

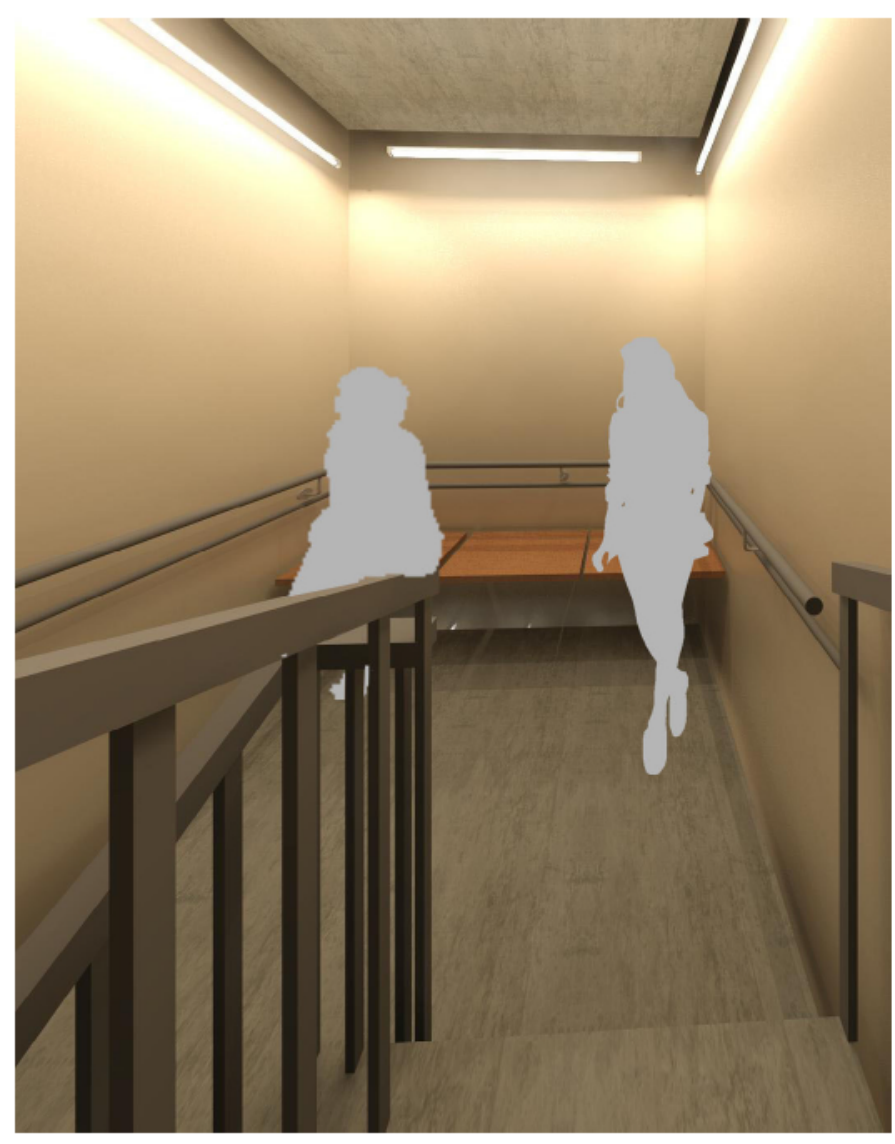

Figure 58: Rendered View: Stairwell

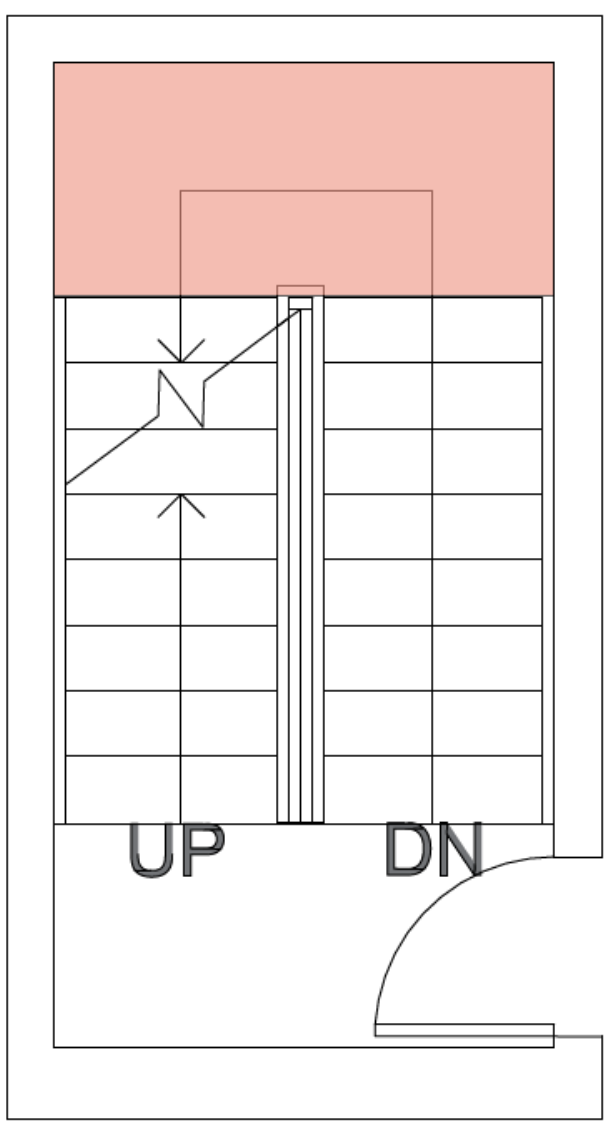

Figure 59: Stair landing plan 


\section{Classification of Alteration work:}

Expanded - Level 2: alterations that may include space reconfiguration.

Expanded - Level 3: alterations which include extensive renovations and/or space reconfiguration

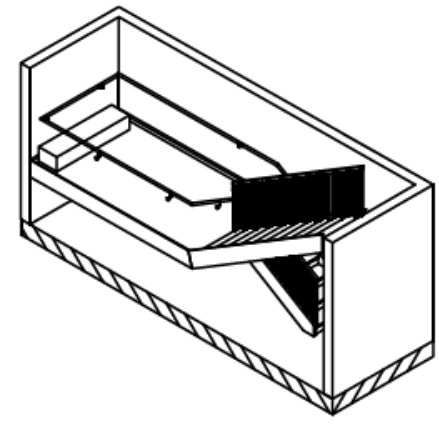

Continuous handrail with seating

Figure 60: Stairwell options diagram

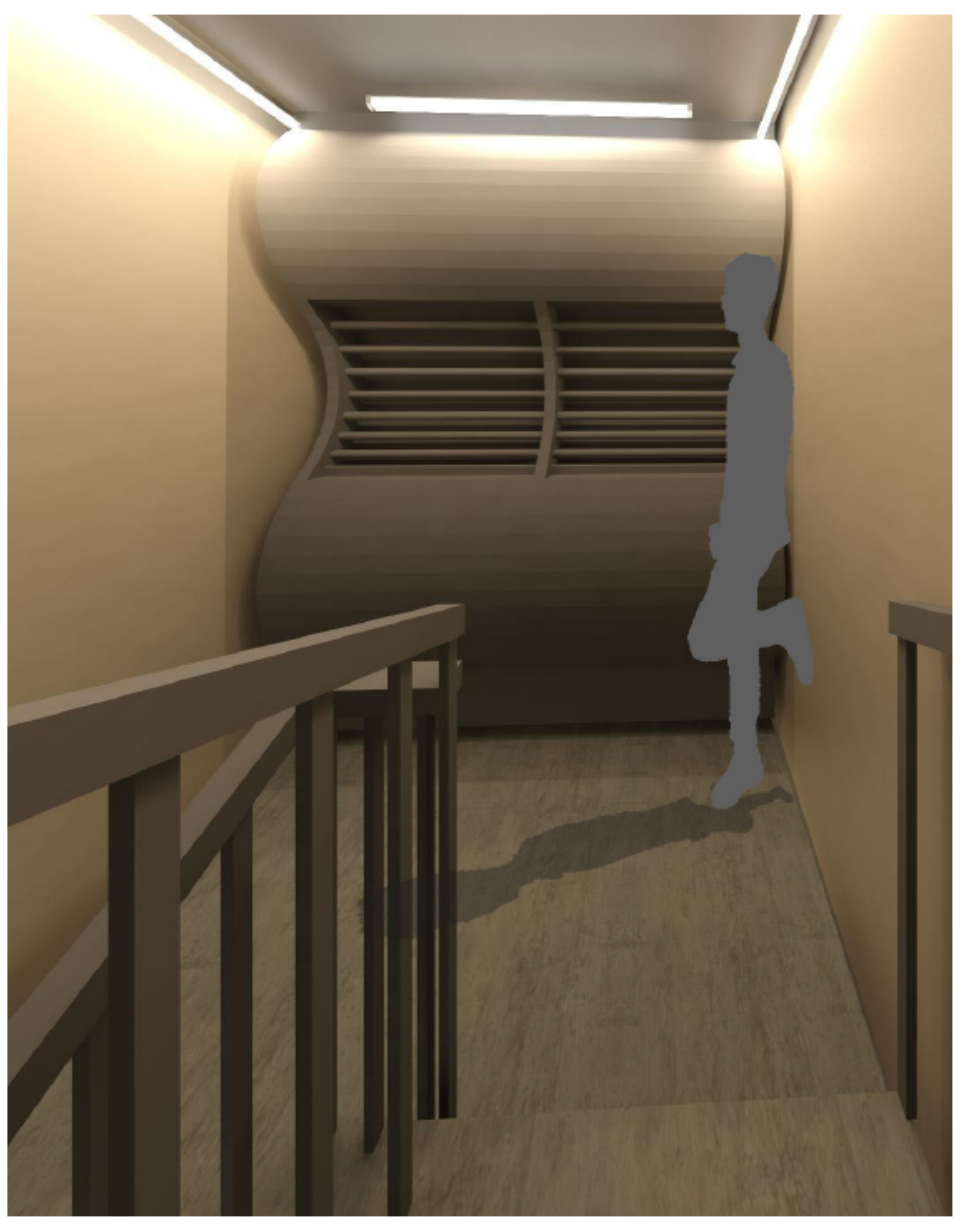

Figure 61: Rendered view of resting area

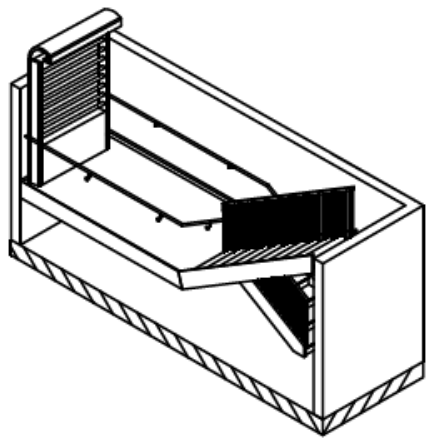

resting area with handrails for stretching

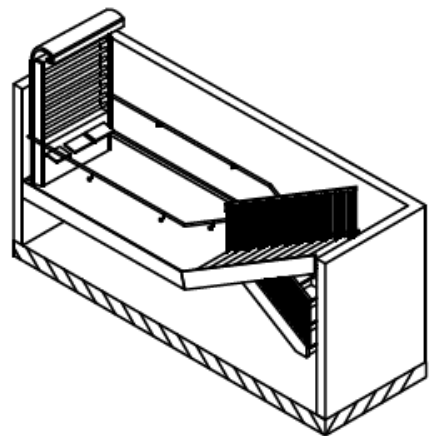

resting area with handrails for stretching and fold-down seating

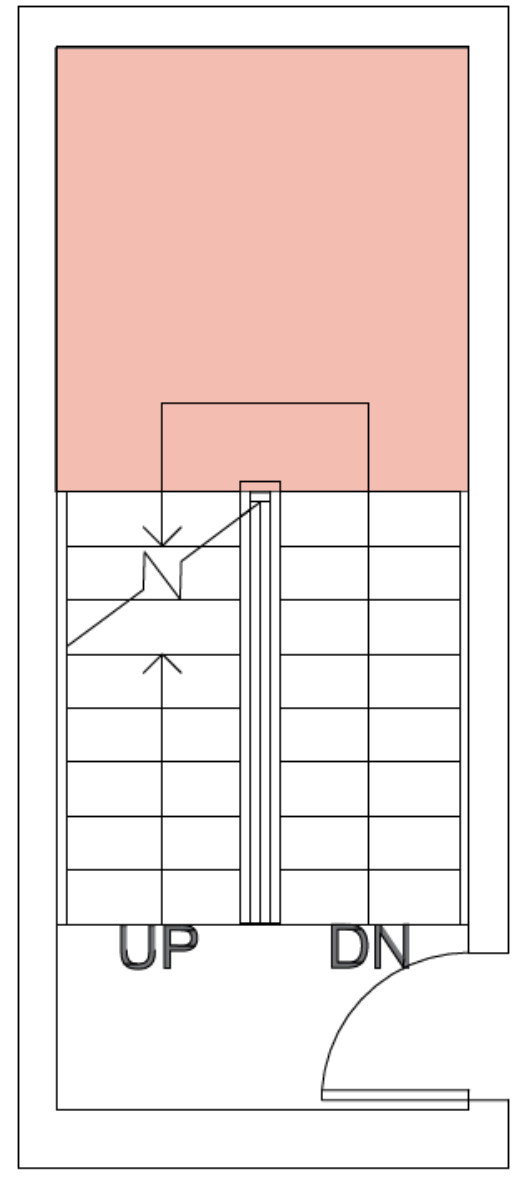

Figure 62: Stairwell Landing plan 


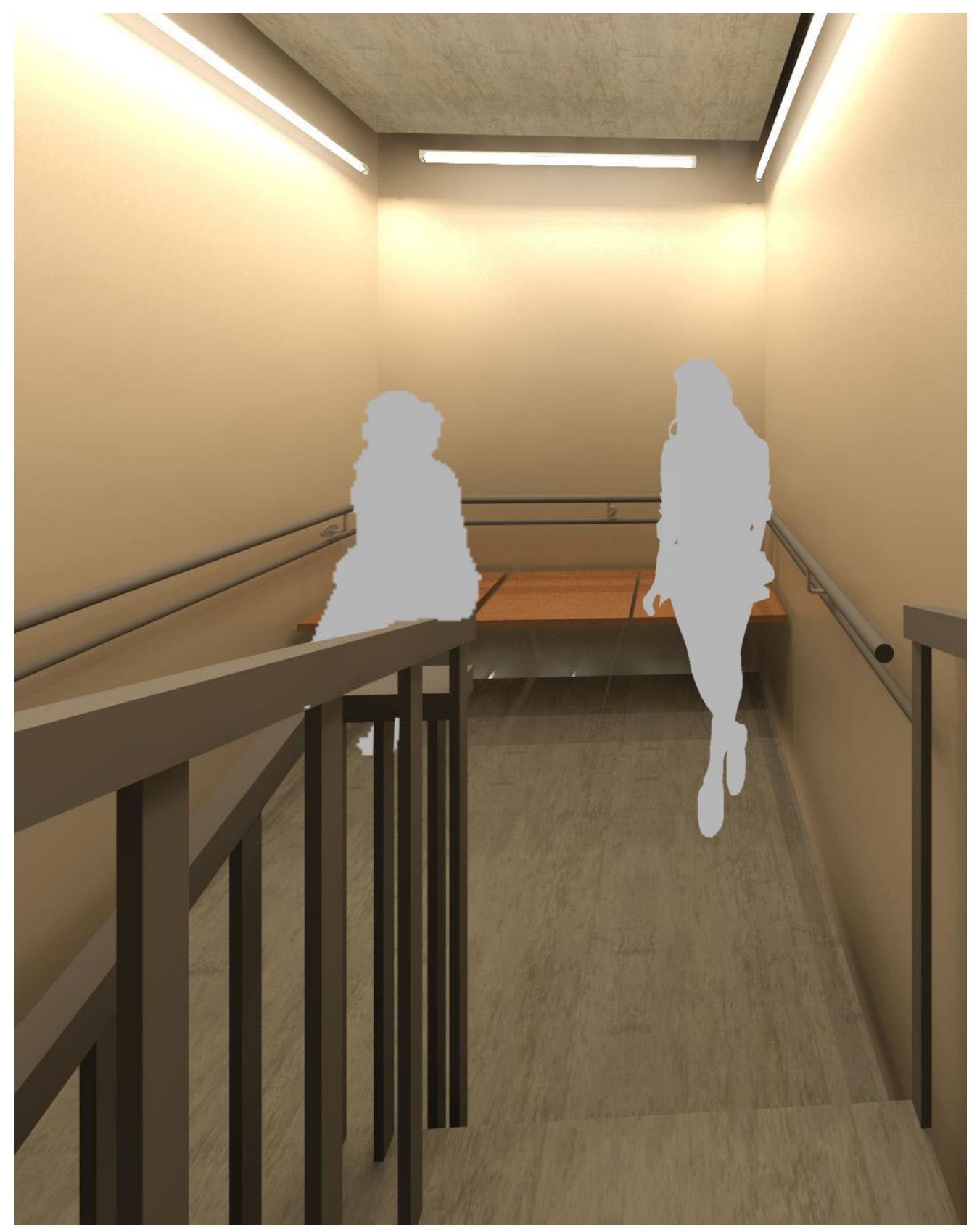

Figure 63. Rendered View: Stairwell 


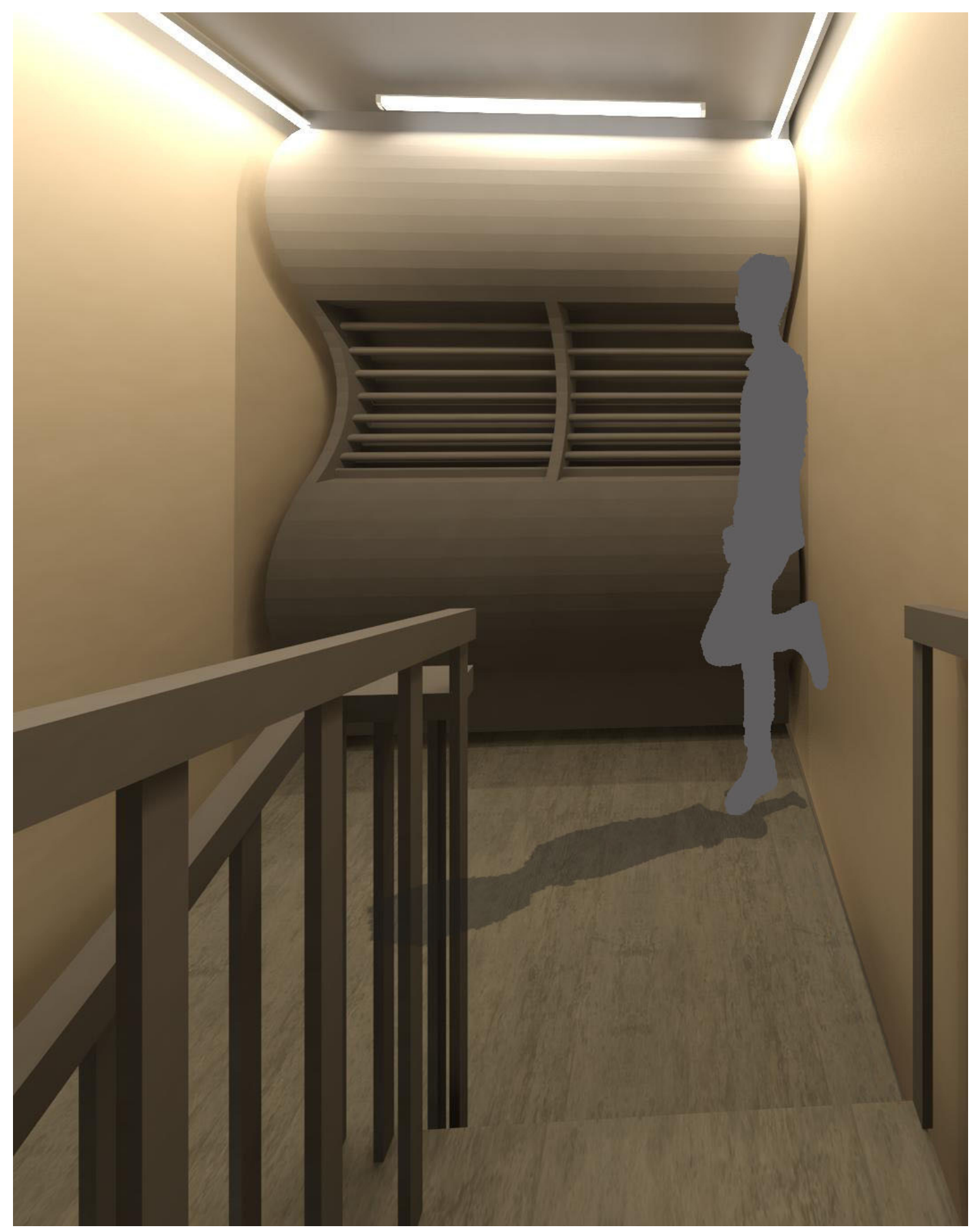

Figure 64. Rendered View: Stairwell 


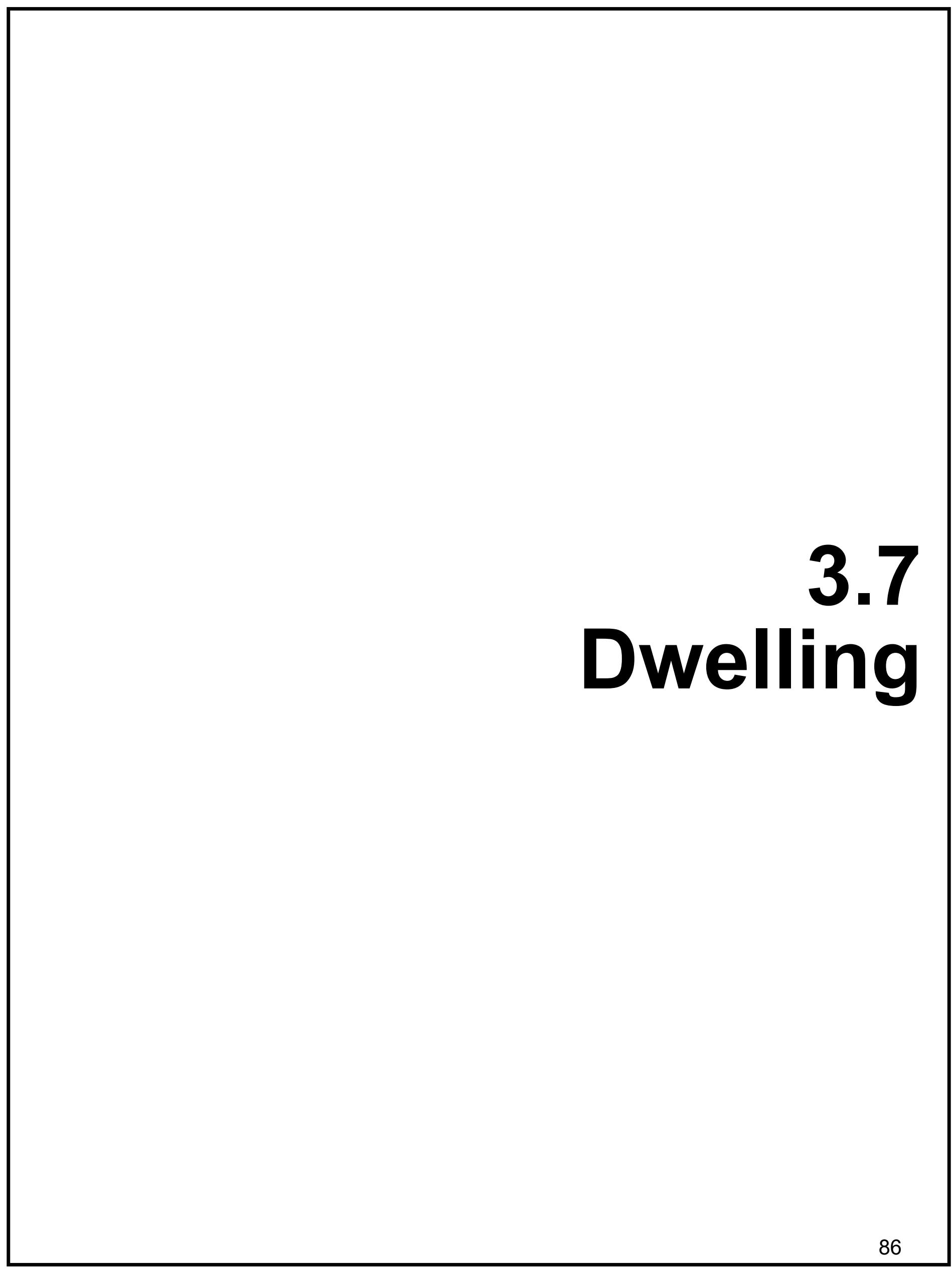




\subsection{DWELLING}

Objective:

Within the dwelling, the quality of the unit can be represented by the level of barrier-free access to household amenities an individual will have. In

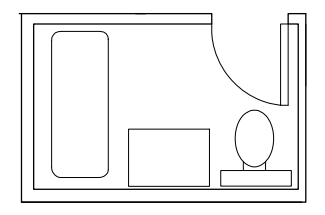

Typical washroom floor plan

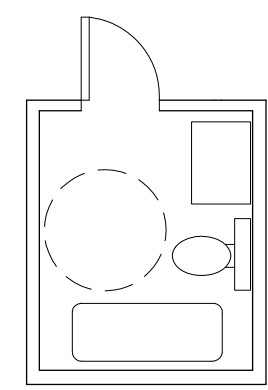

Modified floor plan important to the environmental conditions within a home (Older American Resources (Fillenbaum, 1988)).

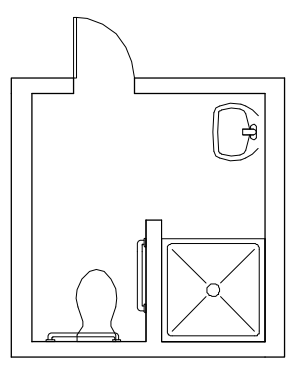

Modified floor plan with walk-in shower

Figure 65: Washrooms Plans 
Make use of universal design while fostering an experience of dignity and comfort to occupants using the washroom.

Provide a varied material palette for visual legibility
A-3.8.3.13.(1)

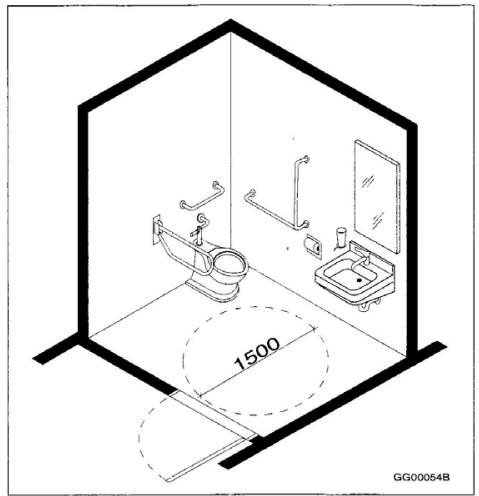

Division B

Figure $A \cdot 3.8 .3 .12 .-A$

Universal washroom with outward swinging door

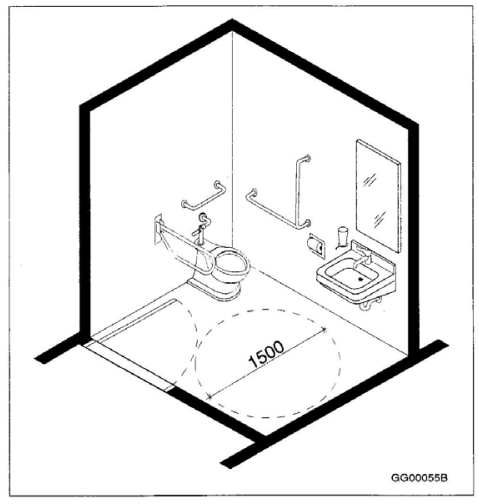

Figure A-3.8.3.12,-B

Universal washroom with inward swinging door

A-3.8.3.13.(1) Water Closets. Wall- or floor-mounted water closets with recessed bases are preferable because they provide the least amount of obstruction. 
Replace door knobs with lever type handles to allow for ease of use. handle detail should allow for comfortable but firm grip.
Install additional grab bars to match the needs of dwelling occupant(s). This can include multiple grab bars near toilet, bathtub or washroom, or continuous grab bars throughout the washroom.Grab bar finishes with texture allow for a better grip and sensorial experience for occupant.
A-3.8.3.11.(1)(c)(vi) Door Pulls. The door pull should consist of a D-shaped handle mounted horizontally. The centre lines are the lines drawn through the long axis and the short axis of the handle. The midpoint of the handle must be located horizontally at 200 to $300 \mathrm{~mm}$ from the hinged side of the door and vertically at 800 to $1000 \mathrm{~mm}$ above the finished floor surface.

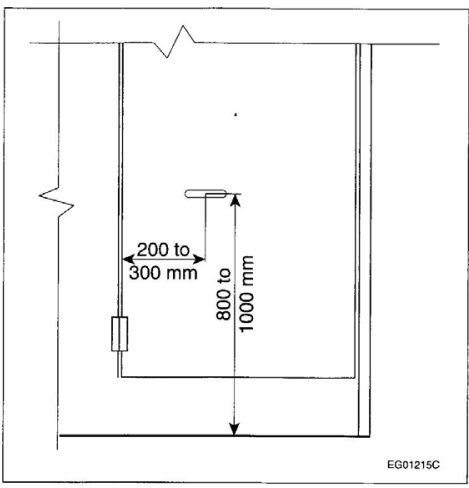

Figure A-3.8.3.11.(1)(c)(vi)-A Door pull location

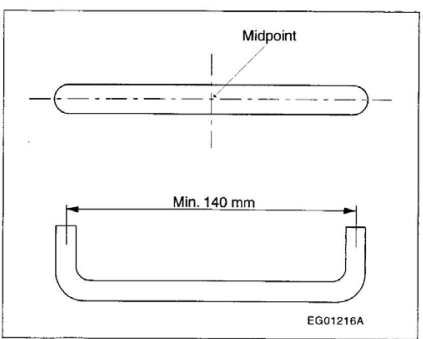

Figure A-3.8.3.11.(1)(c)(vi)-B

Door pull details

A-3.8.3.11.(1)(e)(ii) Additional Grab Bars. It is the designer's prerogative to exceed the minimum requirements found in the NBC and specify the installation of additional grab bars in other locations. These additional grab bars may be of different configurations and can be installed in other orientations.

A-3.8.3.12. Universal Washrooms. Unobstructed areas in front of the lavatory, in front of the water closet and on one side of the water closet are necessary for maneuverability of a wheelchair. Although outward closet and on one side of the water closet are necessary for maneuverability of a wheelchair. Although outward
swinging doors are preferable for accessibility, inward swinging doors are also permitted. Figures A-3.8.3.12.-A swinging doors are preferable for accessibility, inward swinging doors are also pe
and A-3.8.3.12.-B show design options that meet the intent of Article 3.8.3.12.

National Building Code of Canada 2015 Volume 1

Division $B$ 3-25

Figure 67: Excerpt from 2015 National Building Code 


\subsection{DWELLING}

\subsubsection{Provide a comfortable and secure washroom}

Adaptations to improve the bathing experience for those with mobility needs. Make the bathing experience more comfortable and dignified for those with mobility needs.

(1) Grab bars

Provide and customize grab bars

to support the mobility needs of the occupant.

2 Fold-down seat

Seating attached to the walls to help make the bathing experience more comfortable and dignified.

3. Ada compliant toilet

4) Walk-in shower/tub

Walk-in shower or tub to provide ease of entering and use of shower or tub.

(5) Adjustable shower head

6) Reinforced walls

Reinforce existing walls to provide adequate support to anchor grab bars.

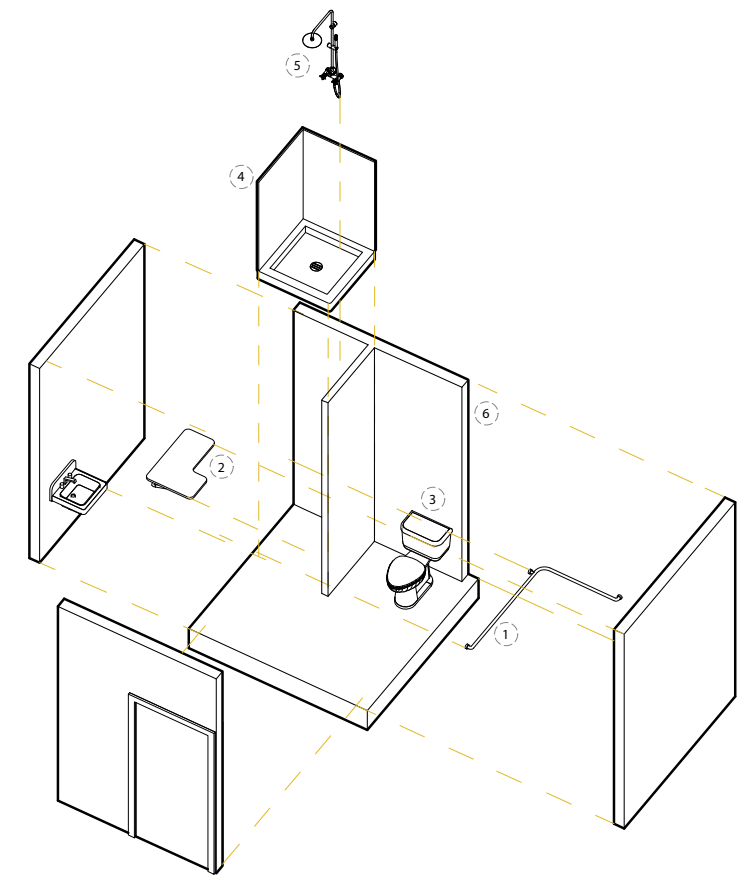

Figure 68: Exploded Axonometric Diagram 


\section{Dwelling}

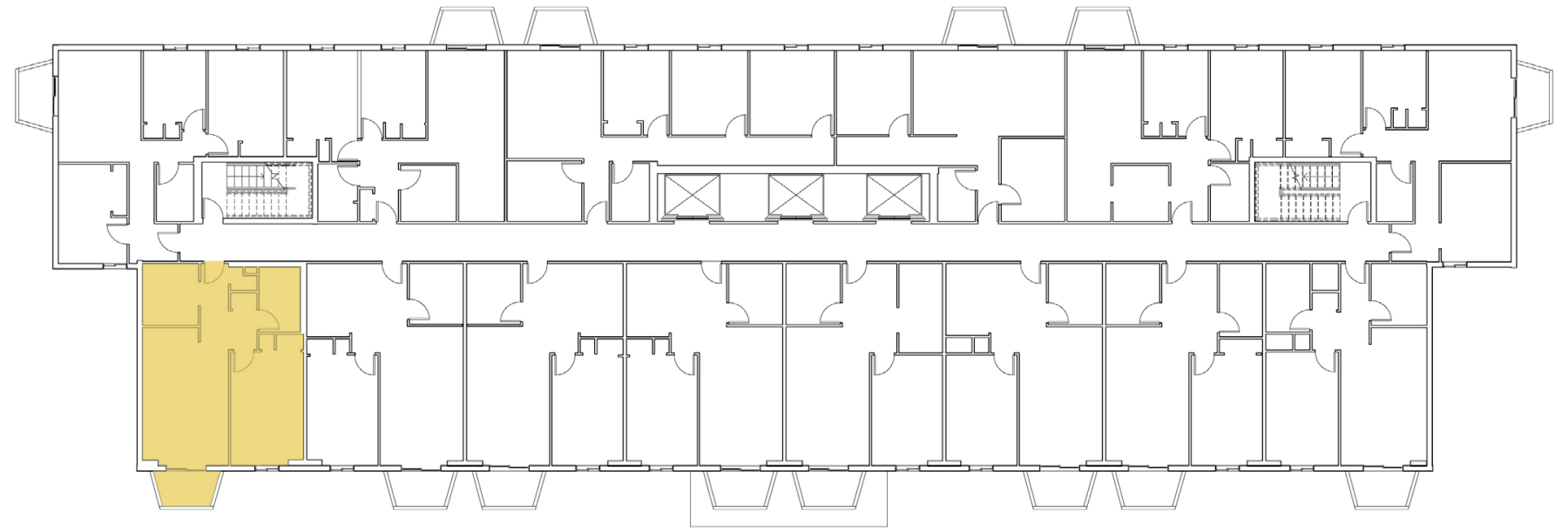

Figure 69. Area Plan: Dwelling 


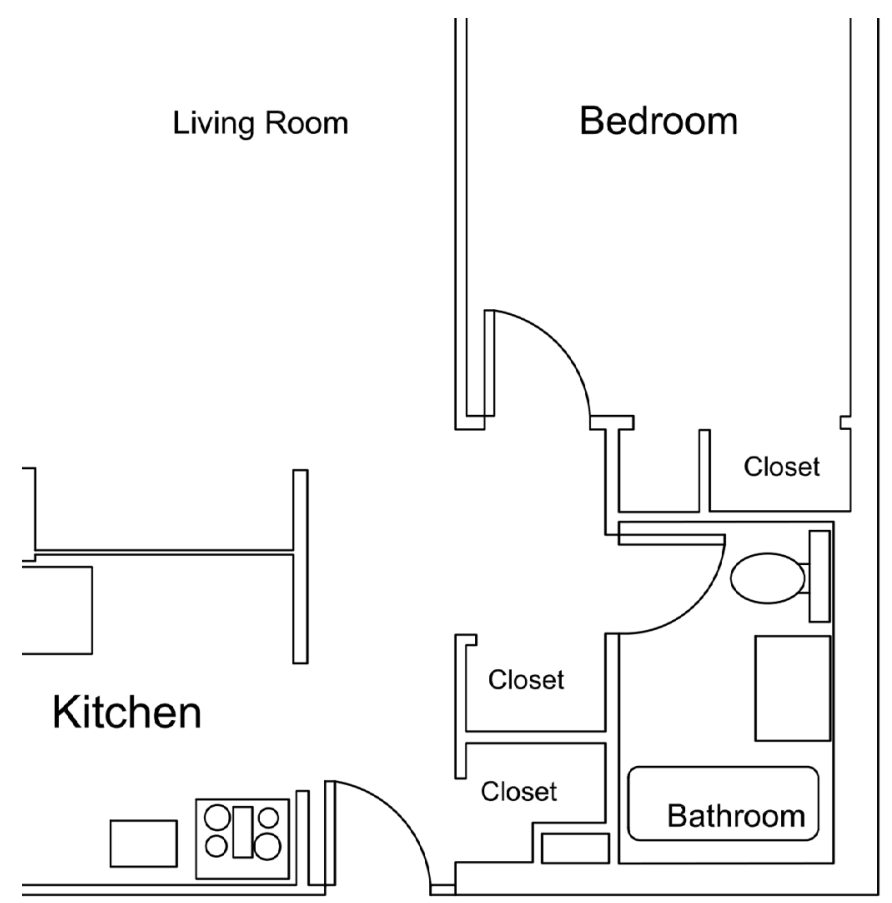

Figure 70. Existing Plan: Dwelling

\section{Design Considerations:}

i. Wide window sill for displaying of plants or other items

ii. A niche in an area of the unit, near a window, that be used as a space for activities such as viewing the outdoors, reading, sewing.

iii. Built in shelving for storage of hobby items.

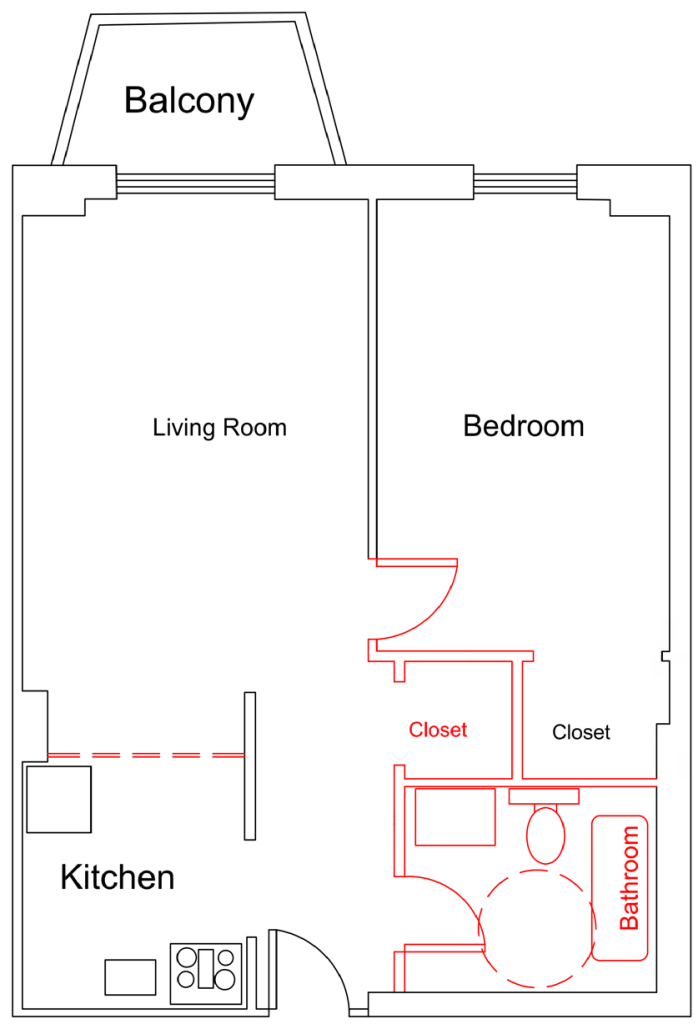


Classification of Alteration Work:

Minimal Alterations - Level 1: existing buildings undergoing Level 1 alterations which include replacement/ addition of elements or fixtures. Alterations require minimal space reconfiguration.

Expanded - Level 2: alterations that may include space reconfiguration.

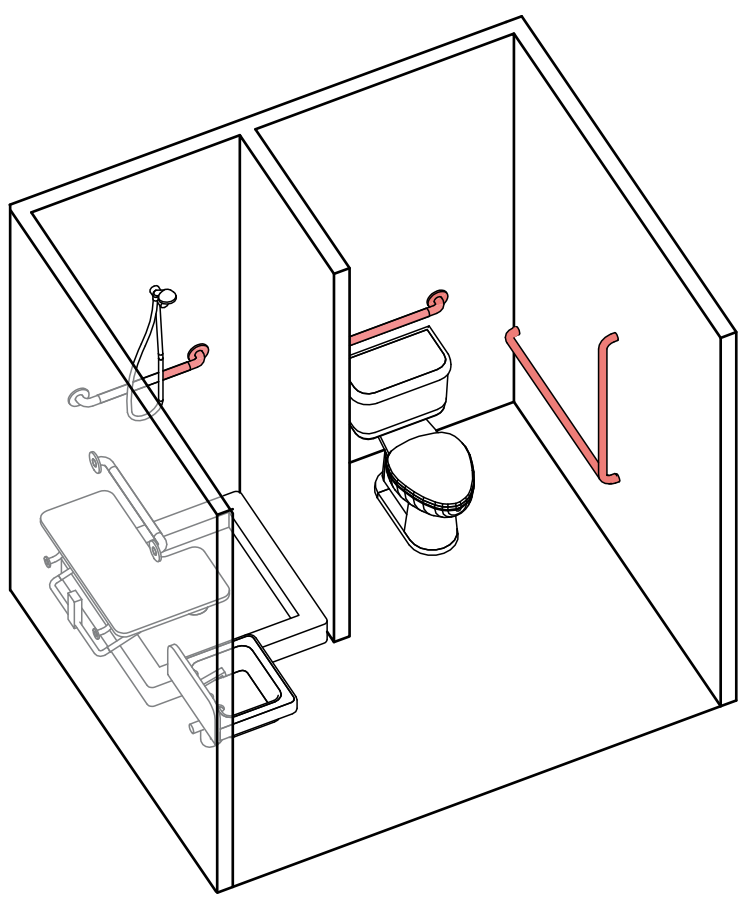

Expanded - Level 3: alterations which include extensive renovations and/or space reconfiguration

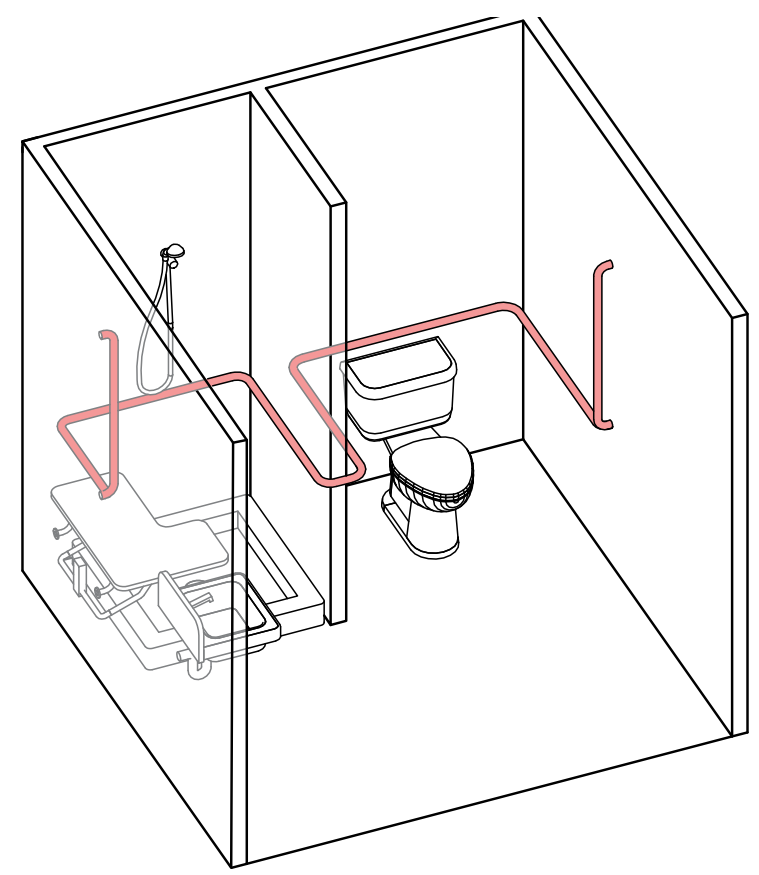

Figure 72: Axonometric: Washroom grab bar intreventions 


\section{Other Design Considerations}

\section{Green Space}

Objective:

Provide green spaces for all occupants and visiors to have an opportunity to socizalize, garden, play, and just enjoy the outdoors. The green spaces help to foster a sense of communiy and inclusion for both young and old.

\section{Rooftops}

Objective:

Provide green spaces for all occupants and visiors to have an opportunity to socizalize, garden, play, and just enjoy the outdoors. The green spaces help to foster a sense of communiy and inclusion for both young and old.

\section{Social gathering spaces}

In providing social gathering spaces for individuals in healthcare facilities, this can help to create a sense of community and place. This in turn can be beneficial to enriching the therapeutic potential of the physical environment.

\section{Connected outdoor spaces}

As previously stated, connections to outdoor spaces have been shown to provide a sense of well-being in individuals. 


\section{Chapter 5 - Conclusion}

The built environment can play a role in the physical and emotional well-being of individuals, and has an effect on how successfully an individual can age in place. Standard building code guidelines and details do not necessarily address the sociocultural aspects of dwelling, and this presents an opportunity for the development of guidelines and details which better serve the evolving physical needs of the aging population.

Based on the research from designing for aging in residential dwellings, this thesis presents guidelines and details that are meant to promote physical well-being and support mental well-being through details for evolving physical mobility and sociocultural changes and needs of the aging baby boomers. The guidelines presented are a speculative "proposal" that explore the role of architecture in the realm of building regulation. The guidelines serve to explore how the process of ageing in place can be supported through architectural strategies that aim to address the qualities of well-being and comfort. This thesis explores the guidelines in a series of strategies that provide the minimum standards and expand on them to create a series of guidelines that each incorporate elements/aspects of well-being and comfort into the design for ageing in place strategies. The guidelines are based on the belief that the role of architecture also lies in the realm of policy making. Rather than a reactive measure the guidelines are meant to be a proactive tool for addressing the needs of specific user groups specifically the ageing population. 
By creating spaces that support the need to perform everyday tasks such as walking, bathing, eating, interacting with others, this supports the autonomy and independence needed to maintain a quality of life that one is accustomed to. The project aims to address the need to provide facilities and services for the aging population in Ottawa that offer a sense of community and identity while helping to maintain an individual's autonomy and independence. 


\section{Bibliography}

Arendt, Hannah. The Human Condition. The University of Chicago Press. 1998.

Brawley, Elizabeth C. Designing for Alzheimer's disease: strategies for creating better care environments. New York: Wiley, c1997.

Brawley, E. (2006). Design innovations for aging and Alzheimer's: Creating caring environments. Hoboken, NJ: John Wiley \& Sons, Inc.

Cohen, E. (1999, January 29). Alzheimer's patients find respite in Snoezelen rooms. Retrieved May 27, 2011 from http://www.pacpubserver.com/new/health/a-b/hm012999.html

Pallasmaa, Juhani. 2012. The Eyes of the Skin: Architecture and the Senses. John Wiley \& Sons Ltd: UK.

Sewell, John. Houses and Homes: Housing for Canadians (Canada: Lorimer, 1994)

Sternberg, Esther M. 2009. Healing Spaces: The science of well-being. Belknap Press of Harvard University Press: Cambridge.

Wright, Gwendolyn. Building the Dream (New York: Pantheon, 1981) 
References:

Brawley, Elizabeth C. 2009. "Enriching Lighting Design." NeuroRehabilitation 25 (3). Netherlands: 189-99. doi:10.3233/NRE-2009-0515.

Calkins, Margaret. 2009. Evidence-based long term care design. NeuroRehabilitation Reading, Mass. (25)3. p.145.

Klages, Kelsey, Aleksandra Zecevic, Joseph B Orange, and Sandra Hobson. 2011. "Potential of Snoezelen Room Multisensory Stimulation to Improve Balance in Individuals with Dementia: A Feasibility Randomized Controlled Trial." Clinical Rehabilitation 25 (7). England: 607-16. doi:10.1177/0269215510394221.

Marquardt, G, and P Schmieg. 2009. "[Dementia-friendly architecture. Environments that facilitate wayfinding in nursing homes]." Zeitschrift fur Gerontologie und Geriatrie 42 (5). Germany: 402-7. doi:10.1007/s00391-008-0029-x.

Marquardt, Gesine. 2011. "Wayfinding for People with Dementia: A Review of the Role of Architectural Design." HERD 4 (2). United States: 75-90.

Marquardt, Gesine, Kathrin Bueter, and Tom Motzek. 2014. "Impact of the Design of the Built Environment on People with Dementia: An Evidence-Based Review." HERD 8 (1). United States: 127-57. doi:10.1177/193758671400800111.

Rabig, Judith, William Thomas, Rosalie A Kane, Lois J Cutler, and Steve McAlilly. 2006. "Radical Redesign of Nursing Homes: Applying the Green House Concept in Tupelo, Mississippi." The Gerontologist 46 (4). United States: 533-39.

Schwarz, Benyamin, Habib Chaudhury, and Ruth Brent Tofle. 2004. "Effect of Design Interventions on a Dementia Care Setting." American Journal of Alzheimer's Disease and Other Dementias 19 (3). United States: 172-76. 
Schwarz Benyamin Ruth Brent. Aging, Autonomy, and Architecture: Advances in Assisted Living, The Johns Hopkins University Press, July 1999

Wang, Bin. (11/01/2012). Public hospitals as the main agent of institutional elderly care: Junlian Nursing Home and Rehabilitation Center for Elderly with Dementia, Shanghai.. Shidai Jianzhu. ()6(128). p.64.

Ward-Smith, Peggy, Sarah M Llanque, and Denise Curran. 2009. "The Effect of Multisensory Stimulation on Persons Residing in an Extended Care Facility." American Journal of Alzheimer's Disease and Other Dementias 24 (6). United States: 450-55. doi:10.1177/1533317509350153. 


\section{Appendix: Design Development}

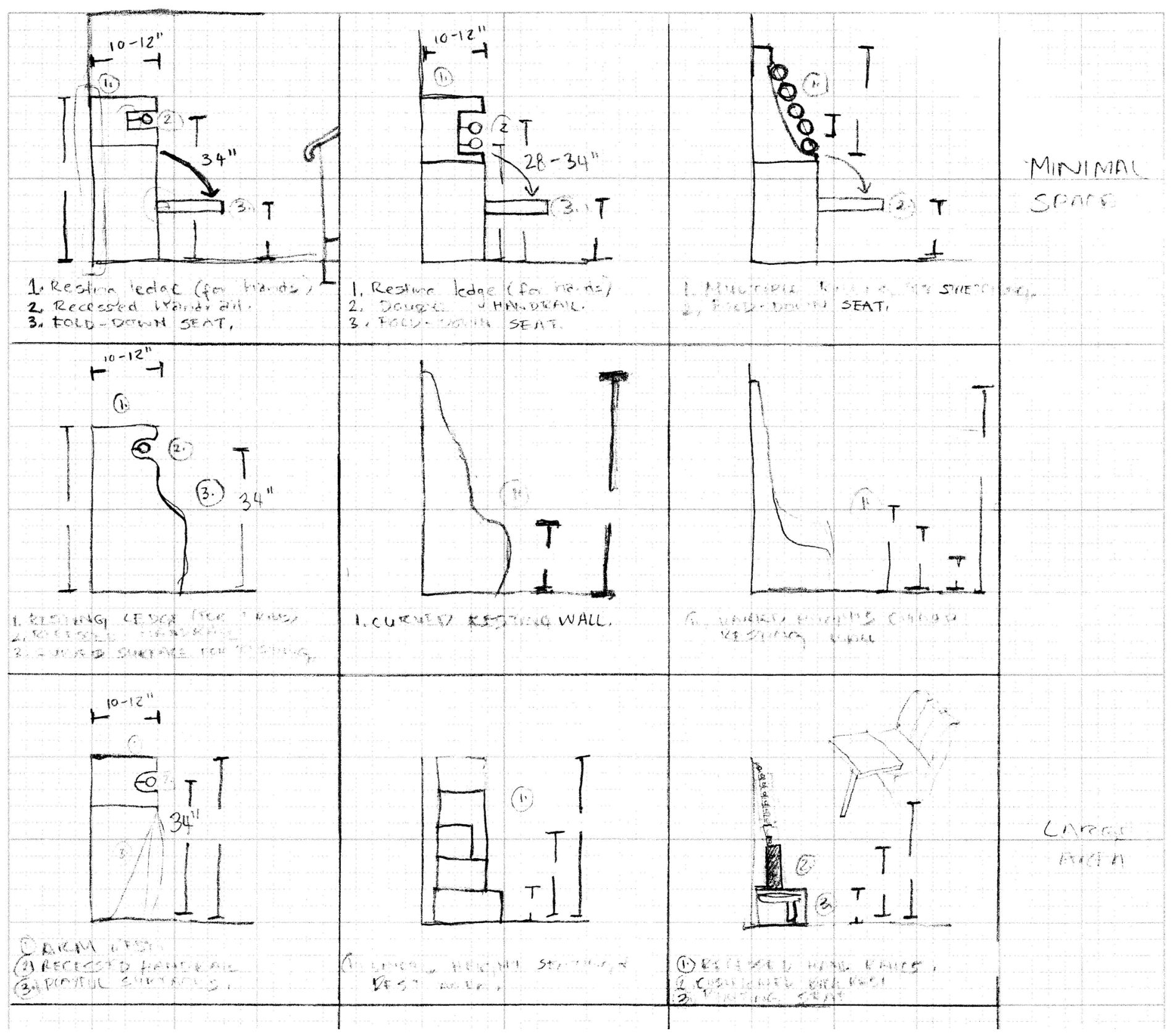




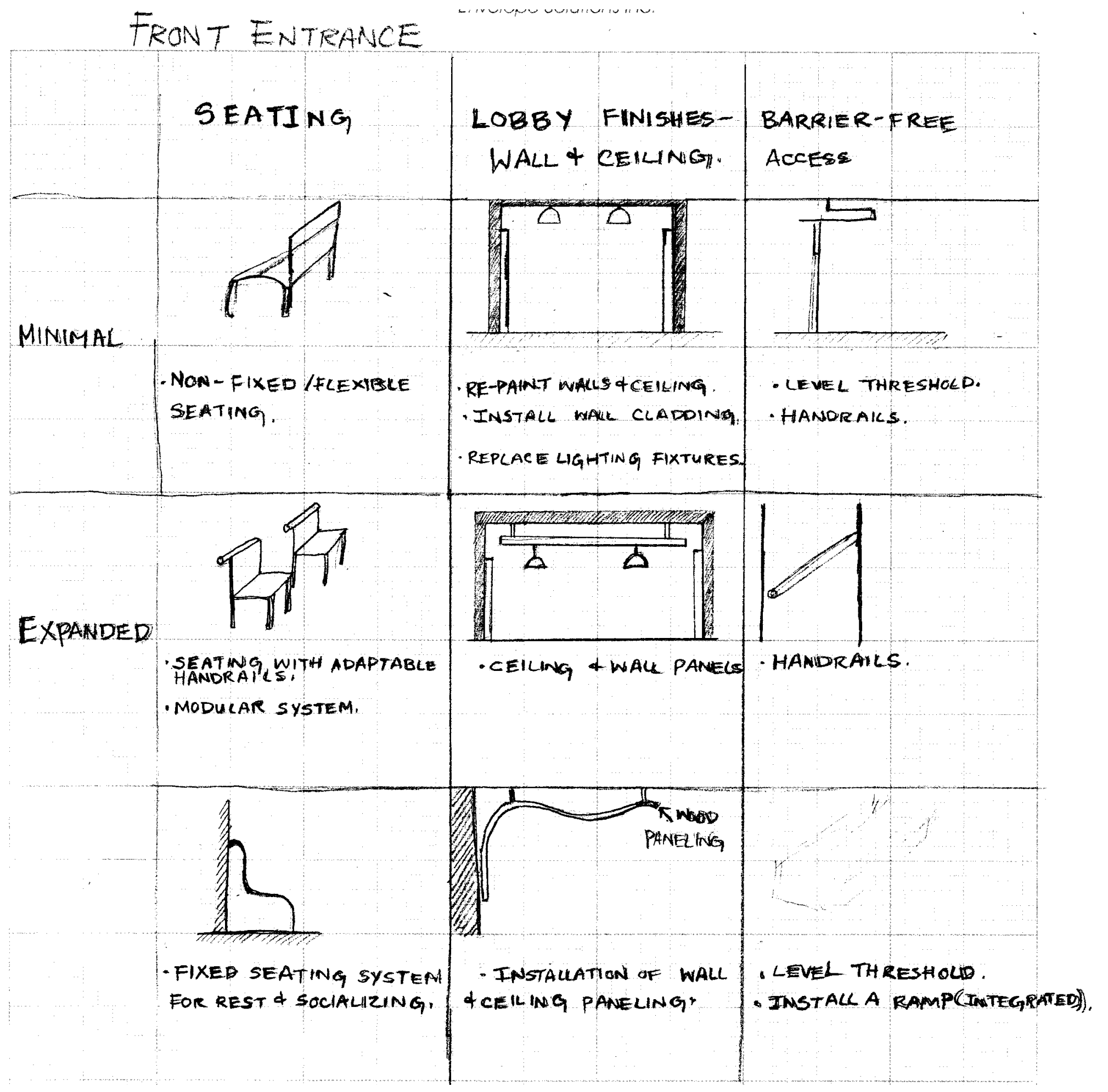

